\title{
Environmental Geophysics at the Southern Bush River Peninsula, Aberdeen Proving Ground, Maryland
}

Energy Systems Division Argonne National Laboratory

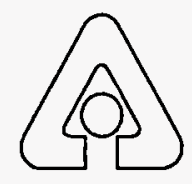

Operated by The University of Chicago, under Contract W-31-109-Eng-38, for the

United States Department of Energy

DISTRIBUTION OF THIS DOCUMENT IS UNLIMITED 


\section{Argonne National Laboratory}

Argonne National Laboratory, with facilities in the states of Illinois and Idaho, is owned by the United States Government, and operated by the University of Chicago under the provisions of a contract with the Department of Energy.

This technical memo is a product of Argonne's Energy Systems (ES)

Division. For information on the division's scientific and engineering activities, contact:

Director, Energy Systems Division

Argonne National Laboratory

Argonne, Illinois 60439-4815

Telephone (708) 252-3724

Presented in this technical memo are preliminary results of ongoing work or work that is more limited in scope and depth than that described in formal reports issued by the ES Division.

Publishing support services were provided by Argonne's Information and Publishing Division.

\section{Disclaimer}

This report was prepared as an account of work sponsored by an agency of the United States Government. Neither the United States Government nor any agency thereof, nor any of their employees, makes any warranty, express or implied, or assumes any legal liability or responsibility for the accuracy, completeness, or usefulness of any information, apparatus, product, or process disclosed, or represents that its use would not infringe privately owned rights. Reference herein to any specific commercial product, process, or service by trade name, trademark, manufacturer, or otherwise, does not necessarily constitute or imply its endorsement, recommendation, or favoring by the United States Government or any agency thereof. The views and opinions of authors expressed herein do not necessarily state or reflect those of the United States Government or any agency thereof. 


\section{DISCLAIMER}

Portions of this document may be illegible in electronic image products. Images are produced from the best available original document. 


\section{Environmental Geophysics at the Southern Bush River Peninsula, Aberdeen Proving Ground, Maryland}

by B.E. Davies, S.F. Miller, L.D. McGinnis, C.R. Daudt, M.D. Thompson, J.E. Stefanov, M.A. Benson, and C.A. Padar

Center for Environmental Restoration Systems, Energy Systems Division, Argonne National Laboratory, 9700 South Cass Avenue, Argonne, Illinois 60439

\section{Published as}

Environmental Geophysics at Aberdeen Proving Ground, Maryland:

Southern Bush River Peninsula

for sponsor's use only

May 1995

Work sponsored by United States Department of Defense, United States Army, Aberdeen Proving Ground, Maryland 
Es
This report is printed on recycled paper, with the exception of color reproductions. 


\section{Preface}

This report provides administrative and technical staff responsible for environmental planning and remediation at Aberdeen Proving Ground with the final results and conclusions from geophysical studies conducted at the Bush River Peninsula beginning in April 1994. A companion report entitled Environmental Geophysics at Kings Creek Disposal Site and 30th Street Landfill, Aberdeen Proving Ground, Maryland (Davies et al. 1995) provides additional regional information concerning areas to the northwest of the sites described in this report. The ground-penetrating radar and seismic studies for these two reports overlap. One technology not listed in the workplan, downhole seismic velocity measurements, was added to the study to assist in the interpretation of seismic reflection data. A detailed description of the methodology and results of these measurements is presented in the companion report (Davies et al. 1995). Resistivity sounding, originally proposed in the workplan, was deleted from the study because it was considered redundant. Staff at Aberdeen Proving Ground, Directorate of Safety, Health, and Environment, and at Argonne National Laboratory guided the work scope and its objectives. 


\section{Contents}

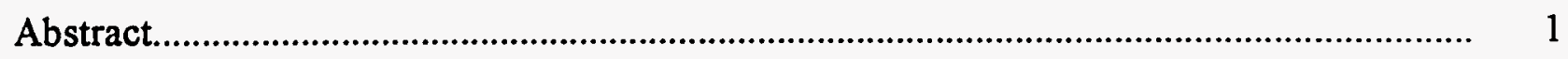

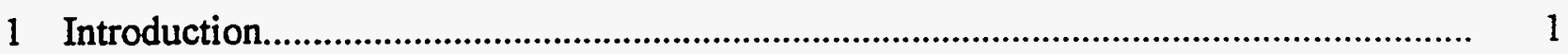

1.1 Physiographic Setting and Site Survey.................................................................. 5

1.2 Geology and Hydrogeology .................................................................................... 5

1.3 Instrumentation and Software .................................................................................... 7

2 Magnetic Surveys..................................................................................................... 11

2.1 Continuous Profiling Magnetometry .................................................................. 11

2.1.1 Tapler Point ........................................................................................... 12

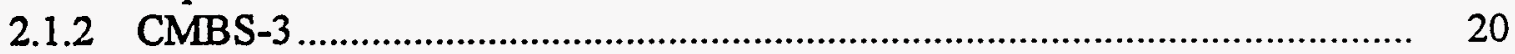

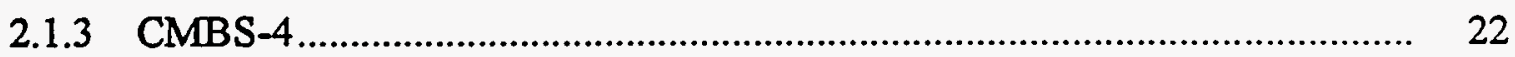

2.2 Magnetic Gradiometer Survey ........................................................................... 22

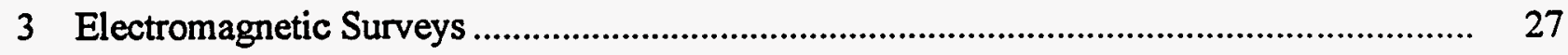

3.1 Time-Domain Millivolt EM-61 Surveys ................................................................ 27

3.1.1 Tapler Point ............................................................................................. 27

3.1.2 CMBS-3 ……........................................................................ 32

3.1.3 CMBS-4

3.2 EM-31 Conductivity Meter Surveys.................................................................. 34

3.2.1 Tapler Point ............................................................................................... 36

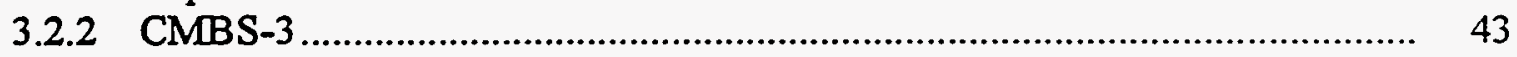

3.2.3 CMBS-4 …….............................................................................. 43

4 Ground-Penetrating Radar Surveys............................................................................ 46

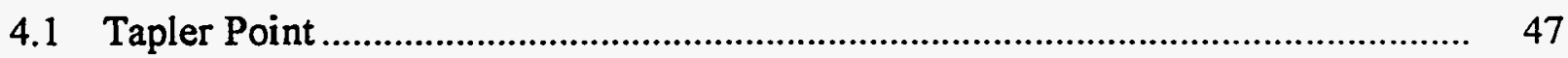

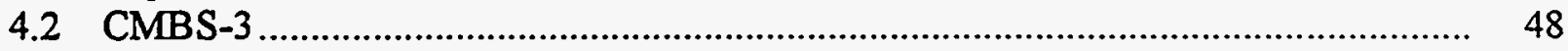

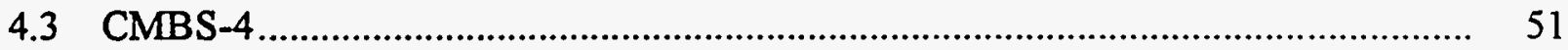

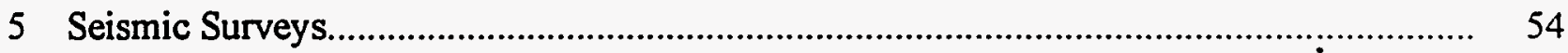

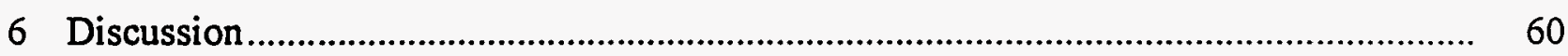

6.1 Waste Disposal at Suspect Chemical Munitions Burial Sites................................... 60

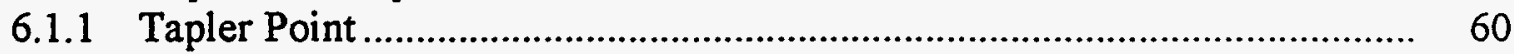

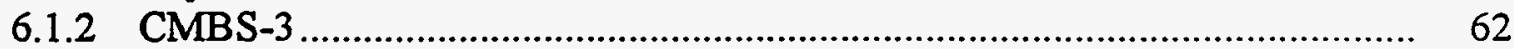

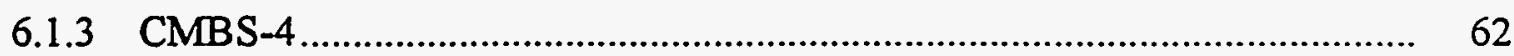

6.2 Hydrogeologic Framework.................................................................................... 62

6.3 Subsurface Paleochannel Locations .......................................................................... 63

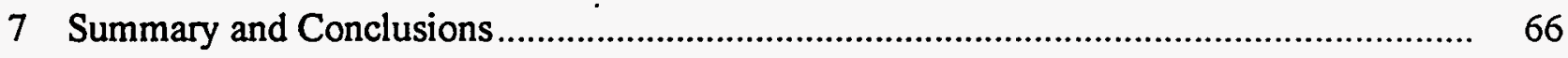




\section{Contents (Cont.)}

\section{Tables}

1 Locations and Descriptions of Magnetic Anomalies Detected at Tapler Point.

2 Locations and Descriptions of Magnetic Anomalies Detected at CMBS-3

3 Locations and Descriptions of Magnetic Anomalies Detected at CMBS-4

4 Locations and Descriptions of Non-Magnetic EM-61 Anomalies

Detected at Tapler Point.

5 Locations and Descriptions of Non-Magnetic EM-61 Anomalies Detected at CMBS-3.

6 Locations and Descriptions of Non-Magnetic EM-61 Anomalies Detected at CMBS-4.

7 Seismic Reflection Profiles near the Tapler Point Study Area.

\section{Figures}

1 Site Features of the Bush River Peninsula, Aberdeen Proving Ground, Edgewood Area... 2

2 Sites and Features at Cluster 18, Southern Bush River Peninsula ................................ 3

3 Geophysical Survey Grids, Southern Bush River Peninsula ..................................... 6

4 Geologic Cross Section of the Bush River Peninsula ............................................... 8

5 Total Field Magnetics Map with Magnetic Gradiometer Anomalies, Tapler Point Area.. 13

6 Total Field Magnetics Map, Northeast Tapler Point, Inside the Security Fence............. 17

7 Total Field Magnetics Map, Southeast Tapler Point, Inside the Security Fence............. 18

8 Total Field Magnetics Map, Southeast Tapler Point, Outside the Security Fence........... 19 


\section{Figures (Cont.)}

9 Total Field Magnetic Maps Illustrating Uncorrected Diurnal Variations, Northwest Tapler Point A: 1-nT Contour Interval

B: 5-nT Contour Interval

10 Total Field Magnetics Map with Magnetic Gradiometer Anomalies, CMBS-3 …............ 23

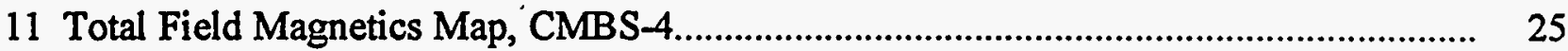

12 A: EM-61 Map, Tapler Point B: EM-61 Map Overlain with Magnetic Contours ........ 28

13 EM-61 Map Overlain with Magnetic Contours, Northwest Tapler Point ........................ 29

14 EM-61 Map Overlain with Magnetic Contours, Northeast Tapler Point......................... 30

15 EM-61 Map Overlain with Magnetic Contours, Southwest Tapler Point......................... 31

16 EM-61 Map Overlain with Magnetic Contours, CMBS-3 …………............................... 33

17 EM-61 Map Overlain with Magnetic Contours, CMBS-4 …........................................... 35

18 EM-31 Electromagnetics Map, Tapler Point...................................................................... 37

19 EM-31 Electromagnetics Map, Northwest Tapler Point ................................................ 38

20 EM-31 Electromagnetics Map, Northeast Tapler Point..................................................... 39

21 EM-31 Electromagnetics Map, CMBS-3 …................................................................. 40

22 EM-31 Electromagnetics Map, CMBS-4 ……........................................................... 41

23 Soil Boring/Monitor Well Location Map, Bush River Peninsula....................................... 45

24 Ground-Penetrating Radar Profile Locations .................................................................. 46

25 A: GPR Profile \#10 B: GPR Profile \#10 with Interpretation ....................................... 48

26 A: GPR Profile \#20 B: GPR Profile \#20 with Interpretation ........................................ 49

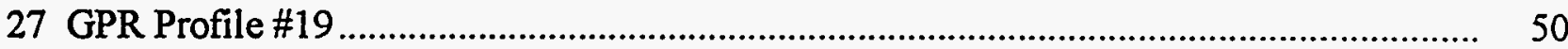

28 A: GPR Profile \#24 B: GPR Profile \#24 with Interpretation ...................................... 52

29 A: GPR Profile \#13 B: GPR Profile \#13 with Interpretation ........................................ 53

30 Seismic Profile Locations .................................................................................................. 55 


\section{Figures (Cont.)}

31 Velocity Depth Model Obtained by Inverting Seismic Refraction Data and Borehole Seismic Data

32 Processed Seismic Reflection Profile for Line BRP-7 ..................................................... 58

33 Processed Seismic Reflection Profile for Line BRP-8 …................................................... 59

34 Recommended Locations for Additional Geophysical Investigation Activities, Tapler Point................................................................................................. 61

35 Approximate Paleochannel Locations Inferred from GPR and EM-31

Data and Boring Logs. 


\title{
Environmental Geophysics at the Southern Bush River Peninsula, Aberdeen Proving Ground, Maryland
}

\author{
by \\ B.E. Davies, S.F. Miller, L.D. McGinnis, C.R. Daudt, M.D. Thompson, \\ J.E. Stefanov, M.A. Benson, and C.A. Padar
}

\begin{abstract}
Geophysical studies have been conducted at five sites in the southern Bush River Peninsula in the Edgewood Area of Aberdeen Proving Ground, Maryland. The goals of the studies were to identify areas containing buried metallic objects and to provide diagnostic signatures of the hydrogeologic framework of the site. These studies indicate that, during the Pleistocene Epoch, alternating stands of high and low sea level resulted in a complex pattern of channel-fill deposits. Paleochannels of various sizes and orientations have been mapped throughout the study area by means of ground-penetrating radar and EM-31 techniques. The EM-31 paleochannel signatures are represented onshore either by conductivity highs or lows, depending on the depths and facies of the fill sequences. A companion study shows the features as conductivity highs where they extend offshore. This erosional and depositional system is environmentally significant because of the role it plays in the shallow groundwater flow regime beneath the site. Magnetic and electromagnetic anomalies outline surficial and buried debris throughout the areas surveyed. On the basis of geophysical measurements, large-scale (i.e., tens of feet) landfilling has not been found in the southern Bush River Peninsula, though smaller-scale dumping of metallic debris and/or munitions cannot be ruled out.
\end{abstract}

\section{Introduction}

An environmental geophysical study was conducted in the southern portion of the Bush River Peninsula at Aberdeen Proving Ground (APG), Edgewood Area (Figure 1). The study area includes five locations identified in the RCRA Facility Assessment (RFA) Report, Edgewood Area, Aberdeen Proving Ground, Maryland (Nemeth 1989) as potential disposal sites. The five sites have been referenced by various names and numbers in different reports. Nemeth (1989) described the sites as the Tapler Point Dredge Material Site (TPDMS) and the four Chemical Munitions Burial Sites (CMBS). Following the RFA, which was a base-wide assessment, the study area was included as a portion of Cluster 18 of the Bush River Study Area Remedial Investigation/Feasibility Study (Figure 1). Geophysical surveys were performed at the following five sites within Cluster 18 (see Figure 2): Site 8 (TPDMS), Site 13 (CMBS-1), Site 14 


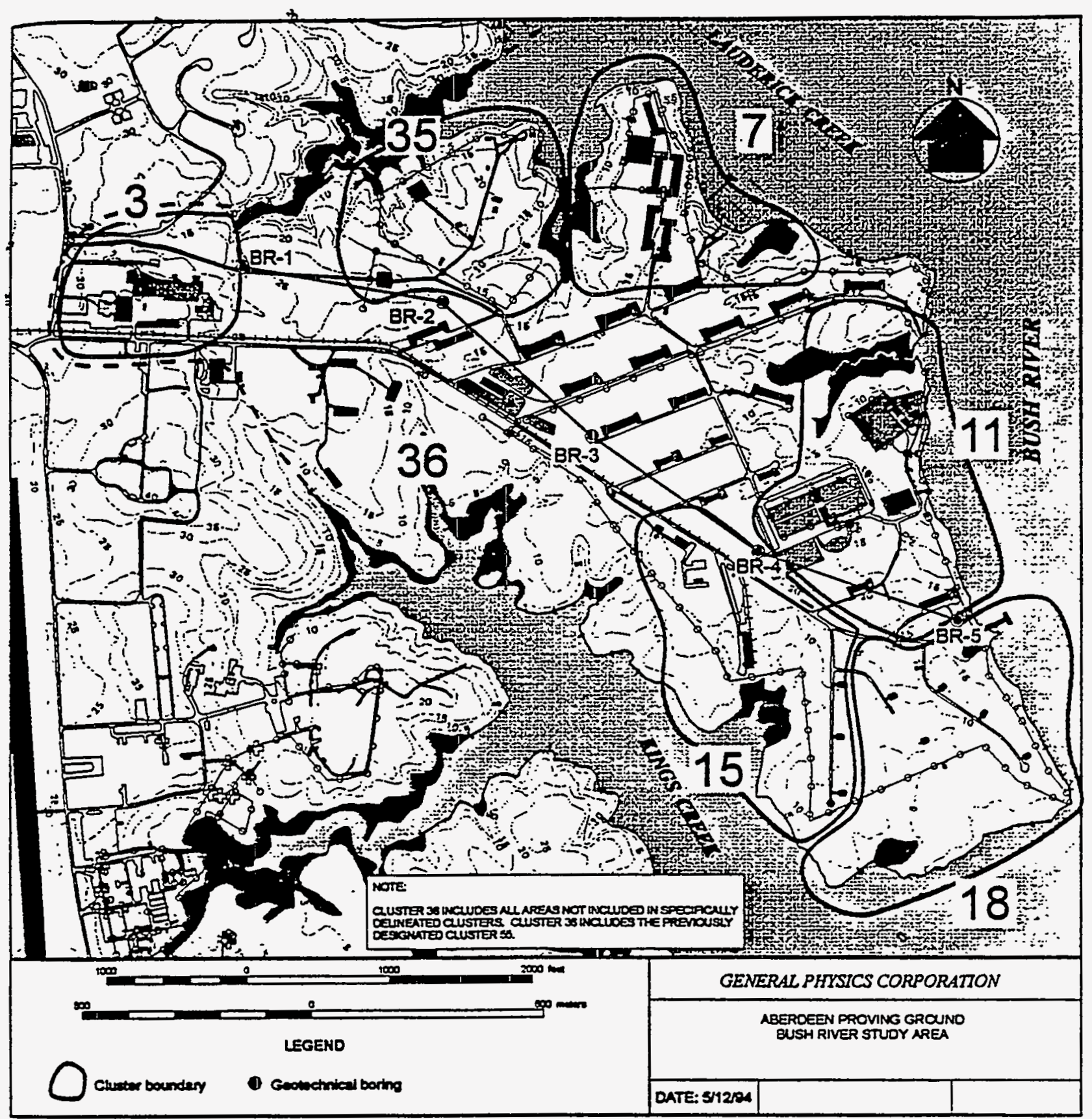

FIGURE 1 Site Features of the Bush River Peninsula, Aberdeen Proving Ground, Edgewood Area 


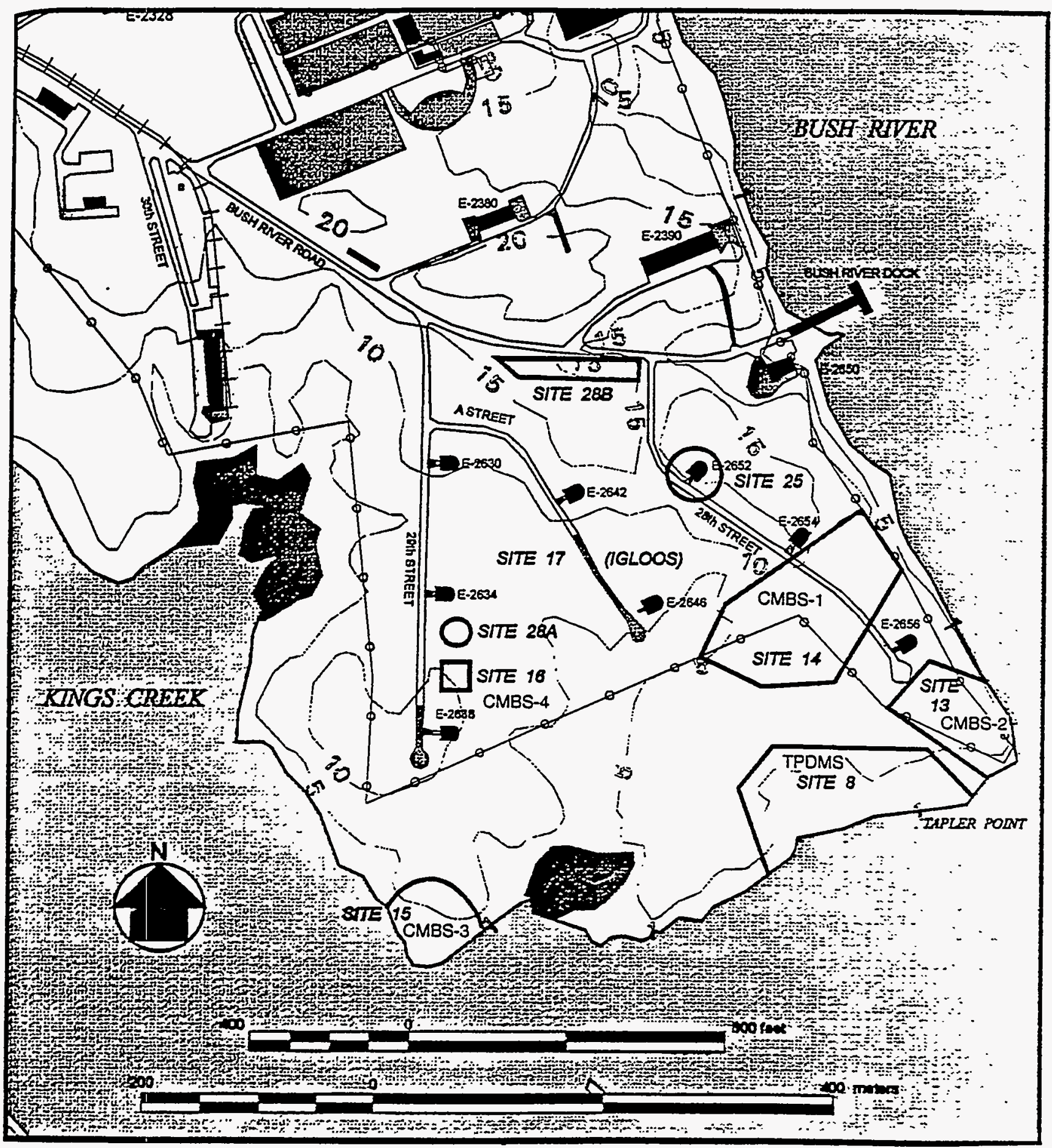

FIGURE 2 Sites and Features at Cluster 18, Southern Bush River Peninsula 
(CMBS-2), Site 15 (CMBS-3), and Site 16 (CMBS-4). The original RFA numbering system, using the acronyms TPDMS and CMBS-1 through CMBS-4, is used throughout the remainder of this report to describe the five study sites.

CMBS-1 through CMBS-4 were identified on aerial photographs taken in 1929 and the early 1940s and analyzed as part of the RFA. The aerial photographs show ground scars at these locations, indicating activities that destroyed vegetation. The resolution of the aerial photographs was not clear enough to determine whether materials were being buried at these sites. Munition disposal procedures during the 1920s and 1930s included the burial of deteriorated or failed munitions in unused portions of APG. No direct evidence of munitions burial at these four sites is available.

The TPDMS is located onshore in the southeastern portion of the Bush River Peninsula, outside the security fence (Figure 2). Dredge material was placed at this location in the early 1940s. The material was obtained when the area around the Bush River Dock was dredged for shipping (Figure 2). No information was found to indicate that the dredged material was contaminated; however, the Bush River Dock was used to ship and receive chemical munitions.

The objectives of the geophysical investigations (as outlined in the site workplans) are as follows:

1. Determine whether the five study areas (CMBS-1 through CMBS-4 and TPDMS) were used for munitions disposal and define the areal extent of disposal;

2. Characterize the hydrogeologic framework beneath the sites to provide information to support the current site monitor well installation program; and

3. Provide information on the geologic integrity and continuity of strata underlying the five sites.

Field activities were conducted during the spring and summer of 1994 . Geophysical techniques used during this study to meet the objectives listed above included seismic reflection and refraction, downhole seismic velocity measurements, magnetics, electromagnetics, and ground-penetrating radar (GPR). Magnetic, electromagnetic, and GPR surveys were performed to define the extent, if any, of chemical munitions disposal at the sites. This study was not designed as an unexploded ordinance (UXO) survey; the geophysical metal detection surveys were performed to determine whether landfilling occurred at the suspected sites. A wide variety of metallic debris, often visible at the surface, was scattered throughout each site surveyed. Listings of the larger magnetic and electromagnetic anomalies are provided in Sections 2 and 3. Not every anomaly is listed or discussed. A discussion of the survey limitations is included in Section 2.1.1. 


\subsection{Physiographic Setting and Site Survey}

The Bush River Peninsula lies within the Atlantic Coastal Plain physiographic province of Maryland. The study area is located in the southern end of the peninsula, which is bounded by Lauderick Creek to the north, Bush River to the east, and Kings Creek to the south (Figure 1). The peninsula is a remnant of subareal erosion that occurred during a low sea level stand followed by a sea level rise and estuarine encroachment into Kings Creek and Lauderick Creek, which are tributaries of Bush River. The river is one of the major tidal estuarine channels on the western shore of Chesapeake Bay. Elevations of the Bush River Peninsula range from greater than $20 \mathrm{ft}$ above mean sea level (msl) in the central portion of the peninsula, to sea level at the shoreline (Figure 2). The elevation of the study area ranges from sea level to greater than $15 \mathrm{ft}$ above msl in the northeastern portion of the survey area.

The surveyed sites cover approximately 15 acres of three separate areas in the southern portion of the Bush River Peninsula. Trees occupy the major portion of each site. Portions of the sites are covered by surface obstructions (i.e., fallen trees and heavy vegetation growth). A large, low-lying phragmite marsh encompasses the area between CMBS-3 and the TPDMS and extends northward to the security fence (Figure 3).

Geophysical survey grids were laid out by using 300-ft surveyor's tapes and a Brunton compass. Three separate $50-\mathrm{ft}$ grid systems of wooden stakes were used to guide the geophysical surveys. The CMBS-3 and CMBS-4 study areas each have a separate grid system. CMBS-1, CMBS-2, and the TPDMS were combined into one large grid because of their proximity to one another (Figure 3 ). This combined grid is referred to in this report as Tapler Point. The three grids are laid out along lines approximately $10^{\circ}$ west of true north.

\subsection{Geology and Hydrogeology}

A late Precambrian crystalline basement platform lies approximately $450 \mathrm{ft}$ beneath the surface of the Bush River Peninsula (Davies et al. 1995). Basement lithologies are similar to those found at the surface in the Piedmont Province, which is located northwest of the fall line (Oliveros and Vroblesky 1989). The crystalline basement surface dips to the southeast at an angle of less than $1^{\circ}$ (Bennett and Meyer 1952; Dingman et al. 1956; Southwick et al. 1969; Otton and Mandle 1984). Previous geophysical studies at Beach Point, located 1,200 ft south of CMBS-3, revealed the Precambrian basement approximately $560 \mathrm{ft}$ beneath the surface (McGinnis et al. 1994a). In areas east of the fall line, including all of the areas discussed in this report, unconsolidated Atlantic Coastal Plain sediments overlie Piedmont basement rocks.

Atlantic Coastal Plain sediments beneath the Edgewood Area of APG were deposited during the Cretaceous Period and the Pleistocene Epoch (Oliveros and Vroblesky 1989; Thurmond 1993). A thin layer of Holocene estuarine sediments covers the wetland areas at 


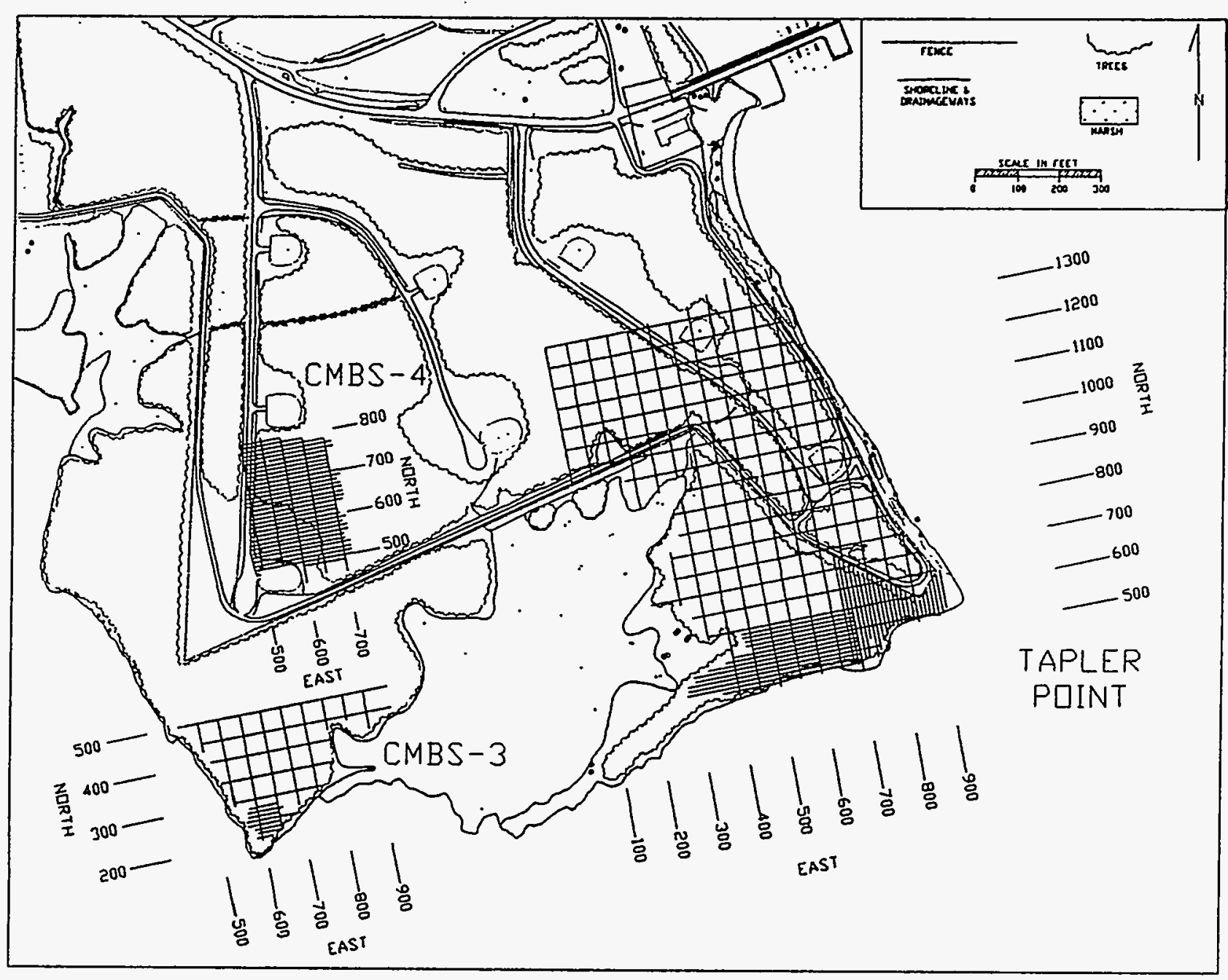

FIGURE 3 Geophysical Survey Grids, Southern Bush River Peninsula

APG. Most of the unconsolidated sediments, which comprise the Potomac Group, were deposited during the Cretaceous Period. The Potomac Group units are continentally derived and represent several depositional systems: mostly fluvial, channel, and overbank or levee deposits. Cretaceous deposits in the area generally consist of interbedded clays and fine- to mediumgrained quartz sands. These Cretaceous sediments likely belong to the Patapsco Formation of the Potomac Group.

The Pleistocene Talbot Formation, which rests unconformably on the Potomac Group, contains minor amounts of Quaternary alluvium (Oliveros and Vroblesky 1989). The gravelly sand, sand, and silty clay deposits are marginal marine in origin and consist primarily of fluvial and estuarine deposits (Southwick et al. 1969). During the Pleistocene Epoch, the sea level fluctuated and channels were cut into the Cretaceous sediments. The Talbot Formation is commonly found as paleochannel-fill complexes deposited during subsequent rises in sea level (Kehrin et al. 1988). Beneath the Bush River Peninsula, the Talbot Formation is thickest in these paleochannel-fill complexes and reaches depths greater than $50 \mathrm{ft}$ below msl (Davies et al. 1995). 
Figure 4 presents a hydrogeologic cross section running northwest to southeast along the Bush River Peninsula (adapted from Thurmond 1993). The location of the cross section is shown in Figure 1. The sediments beneath the Bush River Peninsula are a complex mix of interfingering clays, silts, sands, and gravels. Lorah and Vroblesky (1989) describe a similar section as follows: "Hydrogeologic units were defined partly on the basis of hydrogeologic characteristics of the units; therefore, the boundaries between the hydrogeologic units do not necessarily correspond with the contacts between geologic units." The surficial aquifer sediments are primarily composed of the Talbot Formation and appear to pinch out in the northwestern end of the cross section (Figure 4). Aquifers beneath the surficial aquifer are composed of Potomac Group sediments.

The Pleistocene disconformity is developed on a clay aquitard, which is a member of the Potomac Group sediments. The disconformity, where the base of the Pleistocene sediments is also clayey, is not readily discernible in drill core or geophysical logs. In the discussions that follow, the term "base of the surficial aquifer" refers to the contact between the sandy sediments and the underlying clay, regardless of the relative ages of the two units.

On the basis of observations elsewhere on the Bush River Peninsula (Davies et al. 1995) and studies conducted in other portions of the Edgewood Area, including Beach Point (McGinnis et al. 1994a) and Canal Creek (Lorah and Vroblesky 1989; McGinnis et al. 1994b), it is evident that a well-integrated Pleistocene tributary system was deeply incised into the Potomac Group sediments as a result of successive lowering of the sea level. The tributary system provides the framework for shallow groundwater flow and for potential recharge into the Potomac Group aquifers. Mapping the configuration of this system is one of the objectives of the geophysical studies conducted at the Bush River Peninsula sites.

\subsection{Instrumentation and Software}

Instruments used to collect geophysical data at the site included the following:

- Magnetic gradiometer,

- Cesium vapor magnetometer,

- EM-31 electromagnetic conductivity meter,

- EM-61 electromagnetic induction meter,

- SIR-2 and SIR-3 ground-penetrating radar, and

- Engineering seismograph. 

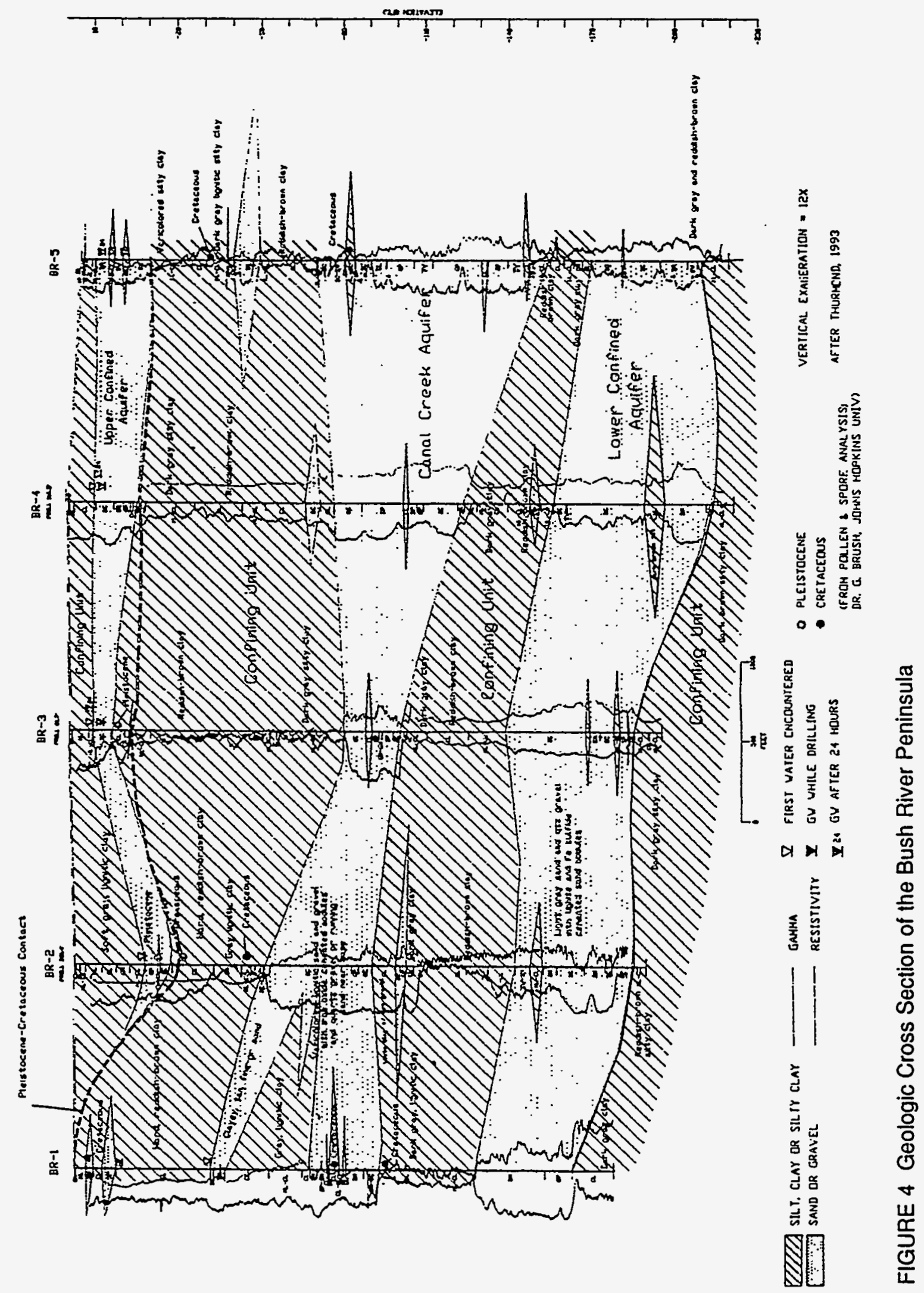
The following paragraphs describe each of the instruments listed above and the software used in data processing.

The Model Mac-51B, a magnetic gradiometer and cable locator manufactured by Schonstedt, Inc., is a dual-mode instrument designed to detect shallow buried iron and steel objects and trace underground cables and pipes. The magnetic gradiometer was used during this study to (1) clear survey areas prior to driving the wooden stake grid markers and geophones and (2) perform magnetic surveys.

Total field magnetic data were acquired by using the Model G-822L cesium vapor magnetometer manufactured by EG\&G Geometrics. The magnetometer is a continuous-recording (10 readings per second), total-field, microprocessor-based instrument capable of resolution of anomalies to one nanotesla $(1 \mathrm{nT})$.

Electrical conductivity measurements were made with a Model EM-31, an electromagnetic instrument manufactured by Geonics Limited that provides mean values of conductivity, in millisiemens per meter $(\mathrm{mS} / \mathrm{m})$, for soils from just beneath the land surface to a depth of approximately $18 \mathrm{ft}$. Apparent conductivities measured by the EM-31 are weighted mean values measured over the entire depth range, with greater weights applied to shallower depths. Data were stored on an OMNI 720 data logger. Internal software permitted downloading directly into a lap-top or desk-top computer.

The Geonics Limited Model EM-61, a portable, time domain, electrical induction instrument that transmits an electrical pulse into the ground, was used to measure secondary electromagnetic fields (in millivolts [mV]) caused by metallic objects beneath the instrument. The coil arrangement allows the EM-61 to be relatively insensitive to surface interference and more sensitive to buried metallic objects. EM-61 data are recorded on three channels (the response from the upper coil, the lower coil, and the coil difference) and stored on an OMNI 720 data logger. Data were collected at a rate of three readings per second.

Reduction of the electromagnetic and total field magnetic data was completed using digital audio tape (DAT) 31 and DAT 61 software provided by Geonics. The United States Geological Survey (USGS) minimum curvature gridding program, MINC (Cordell et al. 1992), was used to plot the data on a grid. Color contour maps presenting the electromagnetic and total field magnetic data were produced by using COLORMAP software developed by Argonne National Laboratory (ANL).

GPR surveying was accomplished by using Geophysical Survey Systems, Inc. (GSSI) models SIR-3 and SIR-2. The SIR-3 was equipped with a model 38 video display and DAT recorder; data were recorded on DAT and downloaded to a personal computer in the field office. Data from the SIR-2 system were downloaded directly to the personal computer. Continuous profiling was performed with both the 100- and 300-megahertz (MHz)-frequency antennas being used in the bistatic mode. The control/video display was mounted directly on an all-terrain 
vehicle, which was used to pull the different antenna arrays through the onshore survey area. An IBM-compatible processing computer was located in a field office to download and check the radar profiles and to allow preliminary data processing in the field. Radan III computer software written by GSSI was used for processing the GPR data.

A 24-channel engineering seismograph (EG\&G model ES-2401) was used to determine the depths and seismic velocities of the sediments underlying the Bush River Peninsula. Seismic refraction data of the entire sedimentary section were obtained by using a trailer-mounted elastic wave generator (EWG) manufactured by Bison Instruments, Inc., for a source, and geophones with a natural frequency of 16 hertz $(\mathrm{Hz})$ for receivers. Shallow and deep high-resolution reflection data were obtained by using the EWG and a 16-pound sledgehammer for sources, and geophones with a natural frequency of $60 \mathrm{~Hz}$ for receivers. All geophones were manufactured by Mark, Inc. Multiple EWG hits or hammer hits were stacked as needed to increase the signal-tonoise ratio. Full 24-channel reflection data were obtained by using a Model RLS-120 roll-along switch with common-depth-point (CDP) cables, manufactured by Input/Output, Inc.

Two shallow seismic refraction lines and downhole seismic data collection techniques were used to further characterize the seismic velocities of the sediments underlying the Bush River Peninsula. A Bison Instruments Model 5012, 12-channel engineering seismograph was utilized to collect these data; a 12-pound sledgehammer served as a sound source. Surveyors used $60-\mathrm{Hz}$ geophones manufactured by Mark, Inc., to collect data from the two shallow refraction lines and a Mark L-10, 8- Hz, three-component geophone to obtain the downhole seismic data.

EAVESDROPPER reflection software, developed by the Kansas Geological Survey (1993), was employed for reflection data processing. The seismic refraction data were processed by using SIPT2 refraction programs, developed by RIMROCK Geophysics, Inc. (1992). 


\section{Magnetic Surveys}

The objectives of the gradiometer and total field magnetic surveys performed at the Bush River Peninsula were to (1) determine whether large-scale (i.e., greater than 30 to $40 \mathrm{ft}$ ) disposal of ferromagnetic debris had occurred at the four potential chemical munitions burial sites and the TPDMS, and (2) avoid shallow magnetic debris (UXO) during the placement of the geophones and survey stakes. The results of these surveys are presented below.

\subsection{Continuous Profiling Magnetometry}

The southern Bush River Peninsula study area contains five study sites (CMBS-1 through CMBS-4 and the TPDMS). As previously discussed, sites CMBS-1, CMBS-2, and TPDMS were combined to form a contiguous study area referred to as Tapler Point. Figure 3 shows the magnetic profile locations and indicates the grid numbering systems for Tapler Point and for CMBS-3 and CMBS-4.

Initially, the Tapler Point area was surveyed along north/south and east/west traverses spaced $50 \mathrm{ft}$ apart (Figure 3). In-field analysis of the preliminary data indicated that the southern portion of Tapler Point contained anomalies that required more detailed examination. Additional surveys were conducted, with profiles spaced $10 \mathrm{ft}$ apart, to further delineate the boundaries of the detected anomalies. Gradiometer surveys were performed between the 50 - $\mathrm{ft}$ survey profiles outside of the security fence at Tapler Point to determine whether any smaller clusters or point source ferrous features were missed during the total field magnetics survey (see Section 2.2). Gradiometer surveys were not performed inside the security fence at Tapler Point.

Like Tapler Point, CMBS-3 was surveyed along north/south and east/west traverses spaced $50 \mathrm{ft}$ apart. In-field data analysis indicated that the southwestern portion of CMBS-3 required more detailed examination. Additional east-west profiles spaced $10 \mathrm{ft}$ apart were collected in the southern portion of CMBS-3 (Figure 3). Gradiometer surveys were also performed to provide $100 \%$ coverage between the 50 -ft survey profiles (see Section 2.2).

The size and relative openness of CMBS-4 allowed magnetic surveying along east-west traverses spaced $10 \mathrm{ft}$ apart. North-south tie lines were collected at 50-ft intervals (Figure 3 ). No gradiometer surveys were performed at CMBS- 4 because of the more closely spaced lines of the total field magnetics survey.

Errors introduced into the magnetic data due to uncorrected diurnal variations and insufficient response speed to changing signals were small compared with the amplitudes of the anomalies detected. Therefore, the anomalies displayed on the magnetic maps are qualitatively significant. Relatively small (10 to $100 \mathrm{nT}$ ) diumal variations in the earth's magnetic field are caused largely by the interaction of fluctuating solar radiation and the ionosphere. Larger changes occur during solar storm events. Data from two areas, CMBS-3 and the east/west-trending, 
fine-grid profiles in the southern end of Tapler Point, were corrected for diurnal variations. Data from identical positions where profiles crossed were compared with the time of data collection to determine the diurnal trend. Data were corrected assuming a linear diurnal variation.

Some error can also be introduced through inadvertent changes in instrument position or attitude relative to the ground surface. Moving around obstacles or changing walking pace may also produce some positioning error. Marks were placed on the data at 50-ft intervals and at the beginning and end of each survey line. Digital and graphic data readouts are included with the data logging computer. If significant errors were noted while conducting the survey, the profile was redone. Careful data acquisition and processing procedures kept errors to a minimum.

\subsubsection{Tapler Point}

The total field magnetics survey grid and site features for Tapler Point are indicated in Figure 3. The survey area is divided by a security fence. The majority of the area is covered by trees. Outside of the security fence, the survey area is accessible except near portions of the southeastern shoreline that are covered by fallen trees and undergrowth. The survey area was limited to the west by an extensive phragmite marsh. Inside the security fence, accessibility was often limited by fallen trees and undergrowth.

A color-contoured magnetic map of the entire Tapler Point survey area is presented in Figure 5. Magnetic anomalies detected in the survey area can, in many cases, be explained by ferrous objects on the surface; however, others remain unexplained. The dominant magnetic features shown in Figure 5 are associated with the security fence, the roadway system, and two ammunition storage buildings (igloos). Table 1 lists 93 magnetic anomalies, their coordinates (at the center of each anomaly), and a brief description of each. If the anomaly encompassed a larger area, a coordinate range is listed. Anomalies associated with the roadway and security fence systems are not listed.

Table 1 lists the significant anomalies in the Tapler Point area beginning in the northwest, inside the security fence, and proceeding in a clockwise direction. Forty separate magnetic anomalies inside the security fence, 23 caused by unknown sources, are listed in Table 1. Fiftythree separate magnetic anomalies are listed for the area outside the security fence, where there is less cultural interference; 25 of these 53 anomalies are caused by unknown sources. No large (i.e., greater than $50 \mathrm{ft}$ ) areas of contiguous unidentified magnetic anomalies were found during the survey, either inside or outside of the security fence. Three areas, however, did contain a number of isolated magnetic anomalies with unknown sources. Larger-scale total field magnetics maps for these three areas are presented in Figures 6,7, and 8. These areas generally correspond to CMBS-1 and CMBS-2, previously identified by historic aerial photographs (Nemeth 1989). 


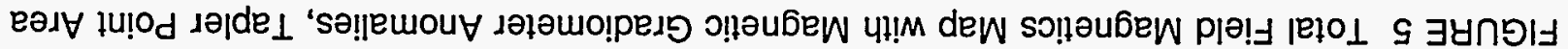

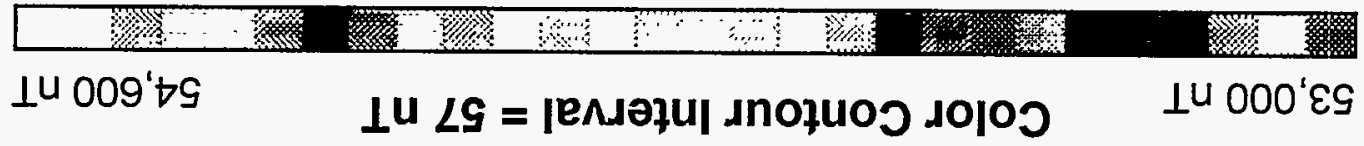

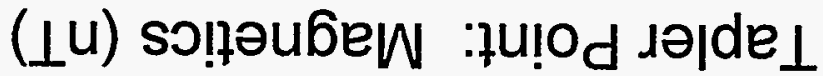

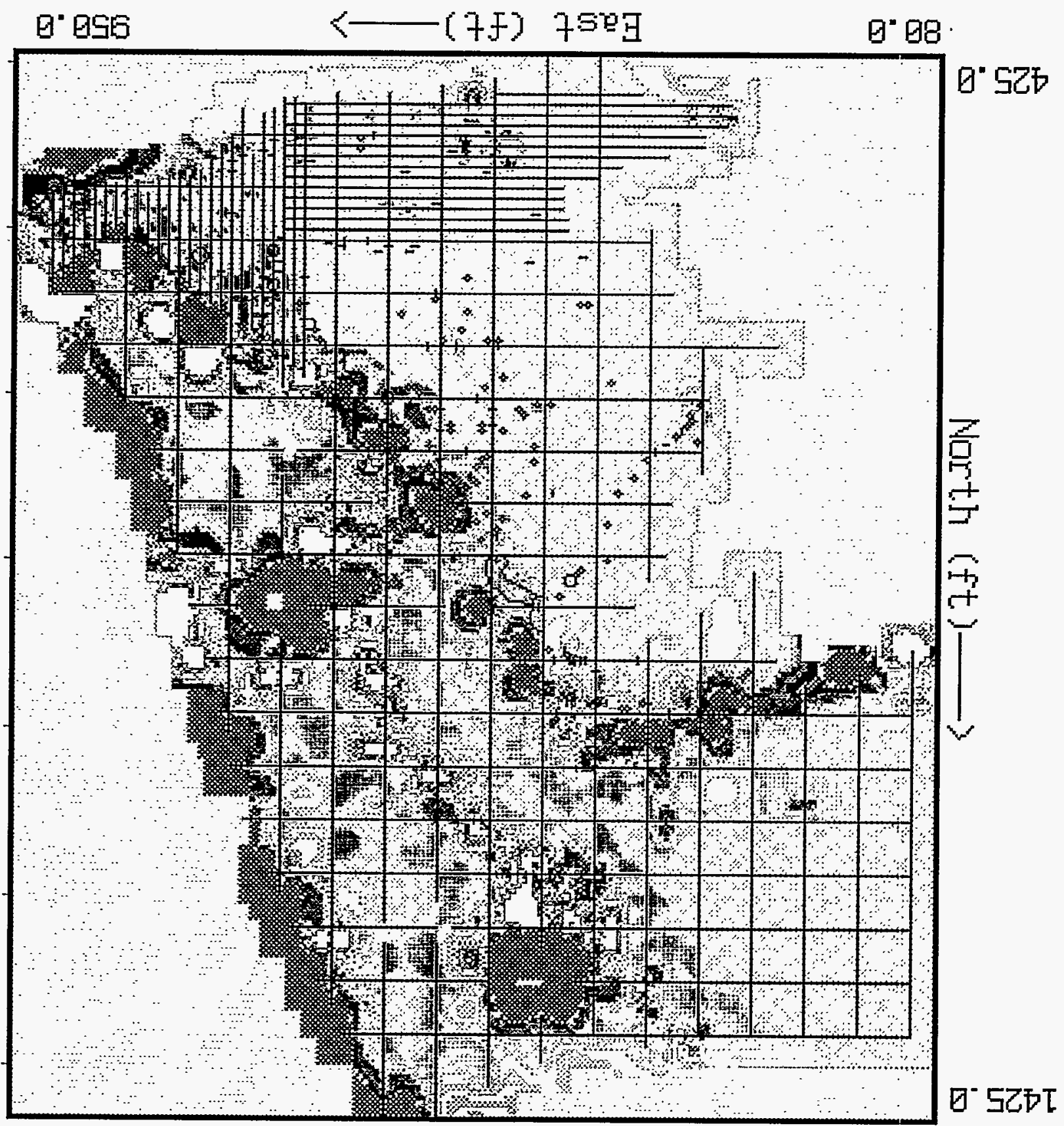


TABLE 1 Locations and Descriptions of Magnetic Anomalies Detected at Tapler Point

\begin{tabular}{|c|c|c|c|}
\hline \multirow[b]{2}{*}{ Number } & \multicolumn{2}{|c|}{ Coordinates } & \multirow[b]{2}{*}{ Anomaly Description } \\
\hline & North & East & \\
\hline Inside & Security & & \\
\hline 1 & 1030 & 100 & Source unknown \\
\hline 2 & 1150 & 120 & Source unknown, small surface depression \\
\hline 3 & 1130 & 200 & Drum on surface \\
\hline 4 & 1150 & 330 & Canister fragment \\
\hline 5 & 1100 & 335 & Fence debris \\
\hline 6 & 1095 & 350 & Fence debris \\
\hline 7 & 1200 & 410 & Source unknown, mound present \\
\hline 8 & 1200 & 440 & Source unknown \\
\hline 9 & 1180 & 450 & Partially buried metal debris \\
\hline 10 & $1265-1330$ & $420-500$ & Igloo E-2654 \\
\hline 11 & 1245 & 455 & Culvert adjacent to Igloo E-2654 \\
\hline 12 & 1250 & 510 & Source unknown \\
\hline 13 & 1275 & 515 & $\begin{array}{l}\text { Source unknown, likely contour relic caused by large } \\
\text { field gradient from Igloo E- } 2654\end{array}$ \\
\hline 14 & 1140 & 550 & NE-SW-trending road culvert \\
\hline 15 & 1110 & 500 & Source unknown \\
\hline 16 & 1000 & 525 & Source unknown \\
\hline 17 & 1140 & 600 & Source unknown \\
\hline 18 & 1260 & 650 & Source unknown \\
\hline 19 & 1015 & 700 & Source unknown \\
\hline 20 & 960 & 650 & $\begin{array}{l}\text { Light post with underground electric conduit } \\
\text { adjacent to Igloo E-2656 }\end{array}$ \\
\hline 21 & $910-980$ & $670-740$ & Igloo E-2656 \\
\hline 22 & 900 & 560 & Source unknown \\
\hline 23 & 925 & 600 & Metal debris \\
\hline 24 & 895 & 600 & Source unknown \\
\hline 25 & 870 & 600 & Source unknown \\
\hline 26 & 885 & 650 & Metal debris (steel culvert) \\
\hline 27 & 900 & 675 & Source unknown, beneath road gravel \\
\hline 28 & 915 & 750 & Source unknown, beneath road gravel \\
\hline 29 & 840 & 600 & Source unknown \\
\hline 30 & 850 & 635 & Source unknown \\
\hline 31 & 850 & 650 & Source unknown \\
\hline 32 & 850 & 710 & Metal debris \\
\hline 33 & 800 & 645 & Fence debris \\
\hline 34 & 750 & 655 & Fence debris \\
\hline 35 & 750 & 695 & Source unknown \\
\hline 36 & 700 & 710 & Source unknown \\
\hline 37 & 700 & $740-750$ & Large-diameter cable and mound \\
\hline 38 & 690 & 850 & Source unknown, mound present \\
\hline 39 & 670 & 800 & Electrical boxes with conduit and wires \\
\hline 40 & 650 & 845 & Source unknown \\
\hline
\end{tabular}


TABLE 1 (Cont.)

\begin{tabular}{lll}
\hline & \multicolumn{2}{c}{ Coordinates } \\
\cline { 2 - 3 } Number & North $\quad$ East & Anomaly Description \\
\hline
\end{tabular}

\section{Outside. Security Fence}

$\begin{array}{lccl}41 & 570-580 & 855-885 & \text { NW-SE-trending old fenceline with fence debris } \\ 42 & 575 & 920 & \text { Old sign on ground } \\ 43 & 565 & 920 & \text { Old sign post in ground } \\ 44 & 560 & 910 & \text { Concrete rubble } \\ 45 & 565 & 900 & \text { Cut-off fencepost in ground } \\ 46 & 570 & 880 & \text { Tire with rim and debris } \\ 47 & 550 & 860 & \text { Source unknown, beach } \\ 48 & 555 & 850 & \text { Source unknown, top of erosion bank } \\ 49 & 540 & 850 & \text { Source unknown, beach } \\ 50 & 560 & 800 & \text { Source unknown, mound present } \\ 51 & 540 & 790 & \text { Source unknown, top of erosion bank } \\ 52 & 600-620 & 790 & \text { Wire and metal debris } \\ 53 & 510 & 740-760 & \text { Source unknown } \\ 54 & 530 & 760 & \text { Source unknown } \\ 55 & 580 & 755 & \text { Tire with rim } \\ 56 & 595 & 760 & \text { Tire with rim } \\ 57 & 630 & 760 & \text { Source unknown } \\ 58 & 560 & 730 & \text { Source unknown } \\ 59 & 615 & 710 & \text { Source unknown, top of mound } \\ 60 & 640 & 710 & \text { Pipe protruding from mound } \\ 61 & 650 & 710 & \text { Source unknown } \\ 62 & 660 & 720 & \text { Pipe protruding from mound } \\ 63 & 710 & 690 & \text { Source unknown } \\ 64 & 500 & 690 & \text { Metal drum } \\ 65 & 475 & 690 & \text { Tire with rim } \\ 66 & 655 & 690 & \text { Source unknown } \\ 67 & 690 & 680 & \text { Source unknown } \\ 68 & 600 & 650 & \text { Source unknown } \\ 69 & 480 & 620 & \text { Source unknown } \\ 70 & 488 & 602 & \text { Shell protruding from top of erosion bank } \\ 71 & 570 & 580 & \text { Source unknown } \\ 72 & 480 & 575 & \text { Tire with rim } \\ 73 & 480 & 550 & \text { Source unknown } \\ 74 & 470 & 520 & \text { Tire with rim and metal sign base } \\ 75 & 490 & 500 & \text { Source unknown } \\ 76 & 510 & 525 & \text { Tires with rims } \\ 77 & 505-520 & 480-490 & \text { Pile of cut-up shells } \\ 78 & 480 & 315 & \text { Tire with rim } \\ 79 & 480 & 285 & \text { Metal drum } \\ 80 & 600 & 540 & \text { Source unknown } \\ 81 & 600 & 620 & \text { Source unknown } \\ 82 & 700 & 530 & \text { Steel rebar } \\ 83 & 710 & 640-650 & \text { Fence debris } \\ & & & \end{array}$


TABLE 1 (Cont.)

\begin{tabular}{|c|c|c|c|}
\hline \multirow[b]{2}{*}{ Number } & \multicolumn{2}{|c|}{ Coordinates } & \multirow[b]{2}{*}{ Anomaly Description } \\
\hline & North & East & \\
\hline Outside & Security For & & \\
\hline 84 & 700 & 250 & Source unknown, mounds present \\
\hline 85 & 750 & 300 & Source unknown, mounds present \\
\hline 86 & 745 & 575 & Metal drum \\
\hline 87 & 745 & 585 & Fence debris \\
\hline 88 & 850 & 540 & Argonne equipment trailer \\
\hline 89 & 870 & 500 & Fence debris, mound present \\
\hline 90 & 940 & 450 & Fence debris \\
\hline 91 & 1000 & 420 & Source unknown \\
\hline 92 & $1015-1035$ & 400 & Three unknown anomalies, buried fencing(?) \\
\hline 93 & 1030 & 320 & $\begin{array}{l}\text { Source unknown, likely contour relic caused by } \\
\text { large field gradient from fenceline }\end{array}$ \\
\hline
\end{tabular}

Figure 6 presents a magnetic map of the wooded area north of Igloo E-2656. Areas related to the security fence, igloo, and roadway appear as anomalous zones. Eight buried anomalies of unknown origin (\#7, \#8,\#12, and \#15 through \#19 on Table 1) are plotted on Figure 6. Anomaly \#9, located west of the roadway, correlates with partially buried metal debris and may be associated with anomalies \#7 and \#8. Unknown buried anomalies \#18 and \#19 have the largest total field gradient east of the roadway.

Figure 7 presents a magnetic map of the wooded area south of Igloo E-2656. Anomalous zones related to the security fence are present to the east, south, and west. Other anomalous zones are associated with the roadway surrounding the area and Igloo E-2656 to the north. Nineteen specific magnetic anomalies are listed in Table 1 for this portion of the Tapler Point survey. Twelve of these anomalies represent unknown buried sources and are plotted on Figure 7. Visible metal debris was scattered throughout this section.

Figure 8 presents a magnetic map of the southeastern tip of Tapler Point, outside of the security fence. This portion of Tapler Point was surveyed on a $10-\mathrm{ft}$ profile spacing. The entire southeastern tip of the area, east of the 870 East north/south profile, is anomalous. Old signs, steel-reinforced concrete rubble riprap, old fence material, and other metal debris were observed in this portion of Tapler Point. Some buried ferrous objects are also present. This area was previously located inside the security fence, which has since been moved inland because of shoreline erosion. The largest total field gradients are associated with the old fence material, including the still-visible, concrete-encased, cut-off fenceposts. 

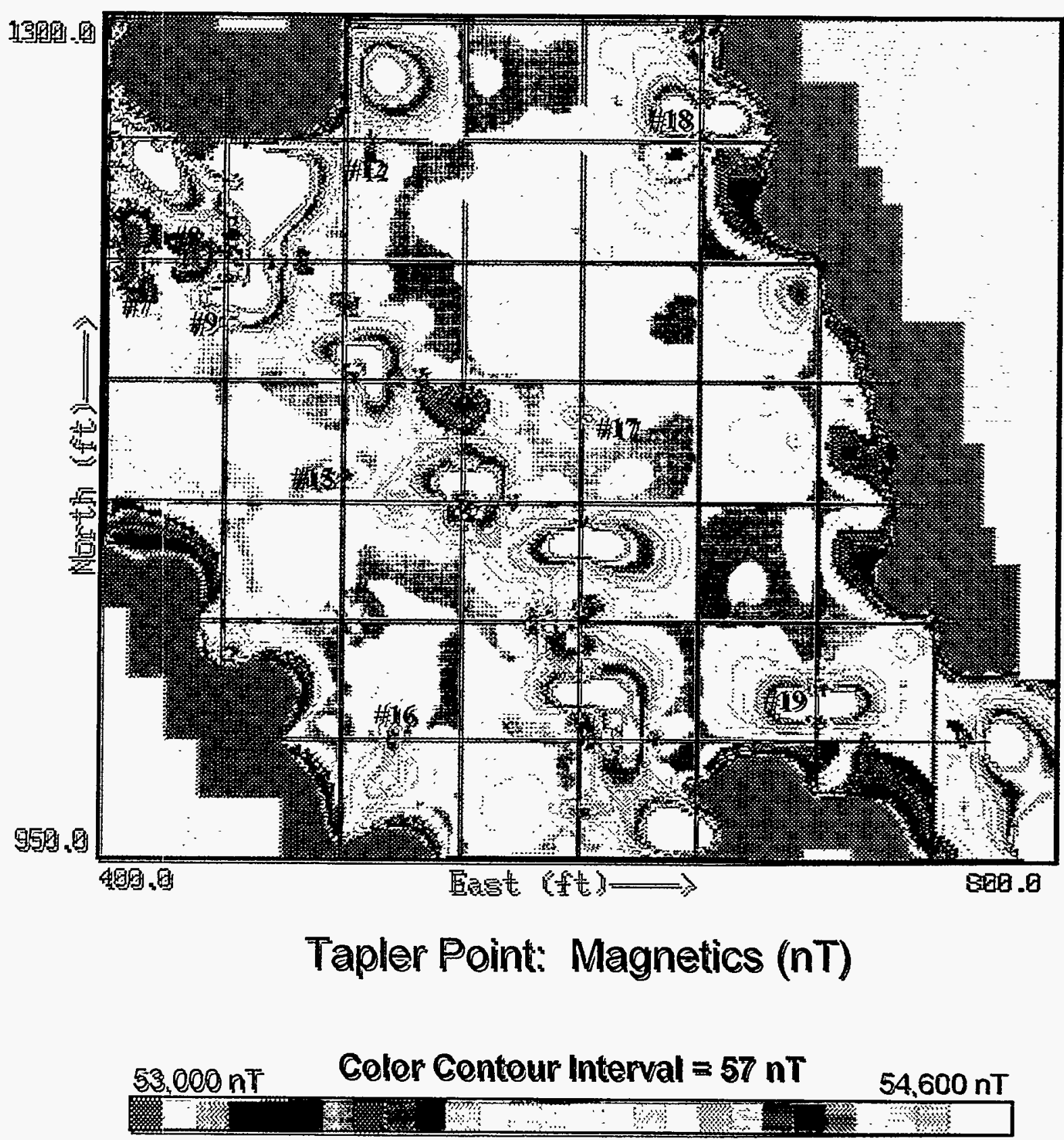

FIGURE C Total Field Magneties Mar, Nertheast Tapter Point, Inside the Security Fence 


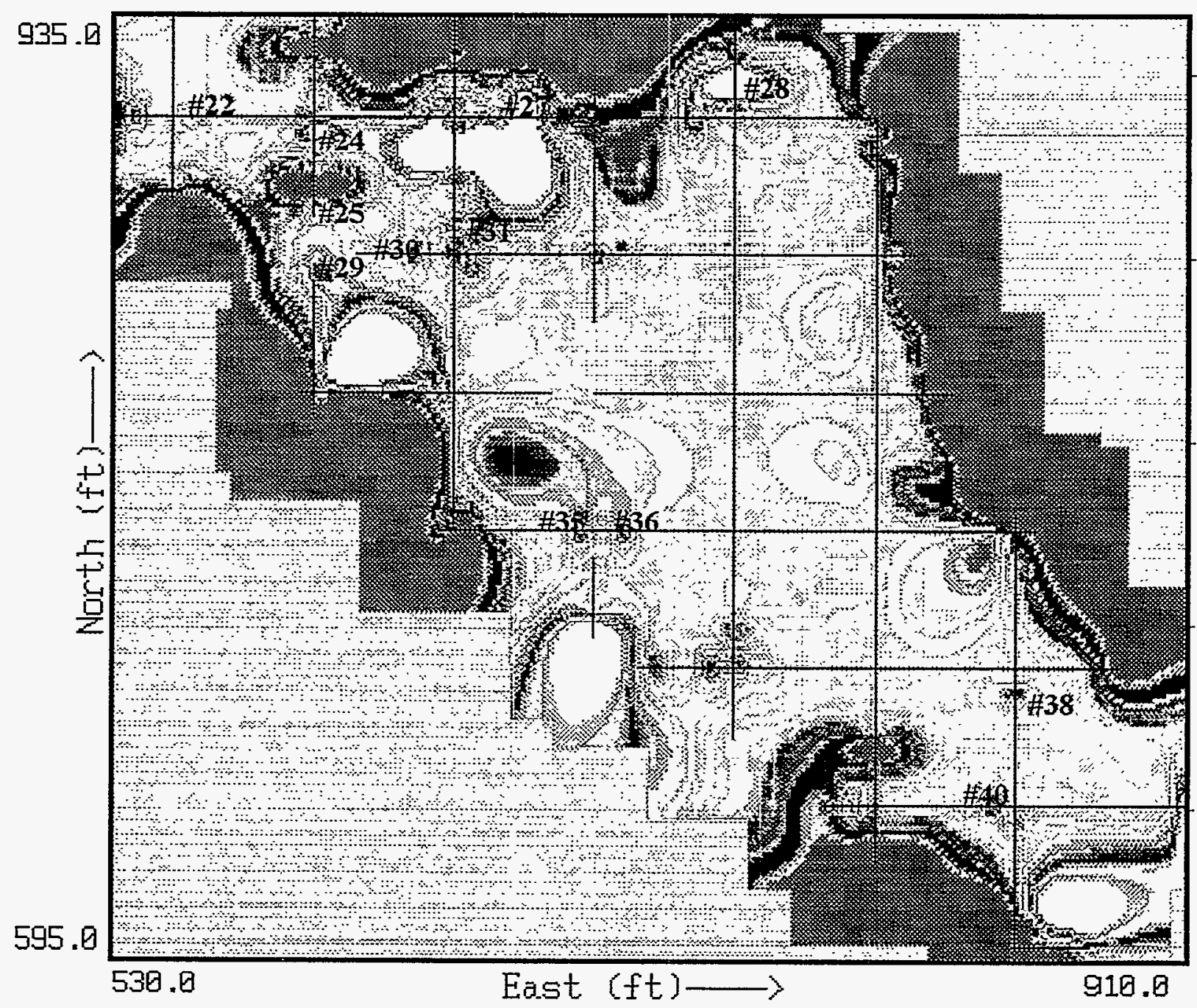

Tapler Point: Magnetics (nT)

\begin{tabular}{|c|c|c|}
\hline $53,000 \mathrm{nT}$ & Color Contour Interval $=57 \mathrm{nT}$ & $54,600 \mathrm{nT}$ \\
\hline & mE & wix \\
\hline
\end{tabular}

FIGURE 7 Total Field Magnetics Map, Southeast Tapler Point, Inside the Security Fence 

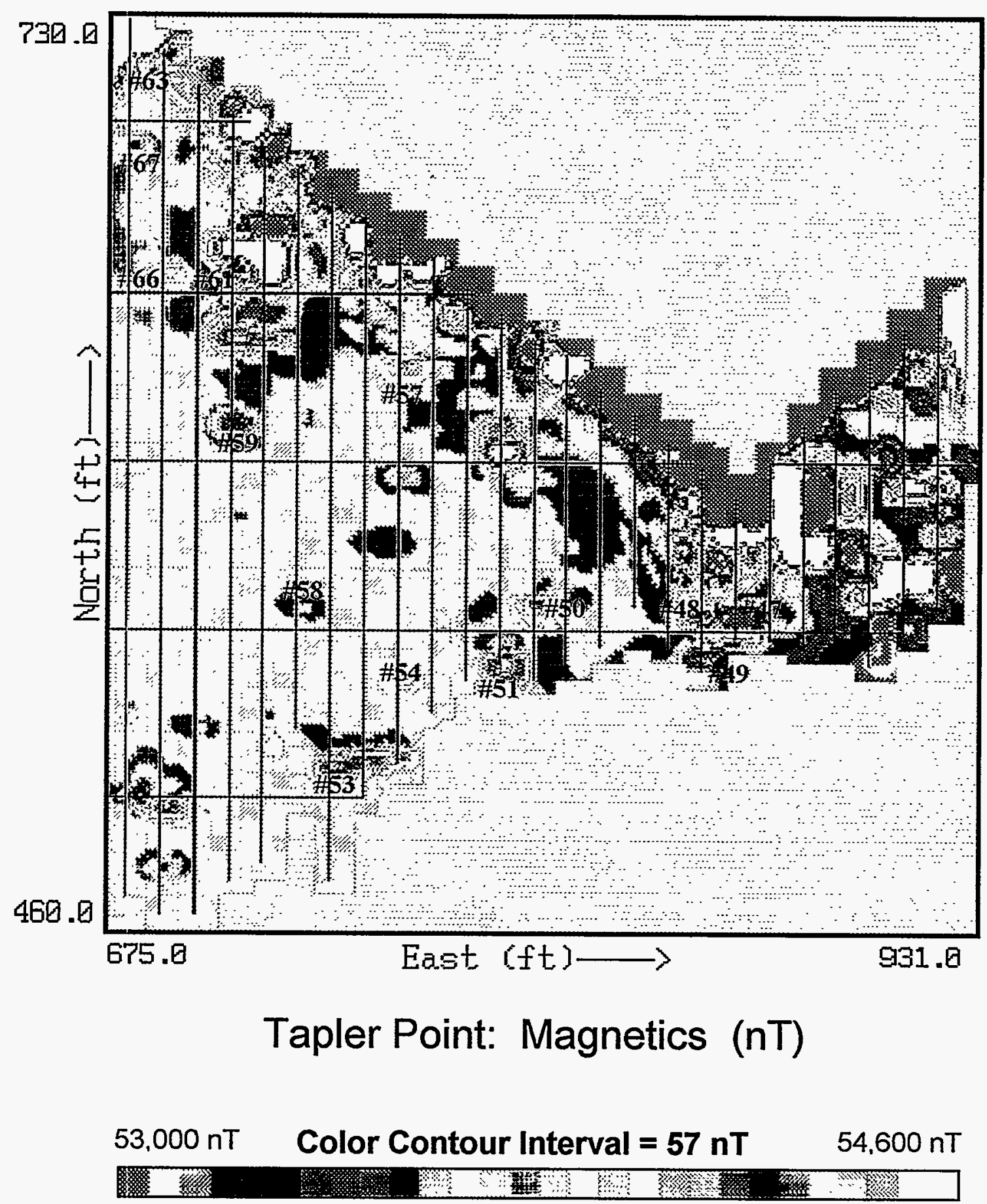

FIGURE 8 Total Field Magnetics Map, Southeast Tapler Point, Outside the Security Fence 
Isolated magnetic anomalies are scattered throughout the area between the 680 East and 870 East north/south profiles (Figure 8). Table 1 list 21 anomalies in this area (Anomalies \#47 through \#67), 14 from unknown buried sources. These 14 anomalies are plotted on Figure 8 . A number of mounds containing soil and some metallic debris are present in this area, although not all of the anomalies are associated with mounds.

Compared with the areas presented on the large-scale maps (Figures 6, 7, and 8), the remainder of the Tapler Point survey area is relatively quiet magnetically. Larger-magnitude anomalies located in southern Tapler Point are caused by visible metallic sources, including old tires with rims, a metal drum, and a pile of cut-up shells. Another anomalous area is located in the vicinity of $750 \mathrm{North} / 300$ East (Figure 5). These anomalies are associated with mounds of soil at this location. In addition, small-magnitude magnetic anomalies with unknown sources are present throughout the survey area (see Section 2.2).

The total field magnetics survey in the southern Bush River Peninsula was not designed to locate and map every ferrous anomaly and UXO within the study area. Figures 5 through 8 present magnetic data with a color contour interval of $57 \mathrm{nT}$. This interval was chosen to visually present the magnetic data to highlight significant anomalies and mute magnetometer fluctuations caused by small diurnal variations, sedimentalogical properties, and tie line (i.e., profile intersection) mismatches. Figures $9 \mathrm{~A}$ and $9 \mathrm{~B}$ illustrate the magnetically quiet northwest corner of the Tapler Point survey area with color contour intervals of 1 and $5 \mathrm{nT}$, respectively. The magnetic low in the northeast portion of these maps may be related to a feature described in Section 3.2.1 (EM-31 conductivity survey). The 1200 North east/west profile was performed the day after the other profiles presented in Figure 9; this resulted in a small diurnal variation. Figure 9A illustrates the slight diurnal variations and the resulting mismatches of tie lines. These variations are much less apparent, although still visible, when the contour interval is increased (Figure 9B). One magnetic anomaly, located at $1300 \mathrm{North} / 110$ East, is visible as a very small feature in Figure 5. Two magnetic anomalies, located at approximately 1215 North and 1235 North/250 East in Figures 9A and 9B, are not visible in Figure 5 because of the larger contour interval. Two factors affect the degree of the magnetometer response: (1) the size and orientation of the ferrous object, and (2) the distance between the object and the instrument. When a survey is conducted using profiles spaced greater than approximately 10 feet apart, these two factors cannot be reconciled; therefore we cannot be certain whether the small, individual anomalies in Figure 9 are "significant" from a UXO standpoint.

\subsubsection{CMBS-3}

The total field magnetics survey grid and site features for CMBS-3 are indicated on Figure 3. The area is covered by trees and bordered to the east by phragmite marsh. Accessibility was occasionally limited by fallen trees and undergrowth, particularly near the shoreline. 
jeñju| Jnoluo $\perp$ L-s :G

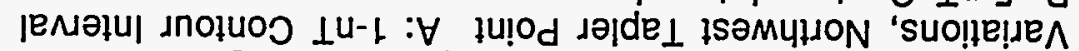

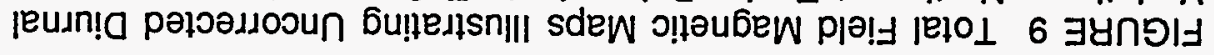

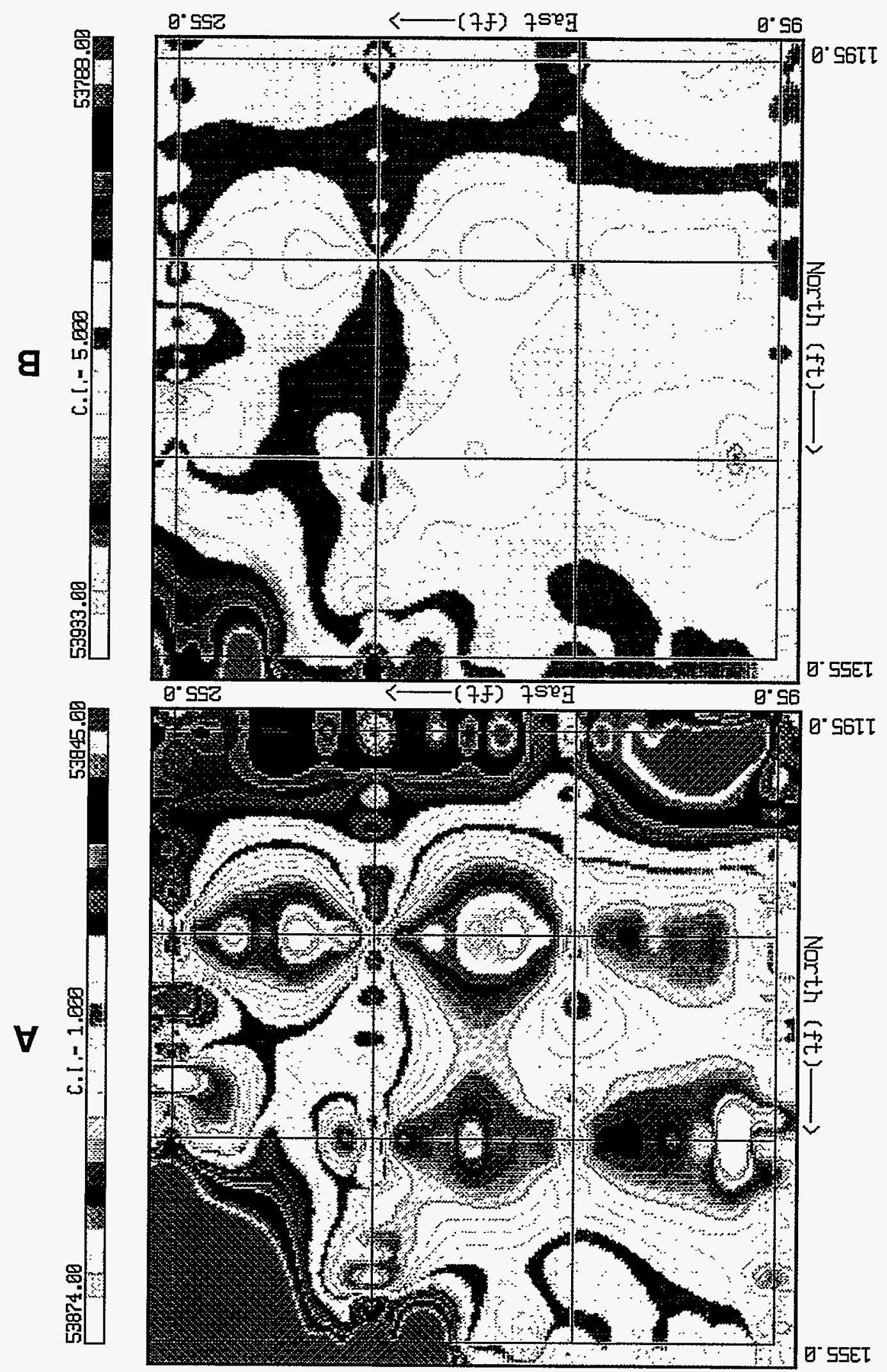


A magnetic map of the CMBS-3 survey area is presented in Figure 10. The color scale contour interval for CMBS-3 has been reduced compared with that used for the magnetic maps of Tapler Point to present this less magnetically anomalous site. Table 2 lists six buried magnetic anomalies with unknown sources located near the southern tip of CMBS-3. No metal objects were observed at these locations. Anomalies \#1 and \#6 (Table 2 and Figure 10) are associated with circular depressions. Small magnetic anomalies are also scattered throughout the site (see Section 2.2).

\subsubsection{CMBS-4}

The total field magnetics survey grid and site features for CMBS-4 are indicated on Figure 3. The area is located between ammunition storage igloos E-2634 (north) and E-2638 (south). The southern portion of CMBS-4 is an open area. Trees cover the northern and eastern portions of the site; these sections are also covered by undergrowth that occasionally limited accessibility.

Figure 11 presents a magnetic map of the CMBS-4 survey area. The color scale contour interval for this map has been reduced compared with that used for the Tapler Point maps. Table 3 lists 19 magnetic anomalies detected at CMBS-4 and includes their coordinates (at the center of each anomaly) and a brief description of each. Anomalies associated with 29th Street (along the western edge of CMBS-4), the two igloos, and the security fence surrounding Igloo E2634 are not listed.

Ten of the 19 anomalies listed in Table 3 are caused by unknown buried sources. These anomalies are plotted on Figure 11. None of the individual anomalies represents an areally extensive feature. The four anomalies in the northern portion of the survey area (\#13 through \#16) are caused by footings with steel bolts for a former observation tower. South of the footings is a small cluster of three anomalies (\#12, also plotted on Figure 11). A partially buried steel rail is present at this location, but it is not known whether this anomaly cluster is caused exclusively by the rail. Additional buried ferrous objects may be present at this location. Mounds containing soil and ferrous objects are present east of Igloo E-2638 (\#4, Figure 11). A comparison of the total field magnetic survey results and the EM-61 (metal detection) survey results is presented in Section 3.1.3.

\subsection{Magnetic Gradiometer Survey}

A magnetic gradiometer was used during the study to clear areas prior to placement of survey stakes and geophones. The gradiometer was also used between $50-\mathrm{ft}$ survey profiles at the Tapler Point survey area outside the security fence and at CMBS-3 to provide $100 \%$ 


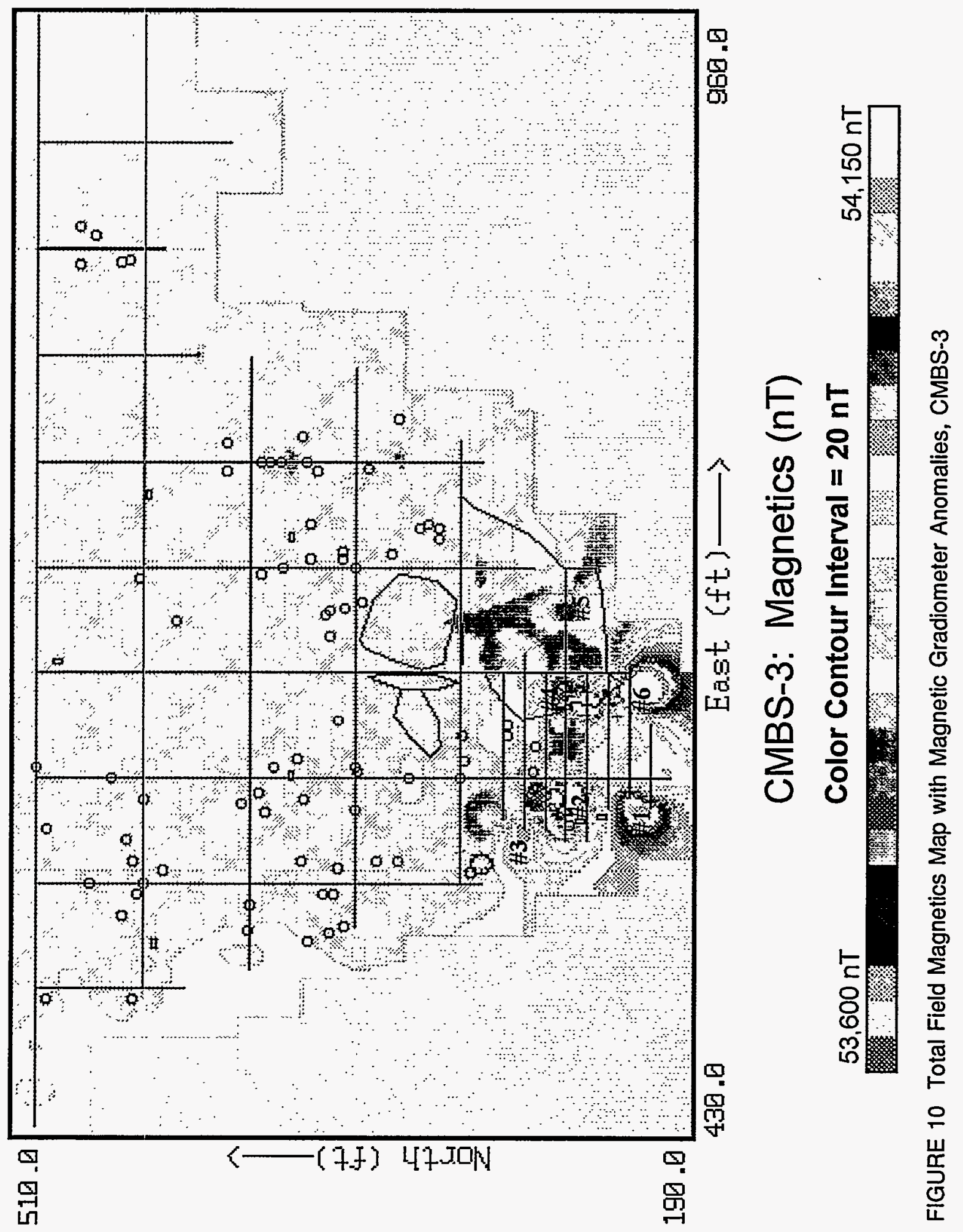


TABLE 2 Locations and Descriptions of Magnetic Anomalies Detected at CMBS-3

\begin{tabular}{cccl} 
& \multicolumn{2}{c}{ Coordinates } & \\
\cline { 2 - 3 } Number & North & East & \multicolumn{1}{c}{ Anomaly Description } \\
& & & \\
& & & \\
1 & $210-220$ & $580-590$ & Source unknown, depression on shoreline \\
2 & 250 & 590 & Source unknown, slight mound \\
3 & 270 & 575 & Source unknown, 10 ft from shoreline \\
4 & 240 & 635 & Source unknown \\
5 & 250 & 675 & Source unknown \\
6 & 220 & 640 & Source unknown, anomaly in bottom of depression \\
\hline
\end{tabular}

coverage of these areas. The locations of anomalies detected during the gradiometer survey are overlain as black outlines on the total field magnetics maps for Tapler Point and CMBS-3 (Figures 5 and 10, respectively).

Small gradiometer anomalies are scattered throughout the area north of Tapler Point, outside the security fence. The shoreline area and the southeastern corner of Tapler Point were surveyed by using the total field magnetometer on a 10-ft line spacing (Figure 5). The blackoutlined areas near the security fence to the north represent partially buried sections of old fencing materials. An almost linear feature of small magnetic anomalies trending northeast to southwest ends in the west-central portion of the site, near the total field anomaly associated with several mounds of debris (discussed in Section 2.1.1).

Small magnetic anomalies are also scattered throughout CMBS-3 (Figure 10). The larger areas outlined in the southern portion of CMBS-3 represent portions of the site where the density of anomalies was too high for individual identification. None of the anomalies detected during the gradiometer survey at CMBS-3 is large; most represent small metal fragments. 


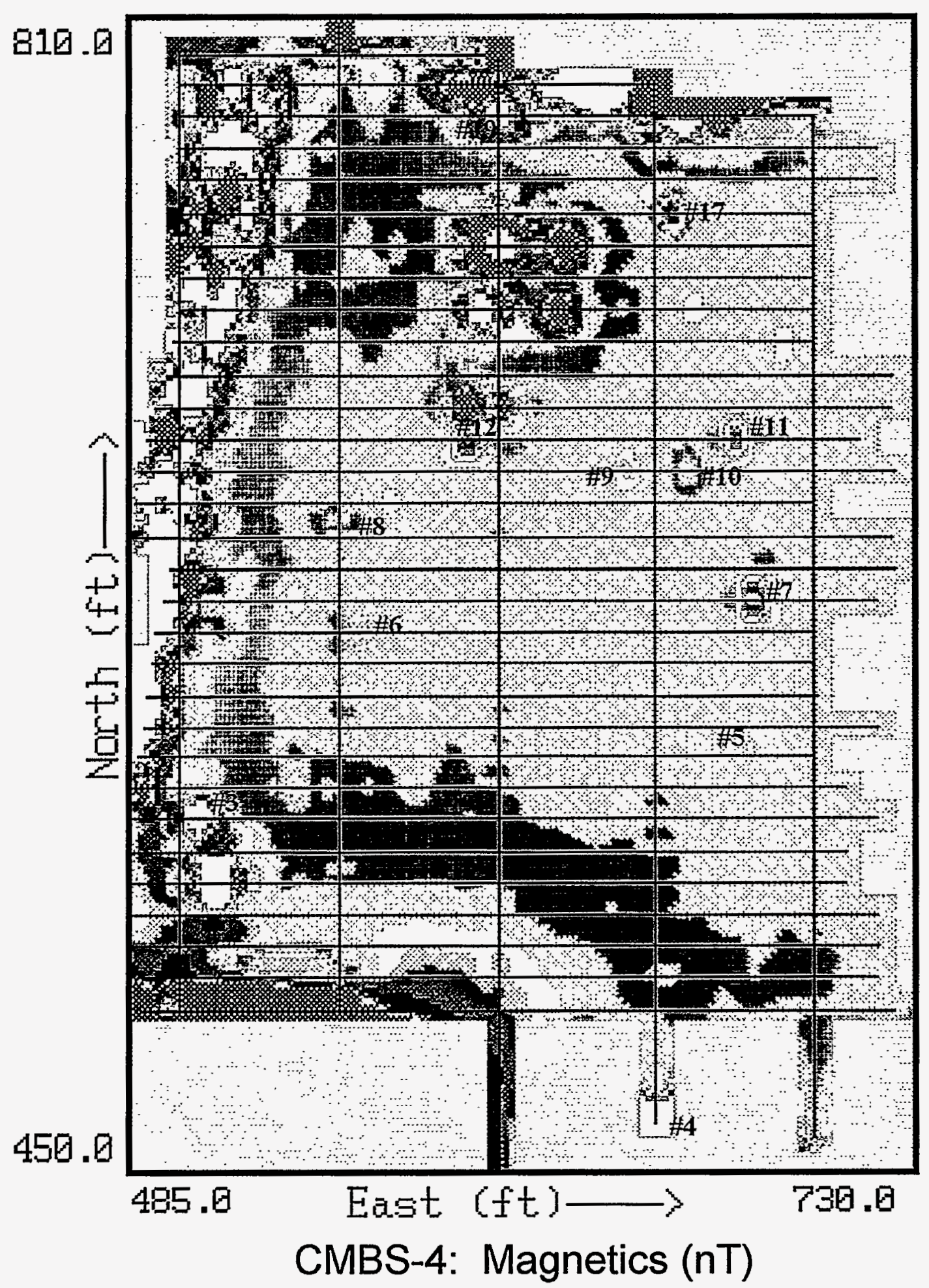

$53,300 \mathrm{nT} \quad$ Color Contour Interval = $38 \mathrm{nT} \quad 54,350 \mathrm{nT}$

FIGURE 11 Total Field Magnetics Map, CMBS-4 
TABLE 3 Locations and Descriptions of Magnetic Anomalies Detected at CMBS-4

\begin{tabular}{rlrl} 
& \multicolumn{2}{c}{ Coordinates } & \\
\cline { 2 - 3 } Number & North & East & \\
\cline { 2 - 3 } & & & \\
1 & 500 & 495 & Sign post \\
2 & 546 & 505 & Light post with underground electric service \\
3 & 560 & 505 & Source unknown \\
4 & 460 & 650 & Source unknown, mounds present \\
5 & 580 & 680 & Source unknown, mounds present \\
6 & 620 & 560 & Source unknown \\
7 & 630 & 675 & Source unknown, depression present \\
8 & 655 & 550 & Source unknown \\
9 & 670 & 640 & Source unknown \\
10 & 670 & 660 & Metal pin flag marker, no EM-61 lower coil response \\
11 & 680 & 675 & Source unknown \\
12 & $680-690$ & $580-600$ & Steel rail with other potential buried anomaly(ies) \\
13 & 718 & 620 & Concrete pad with bolts \\
14 & 720 & 595 & Concrete pad with bolts \\
15 & 738 & 623 & Concrete pad with bolts \\
16 & 740 & 600 & Concrete pad with bolts \\
17 & 750 & 660 & Source unknown \\
18 & 767 & 654 & Cylinder fragment \\
19 & 780 & 600 & Source unknown \\
& & & \\
\hline
\end{tabular}




\section{Electromagnetic Surveys}

Electrical properties of the earth in the southern Bush River Peninsula were measured by using two electromagnetic instruments: the EM-31 (output read in conductivity) and the timedomain EM-61 (output in $\mathrm{mV}$ ). The EM-61 surveys were performed to identify ferrous and nonferrous metallic objects along the same survey profile lines used for the magnetometer surveys (Figure 3). The EM-31 surveys were performed to identify regional trends in the nearsurface (upper $18 \mathrm{ft}$ ) geology and hydrogeology. Large metallic sources were also identified with the EM-31 in the quad-phase mode.

\subsection{Time-Domain Millivolt EM-61 Surveys}

Inspection of the EM-61 data set acquired at Tapler Point indicates that the millivolt measurements obtained from the lower coil ( $\mathrm{CH} 2)$ are sufficient to identify buried metallic sources to a depth of 9 feet along the profile lines. In the following sections, data collected with the EM-61 metal detector are compared with the magnetic data described in Section 2.

\subsubsection{Tapler Point}

EM-61 data were collected at Tapler Point along profiles spaced $50 \mathrm{ft}$ apart in the north/south and east/west directions, similar to the magnetometer survey profiles (Figure 3 ). Some segments of the individual profiles were not completed because undergrowth at the site limited accessibility for the EM-61 instrument. Figure 12A provides a color-contour map constructed from EM-61 CH2 data. As with the total field magnetics, dominant features include the security fence and the ammunition igloos. A comparison with the magnetic survey data is presented in Figure 12B; black-outlined magnetic contours are plotted over the color contour EM-61 data. Figure 12B indicates that the majority of the anomalies found during the EM-61 survey correspond to magnetic (ferrous) anomalies; however, some scattered metallic anomalies detected during the EM- 61 survey do not have magnetometer equivalents. Figures 13, 14, and 15 show expanded views of Figure 12B in order to provide a visual representation of specific nonferrous anomalies detected during the EM-61 survey. Table 4 lists the coordinates and provides descriptions of the EM-61 anomalies, which are discussed below.

Figure 13 presents the EM-61 data overlain by magnetic contours for the northwestern portion of the Tapler Point area. Six anomalies (\#1 through \#6) are plotted on Figure 13; their locations are listed in Table 4. Anomaly \#5 may represent two separate electromagnetic anomalies at the location of a magnetic anomaly discussed in Section 2.1.1 and shown in Figures $9 \mathrm{~A}$ and $9 \mathrm{~B}$. The buried object(s) represented by anomaly \#5 probably contain(s) both ferrous and nonferrous metals. 


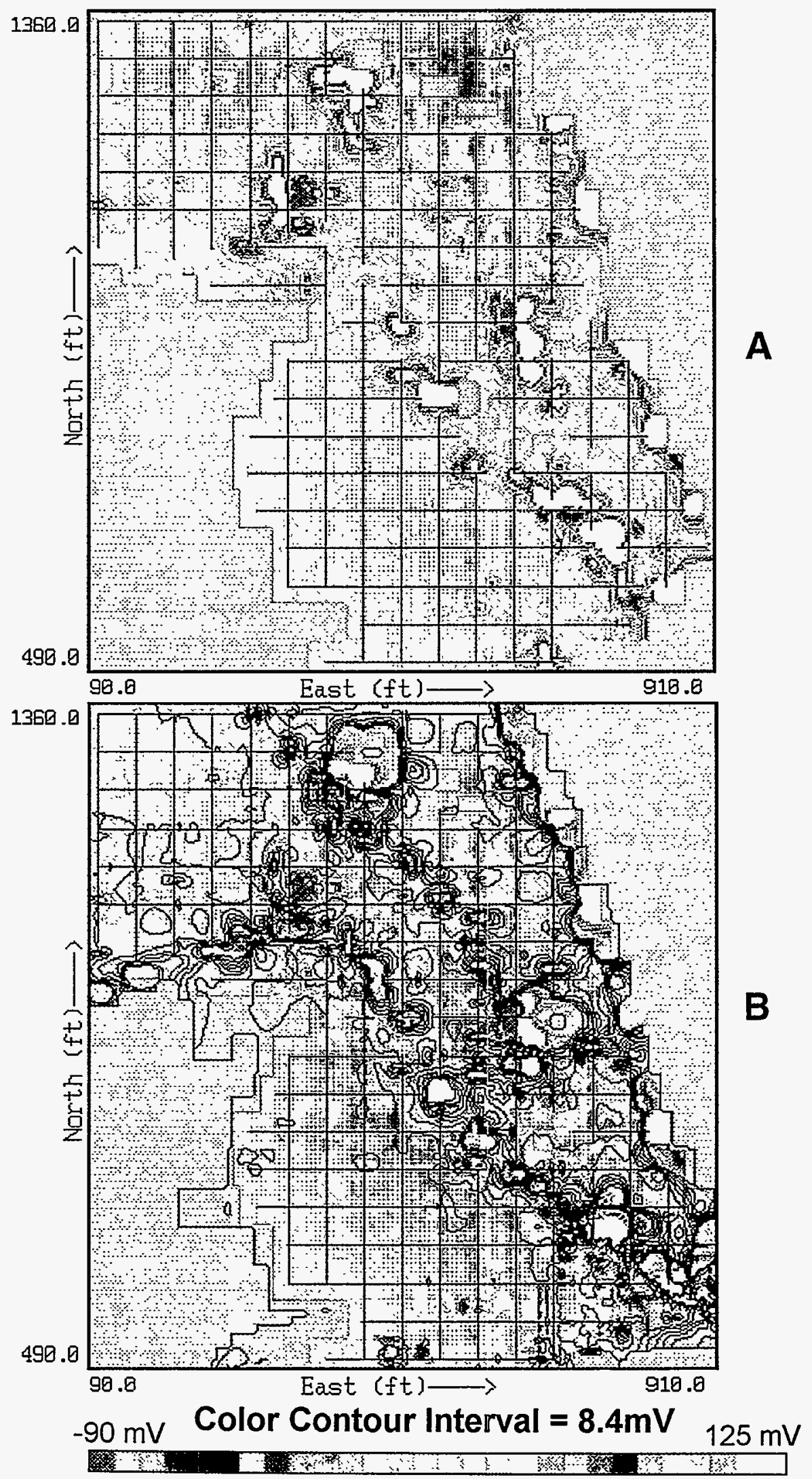

FIGURE 12 A: EM-61 Map, Tapler Point B: EM-61 Map Overlain with Magnetic Contours 


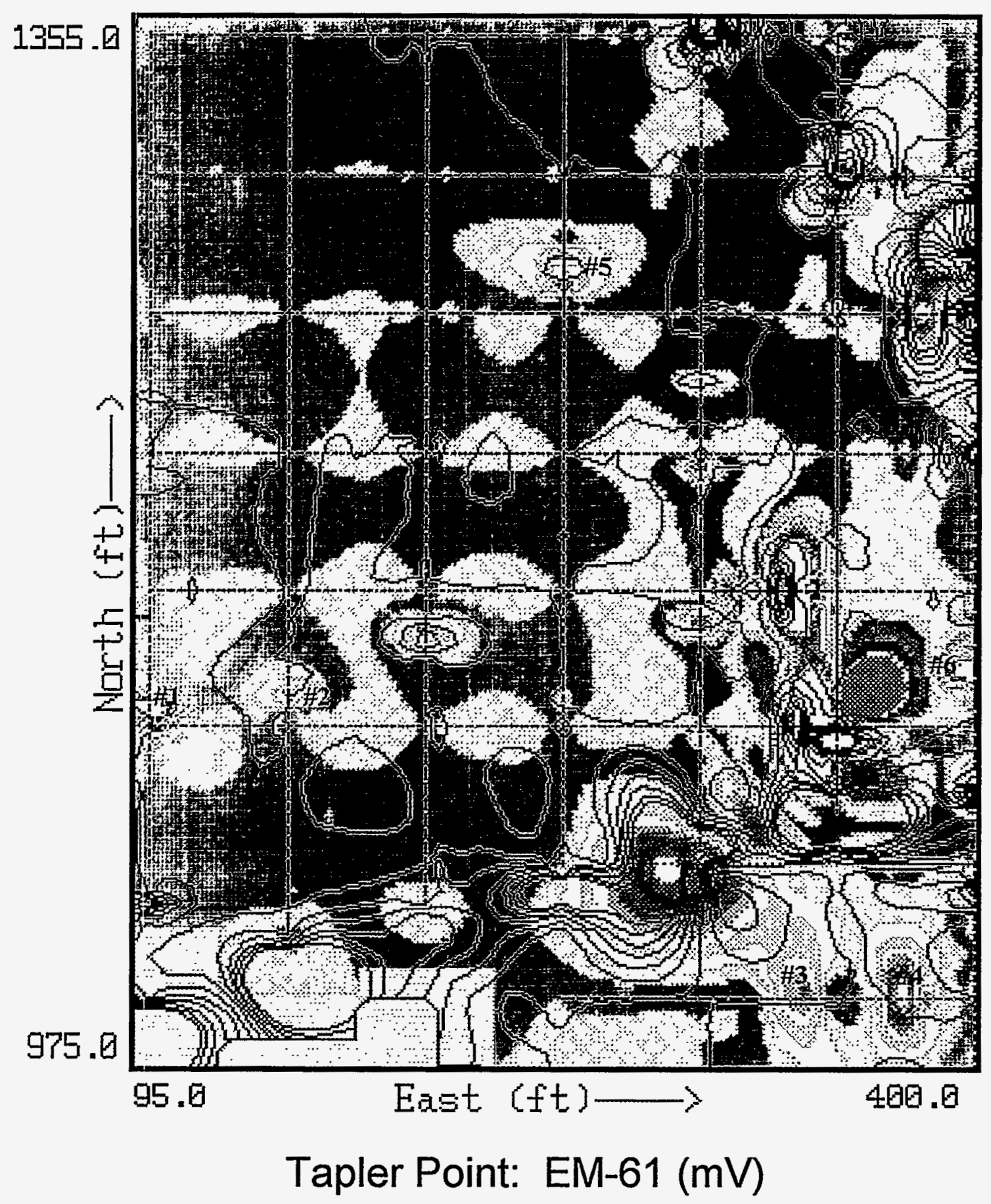

$-90 \mathrm{mV}$ Color Contour Interval = $\mathbf{8 . 4} \mathrm{mV} \quad 125 \mathrm{mV}$

FIGURE 13 EM-61 Map Overlain with Magnetic Contours, Northwest Tapler Point 


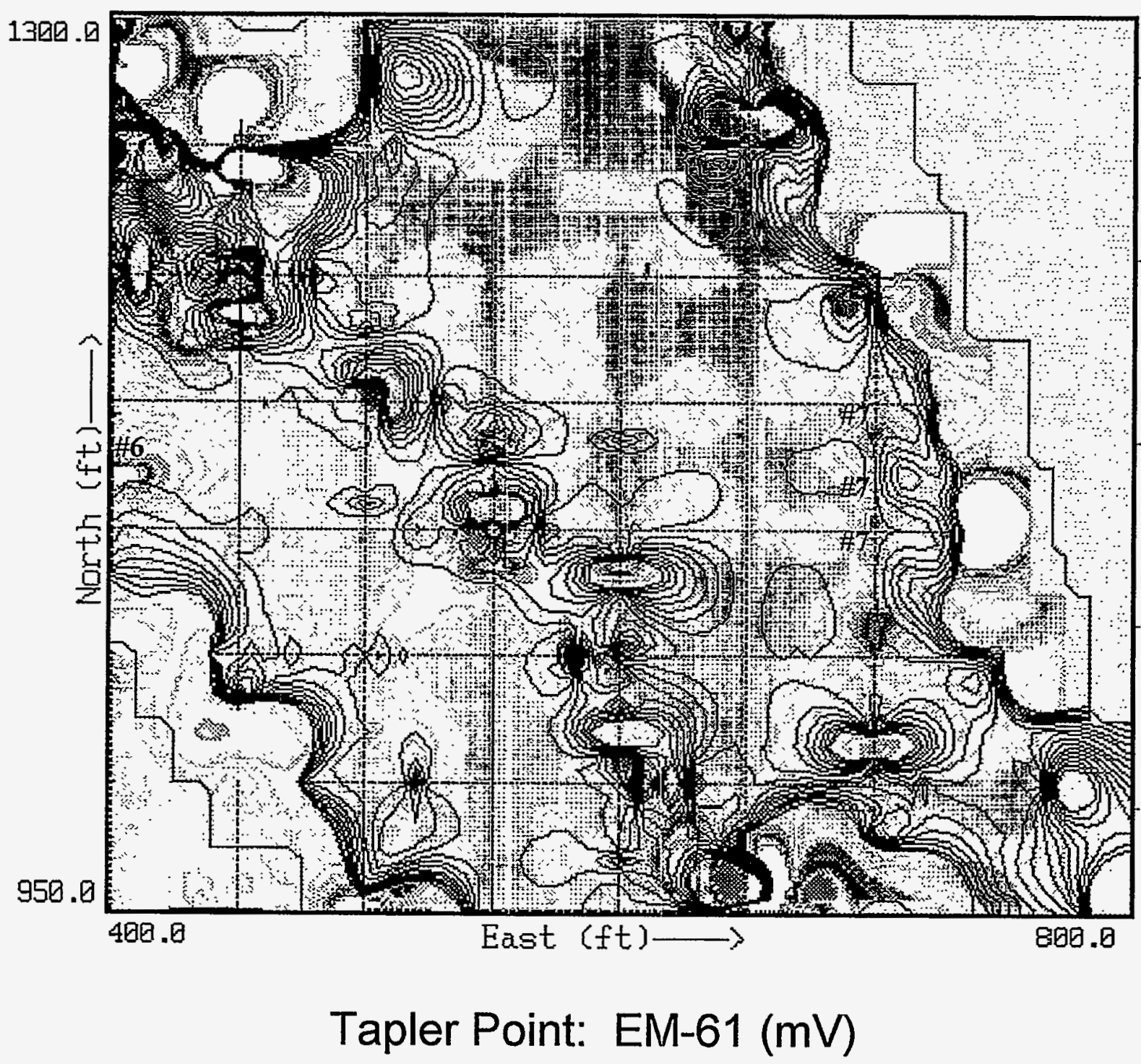

Color Contour Interval $\mathbf{=} 8.4 \mathrm{mV}$

$-90 \mathrm{mV}$.

FIGURE 14 EM-61 Map Overlain with Magnetic Contours, Northeast Tapler Point 


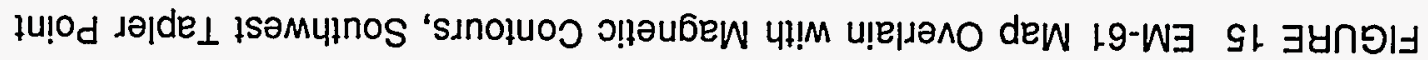

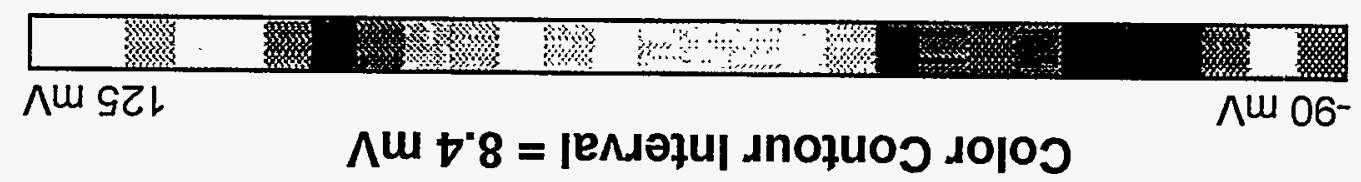

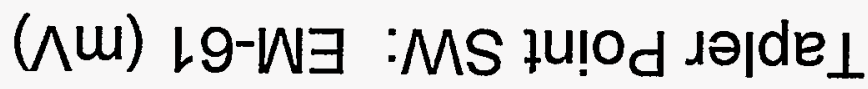

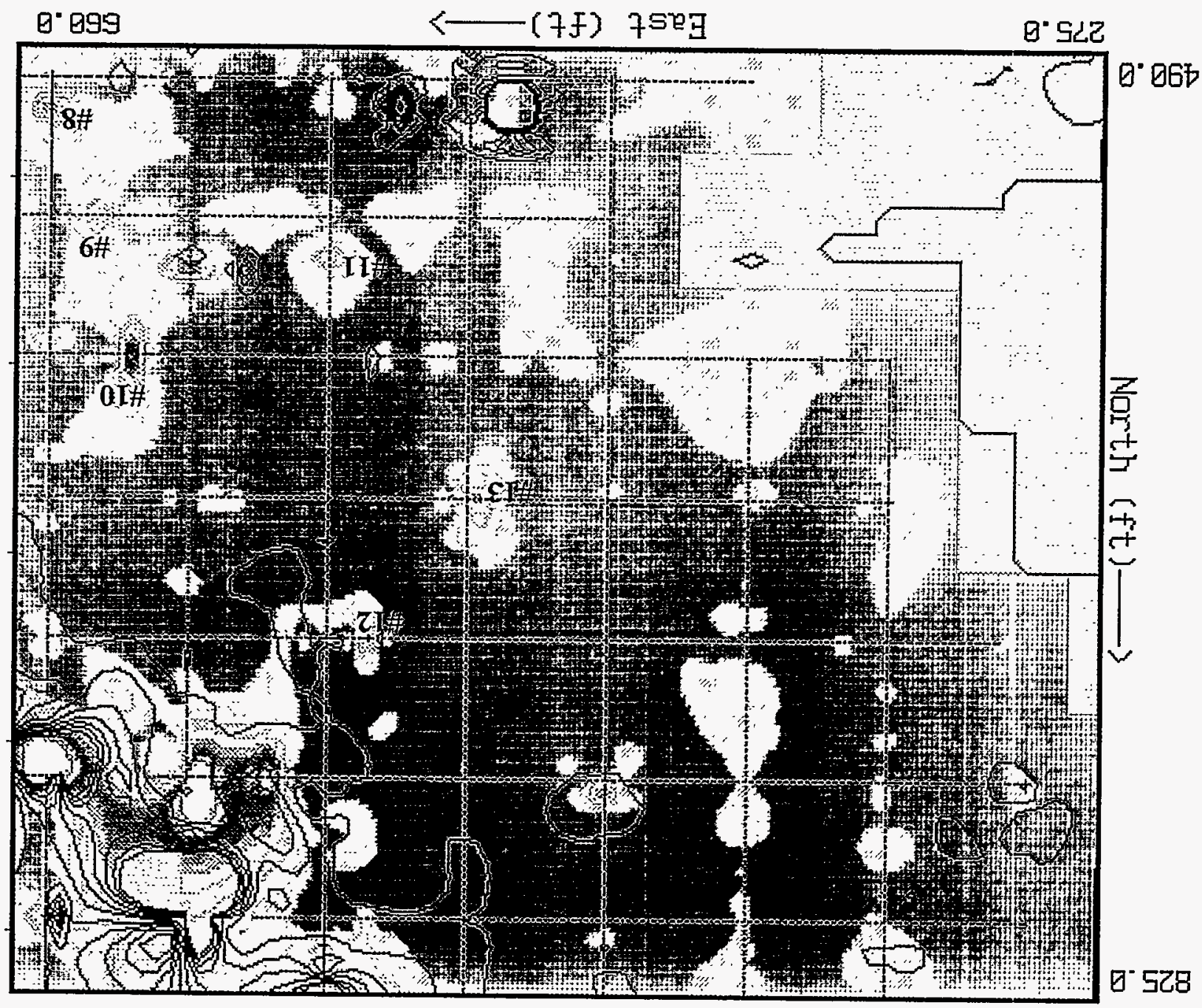


TABLE 4 Locations and Descriptions of Non-Magnetic EM-61 Anomalies Detected at Tapler Point

\begin{tabular}{rcrl}
\hline & \multicolumn{2}{c}{ Coordinates } & \\
\cline { 2 - 3 } Number & North & East & \multicolumn{1}{c}{ Anomaly Description } \\
& & & \\
\hline & 1105 & 100 & Source unknown \\
2 & 1110 & 150 & Source unknown \\
3 & 1000 & 335 & Source unknown, low-lying area \\
4 & 1000 & 365 & Source unknown, low-lying area \\
5 & $1260-1270$ & 250 & Two anomalies, source unknown \\
6 & 1120 & 400 & Source unknown, mound present \\
7 & $1060-1150$ & 700 & Six separate anomalies, source unknown \\
8 & 510 & 650 & Source unknown \\
9 & 550 & 635 & Source unknown \\
10 & 600 & 620 & Source unknown \\
11 & 565 & 550 & Source unknown \\
12 & 700 & 540 & Source unknown \\
13 & 650 & 495 & Source unknown \\
\hline
\end{tabular}

Figure 14 presents the EM-61 data overlain by magnetic contours for the area inside the security fence between igloos E-2654 and E-2656, in an area similar to that shown in the magnetic map in Figure 6. Anomaly \#6 is shown on both Figures 13 and 14 and represents an unknown buried source at the location of a small mound. Anomaly \#7 includes six separate EM-61 anomalies, detected along the 700 East north/south profile, representing buried, nonferrous metallic objects.

Not all of the magnetic anomalies were detected during the EM-61 survey. One magnetic anomaly located at $1260 \mathrm{North} / 650$ East (\#18, Figure 6) was not detected with the EM-61 and may represent a ferrous object located very near the surface at this location.

Figure 15 presents EM-61 data overlain by magnetic contours for the southwestern portion of the Tapler Point survey area, outside of the security fence. Six EM-61 anomalies (\#8 through \#13) without corresponding magnetic anomalies are listed in Table 4 and plotted on Figure 15. Each of these anomalies represents buried, nonferrous metallic objects.

\subsubsection{CMBS-3}

EM-61 data were collected at CMBS-3 along 50-ft and 10-ft profiles similar to those used for the magnetometer survey. Figure 16 presents a comparison of color-contoured EM-61 CH2 


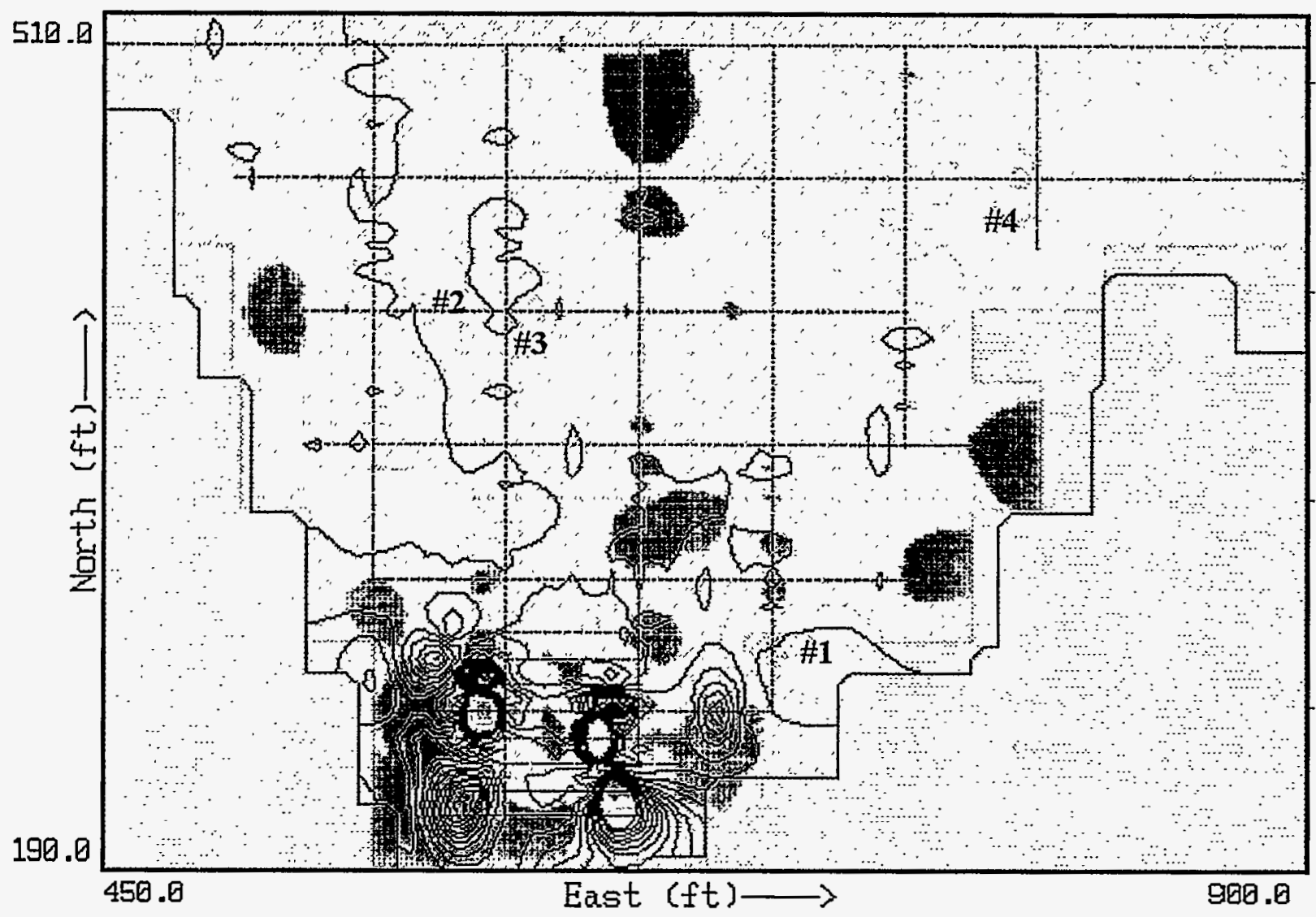

CMBS-3: EM-61 (mV)

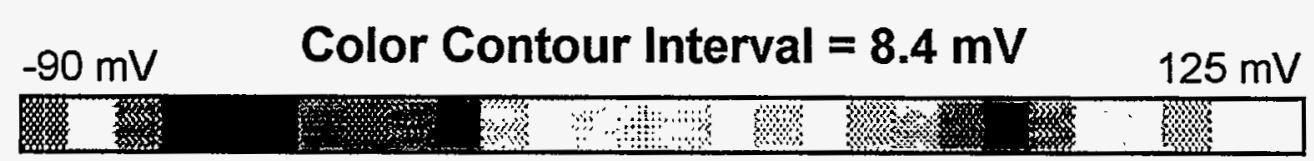

FIGURE 16 EM-61 Map Overlain with Magnetic Contours, CMBS-3 
(lower coil) data overlain by black-outlined magnetic data for CMBS-3. Table 5 lists the locations of four nonferrous anomalies detected at CMBS-3. These anomalies, which are caused by unknown, buried sources that do not correspond to magnetic anomalies, are plotted on Figure 16 (\#1 through \#4). Other anomalies representing small metallic objects are located throughout the survey area, as indicated on Figure 16.

\subsubsection{CMBS-4}

EM-61 data were collected at CMBS-4 along profiles spaced $10 \mathrm{ft}$ apart, similar to those used for the magnetometer survey. A comparison of color-contoured EM-61 CH2 data with the overlain black-outlined magnetic data for CMBS-4 is presented in Figure 17. Table 6 lists the locations of seven nonferrous anomalies detected at CMBS-4. These anomalies are caused by unknown buried sources that do not correspond to magnetic anomalies. The seven anomalies are indicated on Figure 17 (\#1 through \#7). Some anomalies detected during the magnetometer survey at CMBS-4 (including anomalies \#10 and \#17, Table 3), were not detected during the EM-61 survey and represent ferrous objects located very near the surface.

\subsection{EM-31 Conductivity Meter Surveys}

Horizontal conductivity measurements were obtained by using a Geonics EM-31 on 50-ft and 10-ft transects, similar to those used for the total field magnetic surveys (Figure 3). Data were acquired every 0.5 seconds, resulting in data points spaced $1.0-1.5 \mathrm{ft}$ apart, depending on the traverse rate. Fiducial marks were placed every $50 \mathrm{ft}$ to correctly position the data within each profile.

The EM-31 instrument measures the apparent subsurface conductivity from just beneath the land surface to a depth of approximately $18 \mathrm{ft}$. Factors affecting subsurface conductivity

TABLE 5 Locations and Descriptions of NonMagnetic EM-61 Anomalies Detected at CMBS-3

\begin{tabular}{llll}
\hline & \multicolumn{2}{c}{ Coordinates } & \\
\cline { 2 - 3 } Number & North & East & Anomaly Description \\
& & & \\
\hline & 275 & 700 & Source unknown \\
2 & 400 & 570 & Source unknown \\
3 & 400 & 610 & Source unknown \\
4 & 450 & 790 & Source unknown \\
\hline
\end{tabular}



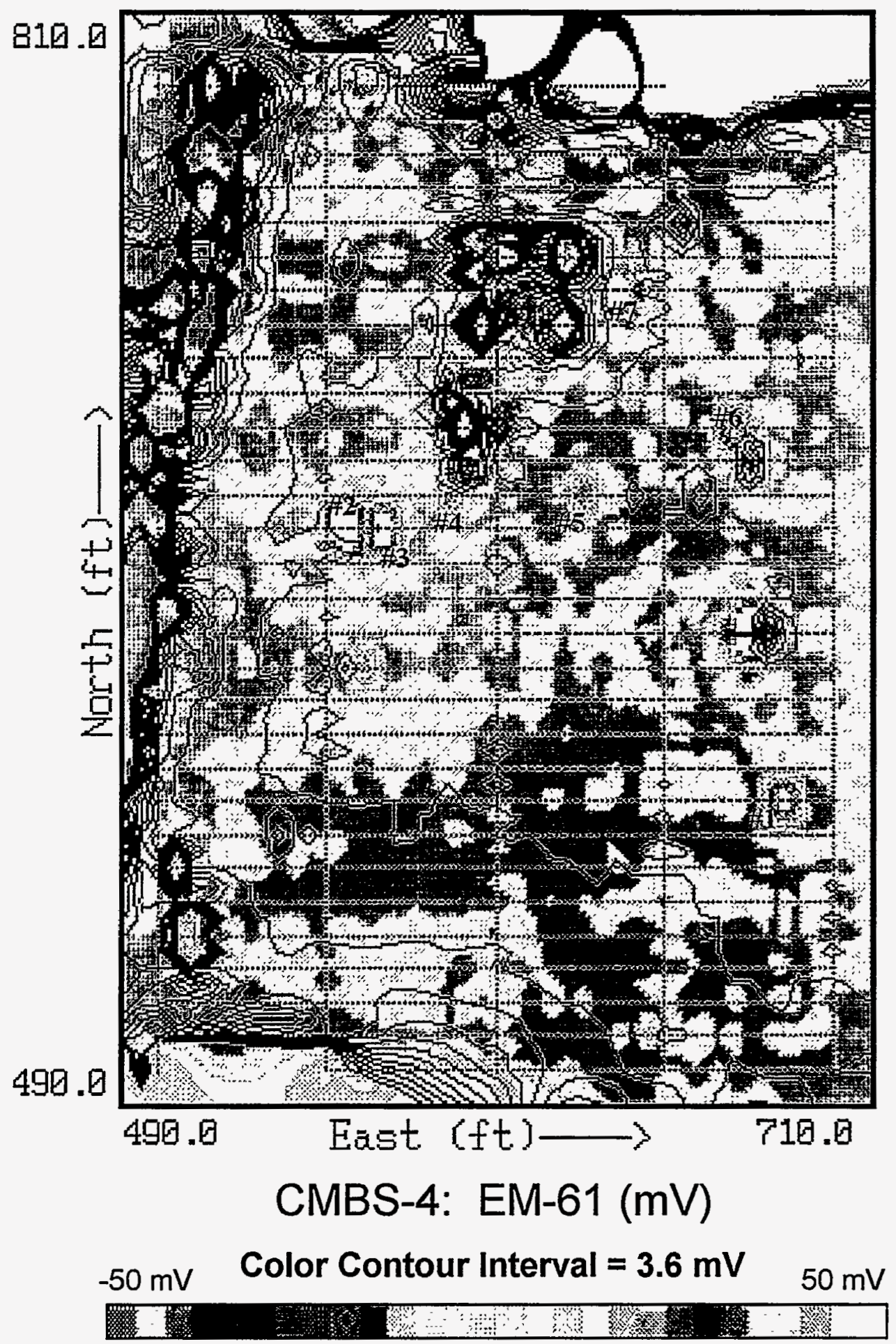

FIGURE 17 EM-61 Map Overlain with Magnetic Contours, CMBS-4 
TABLE 6 Locations and Descriptions of Non-Magnetic EM-61 Anomalies Detected at CMBS-4

\begin{tabular}{llll}
\hline & \multicolumn{2}{c}{ Coordinates } & \\
\cline { 2 - 3 } Number & North & East & \multicolumn{1}{c}{ Anomaly Description } \\
\hline & & & \\
1 & 580 & 685 & Source unknown, mound present \\
2 & 660 & 555 & Source unknown \\
3 & 660 & 565 & Source unknown \\
4 & 670 & 585 & Source unknown \\
5 & 670 & 630 & Source unknown \\
6 & 690 & 670 & Source unknown \\
7 & 730 & 635 & Source unknown, near tower base \\
\hline
\end{tabular}

include the following: percent saturation, chemical composition of the groundwater, sand/silt/clay percentages, type of clay minerals, presence of metals, and presence of amphibolitic roadfill. The EM-31 data were interpreted in conjunction with the magnetic, GPR, topographic, and boring data for the Bush River Peninsula study area. These other data were used to help clarify and discriminate between factors potentially affecting the measured apparent conductivity.

EM-31 surveys were conducted at the Bush River Peninsula sites along the same grid used for the magnetic surveys (Figure 3 ). The results of the EM-31 surveys are presented in Figures 18 through 22. Apparent conductivities shown on the maps range from approximately -90 to $400 \mathrm{mS} / \mathrm{m}$; the greatest conductivity ranges were observed near large surficial metallic objects (fences and ammunition igloos), roadways, and underground utilities. Although metals are good conductors, their shape and orientation in relation to the azimuth of the EM-31 transmitter and receiver can result in an electromagnetic field in which the apparent conductivity, as read by the EM-31, is negative. Negative conductivities are an artifact of crossing highconductivity gradients with the EM-31 boom. When crossed at right angles by the EM-31, an elongated piece of metal (such as a buried pipe or wire) will produce three banded anomaly lineaments. The lineaments will consist of a central minimum bounded by two maxima (Geonics Limited 1992). This EM-31 signature for buried pipes has previously been observed at Beach Point and Kings Creek in APG (see McGinnis et al. 1994a; Davies et al. 1995).

\subsubsection{Tapler Point}

The results of the conductivity survey for the Tapler Point area are shown in Figure 18. The features with the greatest conductivity contrast are associated with the security fence and 


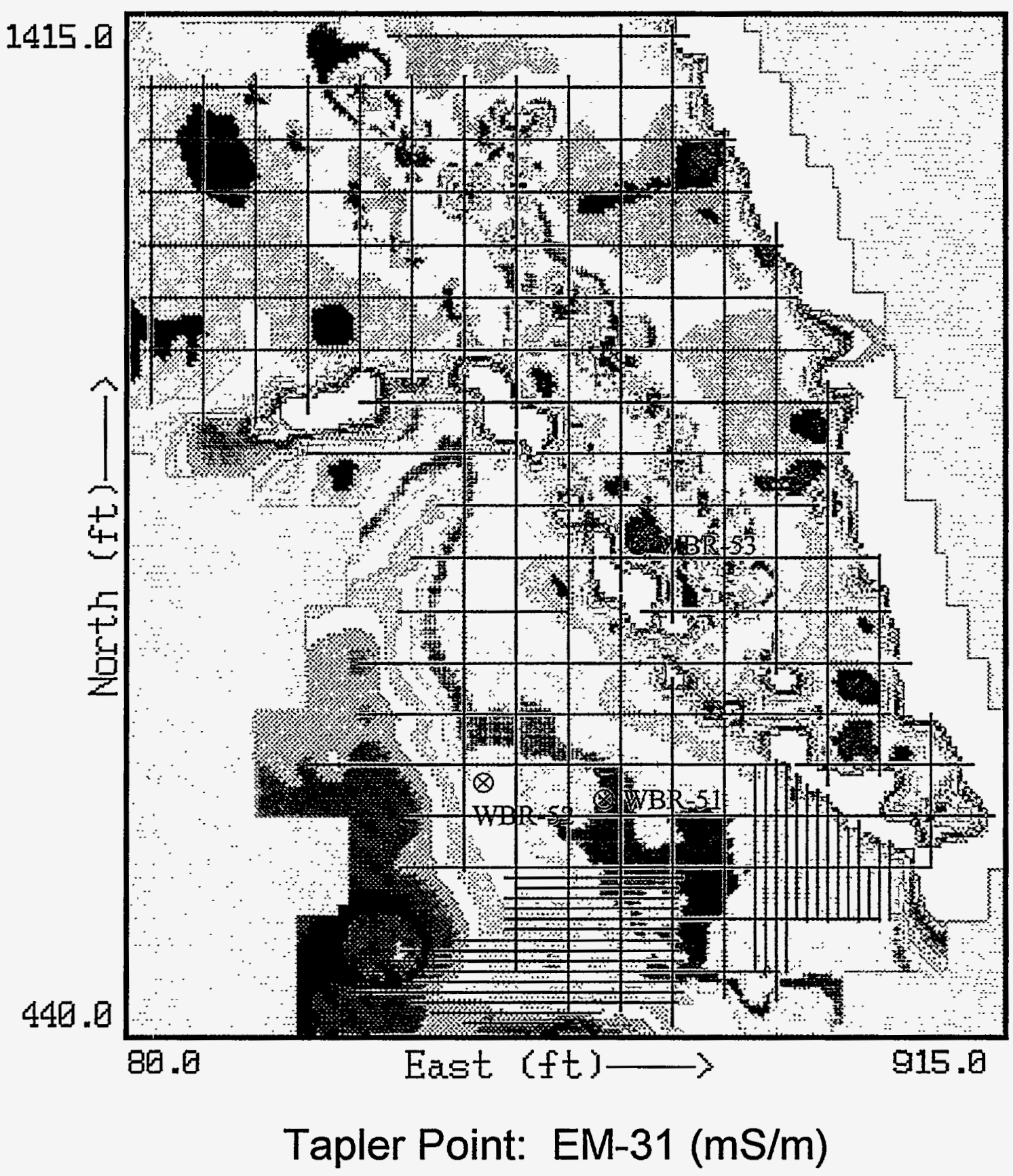

$-50 \mathrm{mS} / \mathrm{m}$ Color Contour Interval $=5.7 \mathrm{mS} / \mathrm{m} \quad 110 \mathrm{mS} / \mathrm{m}$

FIGURE 18 EM-31 Electromagnetics Map, Tapler Point 

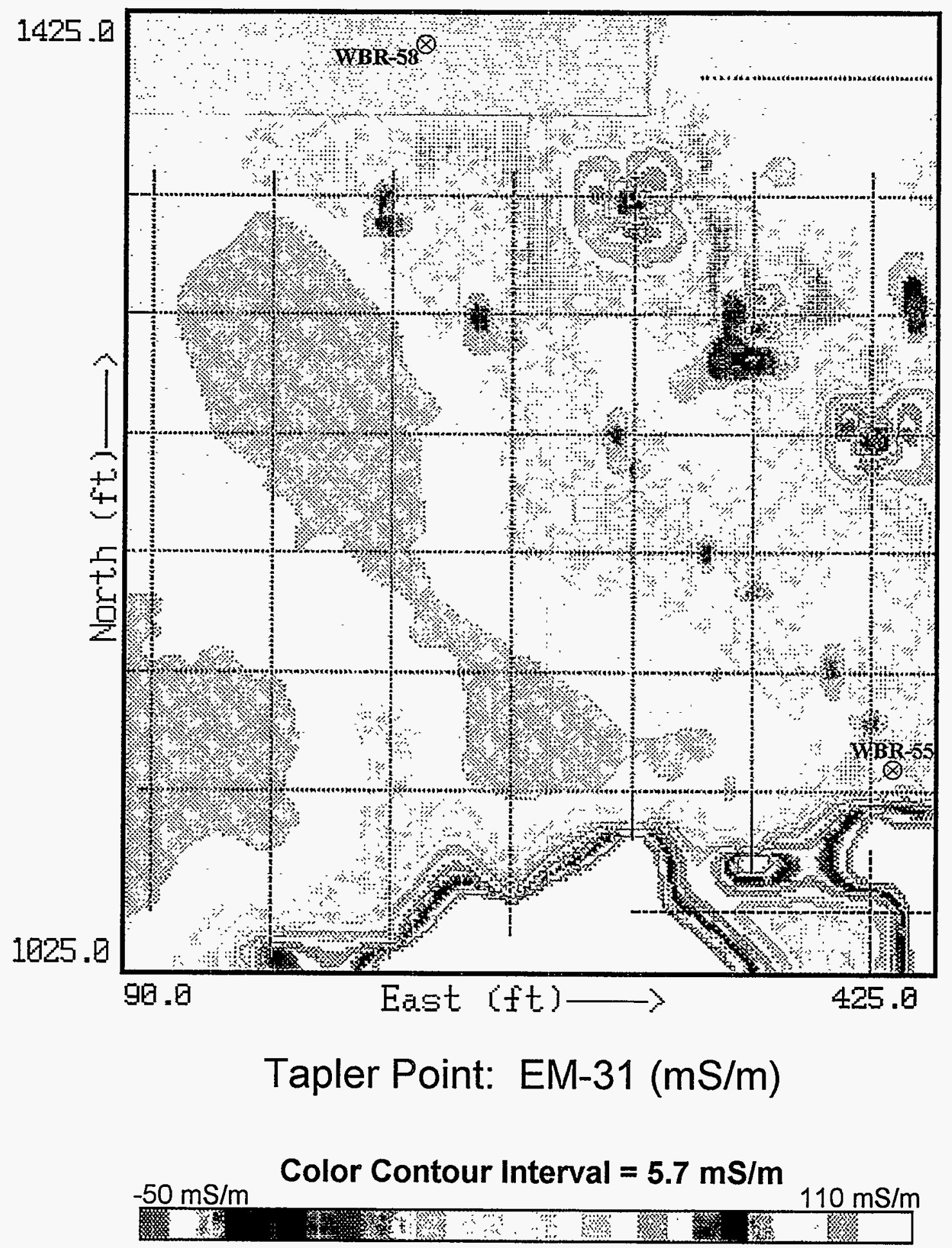

FIGURE 19 EM-31 Electromagnetics Map, Northwest Tapler Point 


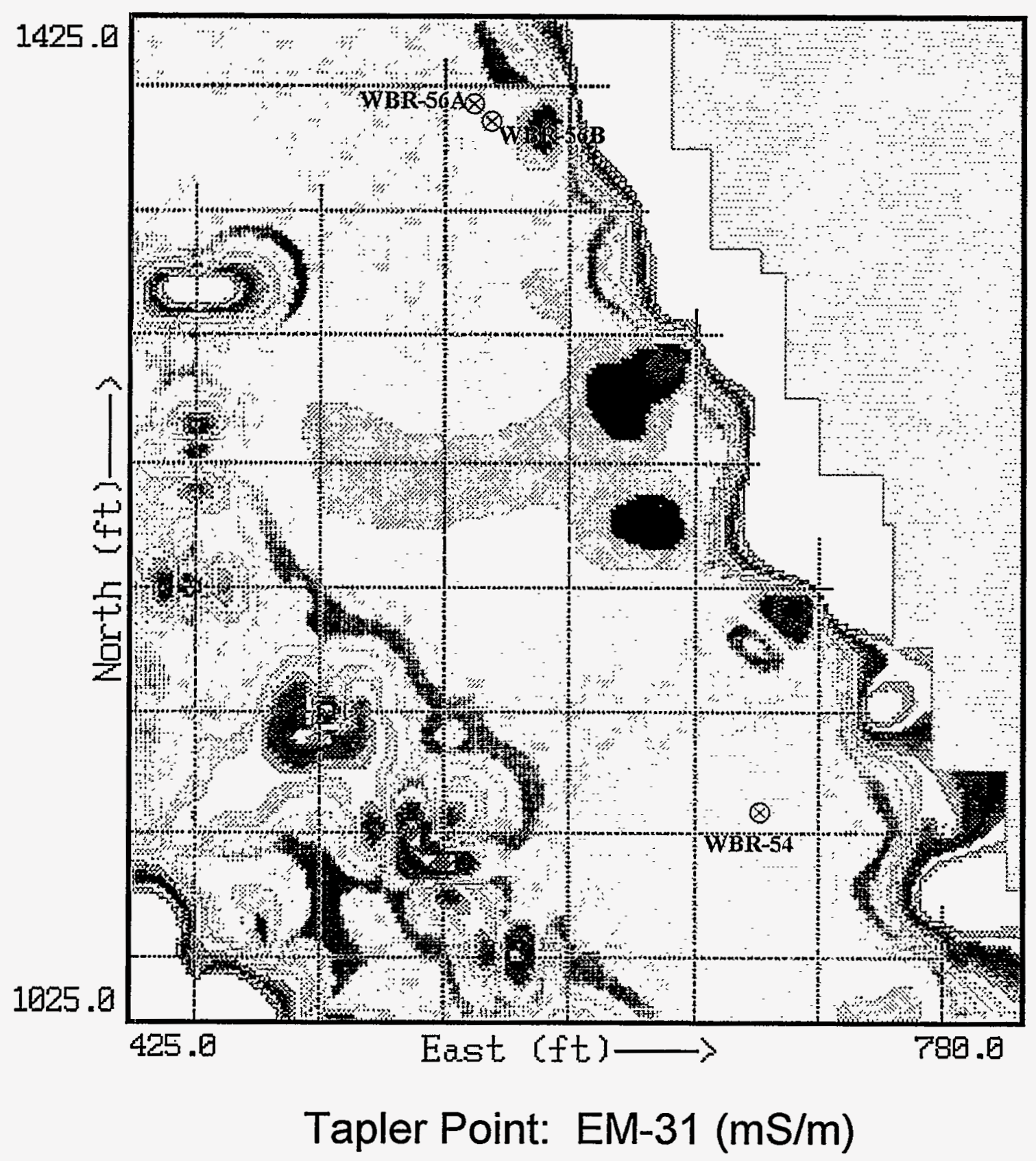

Color Contour Interval $=\mathbf{5 . 7} \mathrm{mS} / \mathrm{m}$

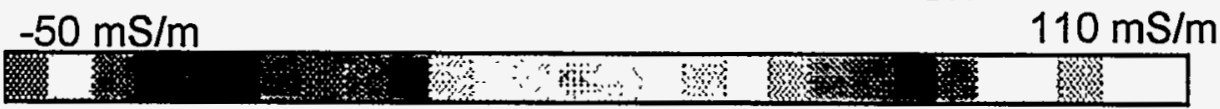

FIGURE 20 EM-31 Electromagnetics Map, Northeast Tapler Point 


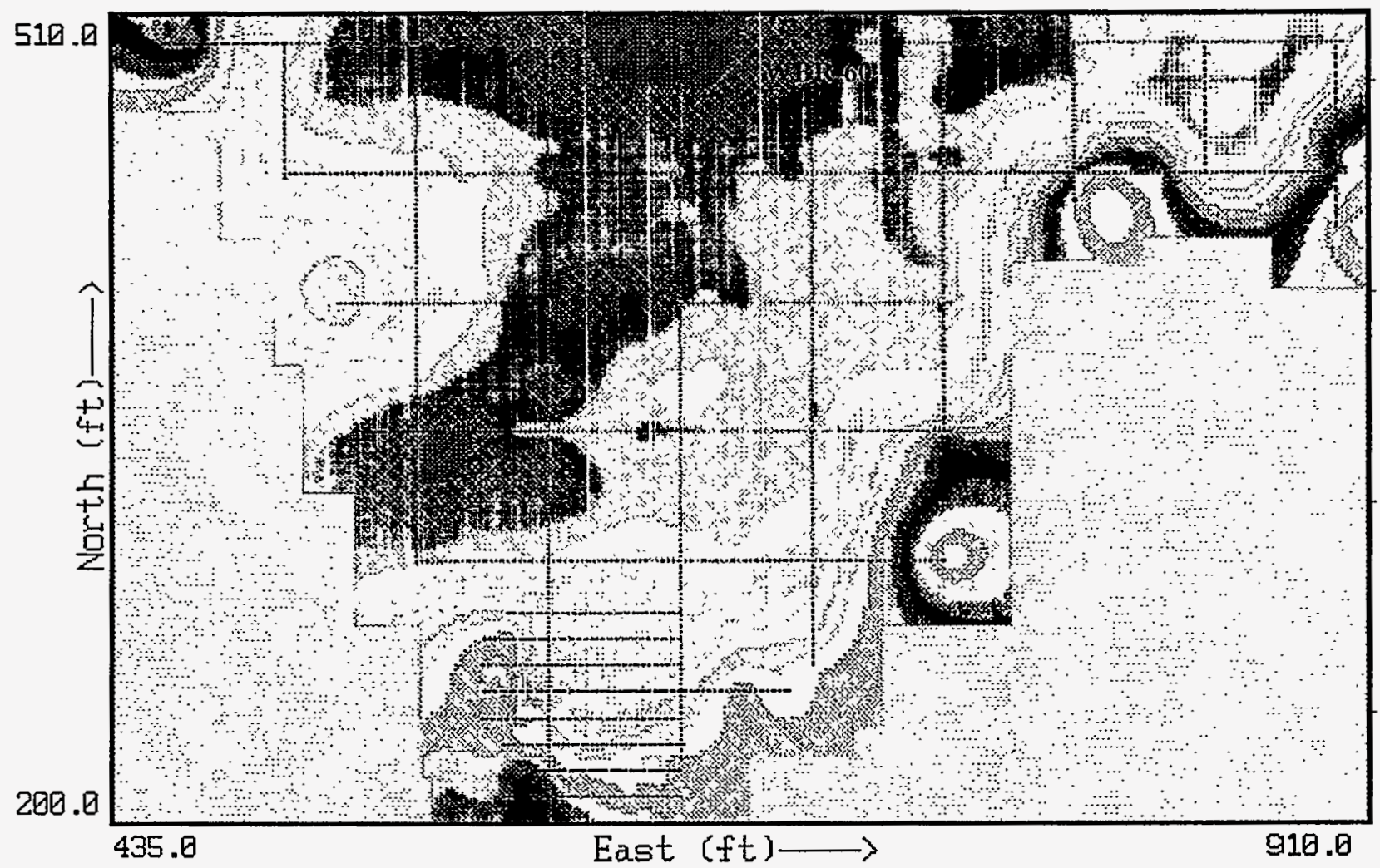

CMBS-3: EM-31 ( $\mathrm{mS} / \mathrm{m})$

Color Contour Interval $=1.3 \mathrm{mS} / \mathrm{m}$

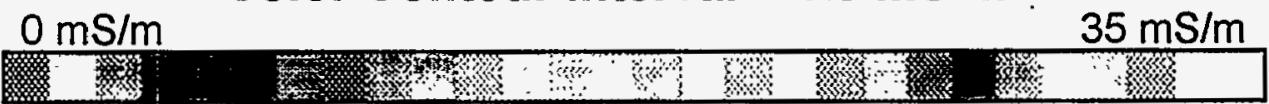

FIGURE 21 EM-31 Electromagnetics Map, CMBS-3

roadway systems. Higher apparent conductivities are also associated with the Bush River and low-lying areas in the southwestern portion of the Tapler Point survey area. The shallow depth to the water table and the presence of surface water cause the higher apparent conductivities found at these locations.

The EM-31 survey of Tapler Point outside of the security fence (Figure 18) does not indicate the presence of lithological changes in this area. Conductivity decreases toward the northeast following the increase in surface elevation. The increased unsaturated thickness toward the northeast results in a decreased apparent conductivity. The interpretation that the decrease in apparent conductivity is not caused by lithologic changes is confirmed by two soil boring/monitor wells (WBR-51 and WBR-52), installed in the area outside the security fence, and soil boring/monitor well WBR-53, located approximately $250 \mathrm{ft}$ northeast of WBR-51 and WBR-52 inside the security fence (see Figure 18). The apparent conductivity found at WBR-53 


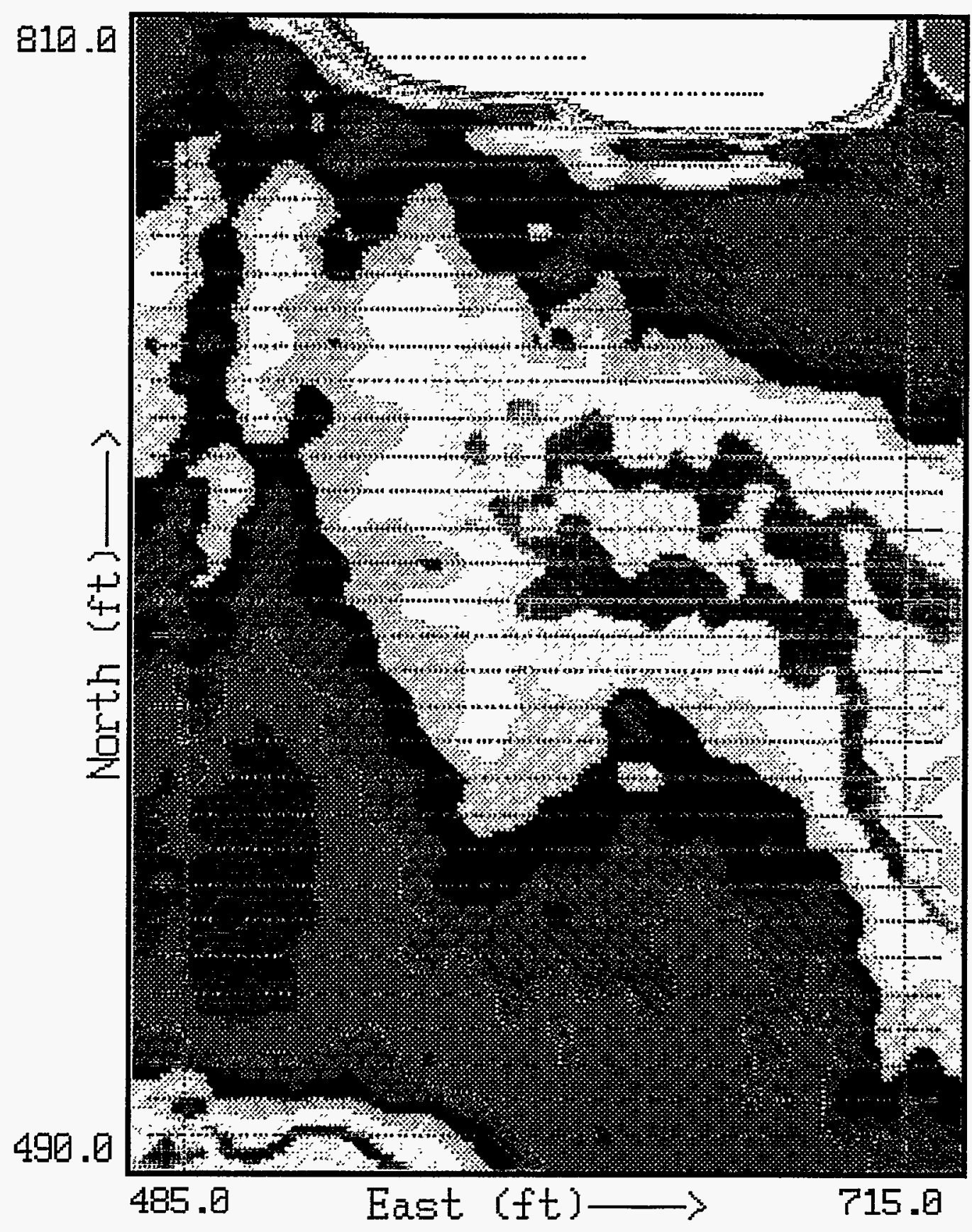

CMBS-4: EM-31 (mS/m)

Color Contour Interval = $1.3 \mathrm{mS} / \mathrm{m}$ $0 \mathrm{mS} / \mathrm{m} \quad 35 \mathrm{mS} / \mathrm{m}$

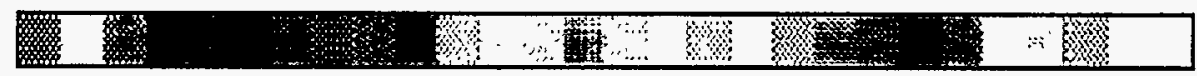

FIGURE 22 EM-31 Electromagnetics Map, CMBS-4 
is approximately $25 \mathrm{mS} / \mathrm{m}$ lower than at WBR-51 and WBR-52. At each boring, the upper 6 to $8 \mathrm{ft}$ consisted mainly of fine-grained silts and clays, followed by sands to below the approximate 18-ft EM-31 measurement depth. The decrease in conductivity is the result of an unsaturated zone that is approximately $5 \mathrm{ft}$ thicker at the location of WBR-53. Drilling logs for the soil boring/monitor wells in the southern Bush River Peninsula are included as Appendix A.

The northwestern portion of the Tapler Point EM-31 survey is presented in Figure 19. Two linear features, trending northwest/southeast, are visible in the northeastern portion of Figure 19. The northeasternmost feature (between approximately 1350 North/350 East and 1250 North/450 East) is 28th Street and associated underground utilities. This feature has a signature of strong conductivity lows bounded on each side by conductivity highs. The second linear trend, approximately 80 feet southeast and parallel to 28th Street (between approximately 1350 North/250 East and 1125 North/400 East), probably represents an old roadbed, a utility cable, or both. The EM-31 signature for this feature is again a minima bounded by two maxima. Additional evidence indicating that this may be a former roadbed is provided by the GPR data (see Section 4.1).

An area of low conductivity is present in the western portion of Figure 19. Because of the linear nature of the anthropogenic conductivity anomalies bounding this section of the electromagnetic survey to the northeast, it is not clear whether this lower conductivity represents lithologic changes. A relatively shallow (approximately $20 \mathrm{ft}$ below ground surface) paleochannel is present at the location of soil boring/monitor well WBR-55, shown in the southeast corner of Figure 19. Evidence of the paleochannel is apparent on the boring log for WBR-55 (Appendix A); the log indicates an organic-rich zone at depths between approximately 3.3 and $8.5 \mathrm{ft}$, grading into sandy sediments to a depth of $18.6 \mathrm{ft}$. These sediments represent a finingupward, channel-fill sequence. Further evidence of a paleochannel at this location is provided by GPR data (see Section 4.1). The EM-31 signature for this shallow paleochannel is a conductivity high caused by the organic-rich, fine-grained sediments present above $8.5 \mathrm{ft}$. The trend of the paleochannel is obscured by the two parallel anthropogenic features and the fenceline. The paleochannel may extend toward the east/northeast along the current drainageway.

Figure 20 shows the northeastern portion of the Tapler Point EM-31 survey. This area is topographically higher than the northwestern section. An east/west-trending, low-conductivity feature is centered at approximately 1250 North on the survey grid. This feature may represent a decrease in fine-grained sediments at this location. North and south of the low-conductivity feature are areas of relatively higher conductivity. The alternating high and low conductivities indicate areas with either higher and lower clay content, or water content changes within the unsaturated zone. It is not clear whether these features represent shallow paleochannels.

Subsurface paleochannel features are mapped as EM-31 anomalies that have either relatively higher or lower conductivity signatures. This is the result of the sometimes-conflicting factors affecting the subsurface conductivity at a particular location. The paleochannel described above and shown in Figure 19 has a relatively higher apparent conductivity compared with the adjoining area. The higher conductivity results from the upper portion of a shallow 
paleochannel-fill sequence. A deeper paleochannel feature, with fill in the upper $18 \mathrm{ft}$ (similar on average to the adjoining sediment), would not have an EM-31 signature. Conversely, a deeper paleochannel may be indicated by EM-31 measurements if the channel flank sediments are different from those of the upper part of the channel fill (see Section 3.2.3). Specific offshore EM-31 data for the area surrounding the southern Bush River Peninsula have been collected and will be presented in a companion report (Miller et al. 1995). Most paleochannel features detected offshore with the EM-31 exhibit relative conductivity highs (see also Davies et al. 1995). These high-conductivity features are attributed to the recent Holocene sediments filling the upper portions of the paleochannels. These sediments have a high clay content and also a higher water content because of the lack of compaction. Both of these factors result in higher conductivities. Also, offshore water is more brackish than the onshore groundwater, therefore, offshore sediments with a greater water content will exhibit greater conductivities. The EM-31 measures conductivity as a weighted average - with greater weight given to near-surface conductivities. The high values seen offshore are a direct result of this weighted average correlated to the high-porosity, clayey Holocene sediments. This type of channel fill can also be seen as organic-rich sediments onshore.

\subsubsection{CMBS-3}

Results of the conductivity survey for the CMBS-3 area are shown in Figure 21 . The color-contour interval on this map is reduced compared with that used in the Tapler Point EM31 maps, allowing more subtle conductivity changes to be seen. Figure 21 indicates a broad conductivity low in the center of the site surrounded by higher conductivity values to the east, south, and west. The lower conductivity at this location is caused by greater amounts of sand in the subsurface compared with the adjoining sediments. Soil boring/monitor well WBR-60 is located at 480 North/685 East on the survey grid (Figure 21). The drillers log for WBR-60 indicates that the lithology of the upper $20 \mathrm{ft}$ consists primarily of fine-grained sediments, with a sand unit between $14.5 \mathrm{ft}$ and $16.5 \mathrm{ft}$ below ground surface (Appendix A). This sand unit is responsible for the slight decrease in conductivity. An additional coarse sand and gravel unit is located at the base of soil boring WBR-60 at a depth between $25.5 \mathrm{ft}$ and $29.8 \mathrm{ft}$, below the depth of EM-31 measurement. It is uncertain whether the EM-31 feature represents a shallow paleochannel.

\subsubsection{CMBS-4}

The results of the EM-31 survey for the CMBS-4 area are presented in Figure 22. The color-contour interval is the same as that used for the CMBS-3 map (Figure 21). A highconductivity feature, with increased conductivity toward the east, is located approximately in the center of the survey area. Surface water drainage is also toward the east at this location. This high-conductivity feature represents an increase in clay content. The interpretation is that this feature is a paleochannel flank with channel-fill deposits to the south and, potentially, to the 
north. GPR data and logs for wells adjacent to CMBS-4 support this interpretation (see Section 4.3).

Drillers logs for soil borings/monitor wells WBR-26, WBR-48, and WBR-61A, located to the west, southwest, and south of CMBS-4, respectively (see Figure 23), reveal that fine-grained sediments are present in approximately the upper $13 \mathrm{ft}$ at these locations. (No soil borings were located within the boundaries of the CMBS-4 study area.) Beneath the fine-grained sediments in the two deep monitor wells, sand deposits to depths of approximately $45 \mathrm{ft}(\mathrm{WBR}-48)$ and greater than $50 \mathrm{ft}$ (WBR-61A) indicate the location of a deep paleochannel. Additional GPR evidence of a paleochannel at this location is presented in Section 4.3. 


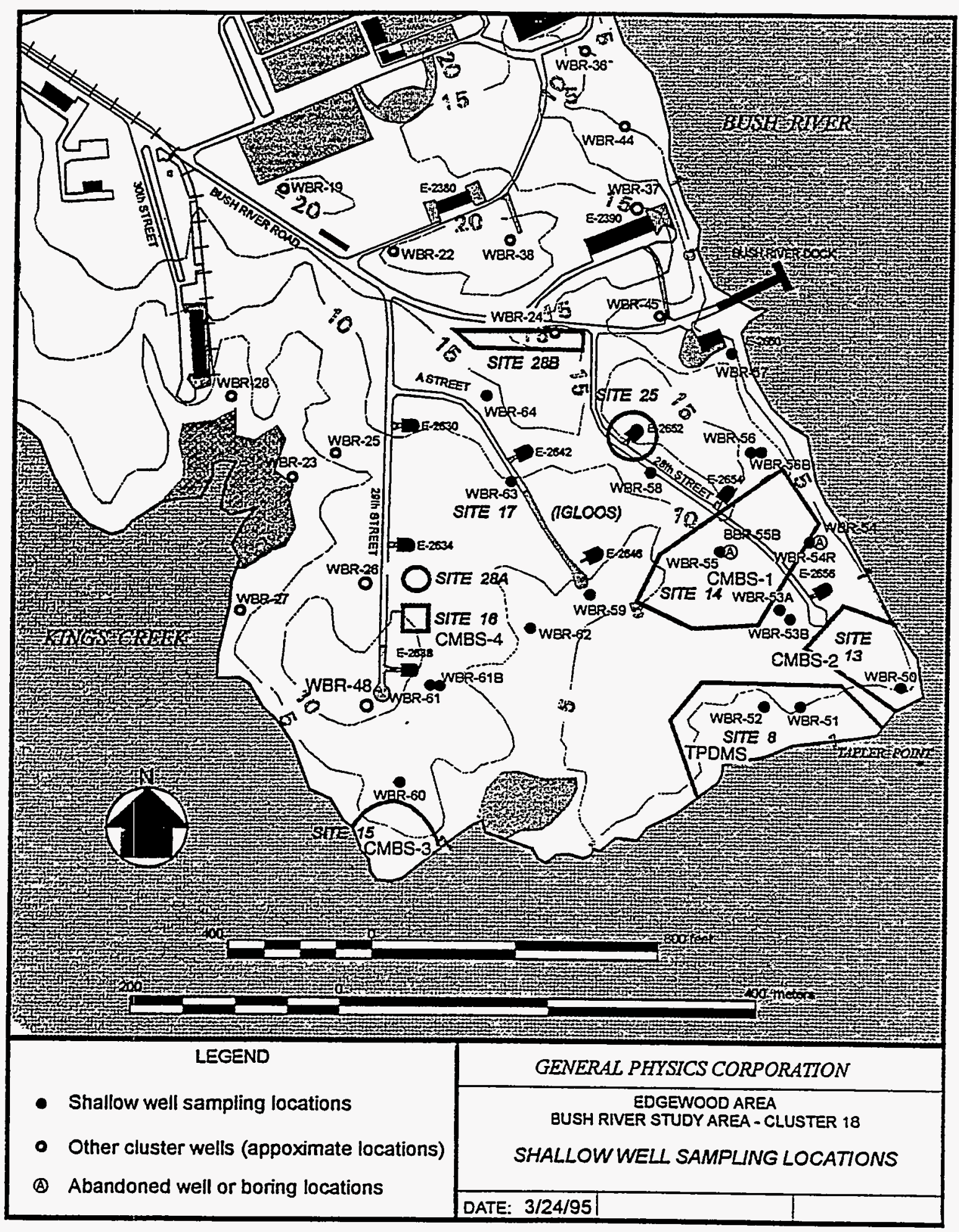

FIGURE 23 Soil Boring/Monitor Well Location Map, Bush River Peninsula 


\section{Ground-Penetrating Radar Surveys}

The primary objectives of the GPR surveys were to provide a better understanding of the shallow stratigraphy of the southern Bush River Peninsula and to help locate buried anthropogenic anomalies. GPR surveying was restricted in areas of dense vegetation. Ninety-six profiles were collected on 26 transects along the fenceline, roadways, existing paths, and several trails cleared specifically for GPR access. Figure 24 shows the locations of GPR profiles collected in the study area.

Both the 100- and $300-\mathrm{MHz}$ antennas, in a bistatic configuration, were used along the GPR profiles. The antennas were separated by a fixed distance of $4.5 \mathrm{ft}$. Profiles were collected in a continuous mode by using an all-terrain vehicle to tow the antennas. Data were collected at range settings between 100 and 500 nanoseconds (ns); however, most data were acquired at $200-400 \mathrm{~ns}$ in order to obtain higher data quality. In general, the $100-\mathrm{MHz}$ antenna provided slightly deeper penetration, while the $300-\mathrm{MHz}$ antenna provided better resolution of

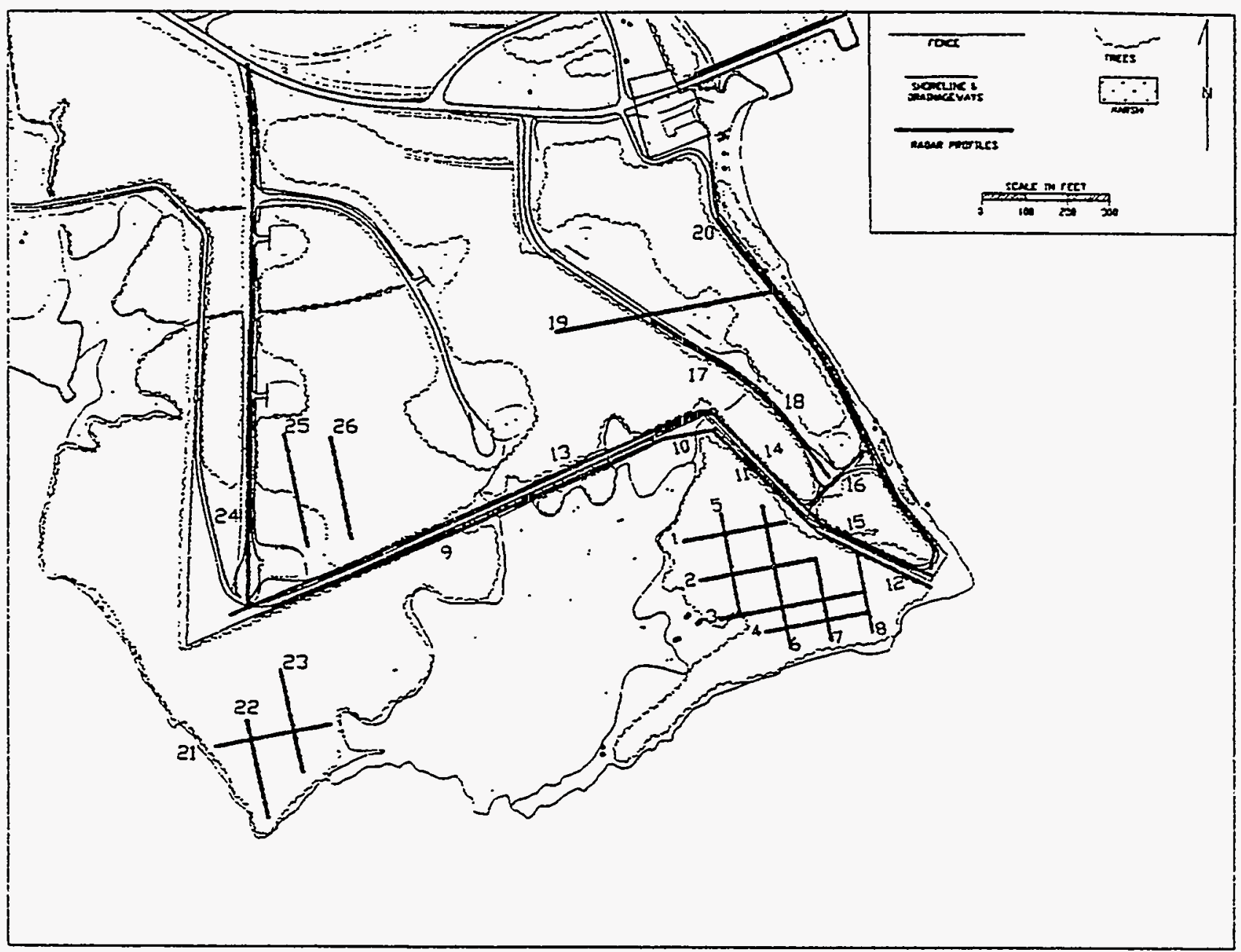

FIGURE 24 Ground-Penetrating Radar Profile Locations 
anthropogenic features. A low-pass, three-point box car filter was used on all profiles discussed in this report. Adjustments in gains were made for some of the profiles to help remove highfrequency noise and enhance structures at depth. The approximate depths given for the profiles were calculated using a two-way travel time of $9 \mathrm{~ns} / \mathrm{ft}$, which is based on field velocity measurements in other studies conducted at APG (see Davies et al. 1995; McGinnis et al. 1994a) and manufacturer recommendations for average soil conditions (GSSI 1987). These depths are approximate and should be used with caution.

In the following three sections, GPR profiles are presented for Tapler Point, CMBS-3, and CMBS-4, respectively.

\subsection{Tapler Point}

GPR data were collected for 20 profiles along the roads and grid system in the Tapler Point area of the Bush River Peninsula (see profiles \#1 through \#20, Figure 24). Six east/west profiles (\#1 through \#4, \#10, and \#19) and four north/south profiles (\#5 through \#8) were located along the Tapler Point grid system and comprised 2,790 linear $\mathrm{ft}$ of data. The remaining ten profiles in the Tapler Point area were conducted along the site roadways. These profiles were generally longer than profiles located on the grid system and accounted for 5,847 linear $\mathrm{ft}$ of GPR data. GPR data revealed no evidence of solid waste in the southern portion of the Tapler Point study area. The GPR profiles collected at the location of the TPDMS (profiles \#1 through \#8, Figure 24) did not reveal the thickness of the dredge material deposited at this location.

Figures 25A and 25B illustrate a GPR profile collected west to east along the 1050 North grid line (profile \#10, Figure 24). The profile was collected with the $300-\mathrm{MHz}$ bistatic antenna with a range setting of $200 \mathrm{~ns}$. An easterly dipping reflector, which may represent the west flank of a paleochannel, is apparent in the middle of the profile, beginning at approximately 330 East. This is also the approximate location of an EM-31 anomaly shown in Figure 19 and discussed in Section 3.2.1. An interpretation of this feature is shown in Figure 25B. The apparent dip is approximately $15^{\circ}$ to the east. The eastern side of the paleochannel was not observed. The interpretation given in Figure 25B shows a layer of channel fill at the base of the paleochannel and prominent, flat-lying reflectors beneath the channel cut. This easterly dipping feature was also observed using the $100-\mathrm{MHz}$ antenna, but was less prominent - apparently because of a loss of resolution using the lower-frequency antenna.

A series of dipping reflectors were observed in the northern portion of Profile $\# 20$ (Figures 26A and 26B), which was collected with the $100-\mathrm{MHz}$ antenna at a range setting of $200 \mathrm{~ns}$ along the easternmost fenceline in the Tapler Point area. The maximum apparent dip along the profile is $6^{\circ}$, although the true dip might be significantly greater. The location of these shallow, dipping reflectors corresponds to an area of alternating high and low EM-31 anomalies (Figure 20). The reflectors are believed to represent a fluvial meander channel environment with cut-bank erosion and subsequent deposition. 

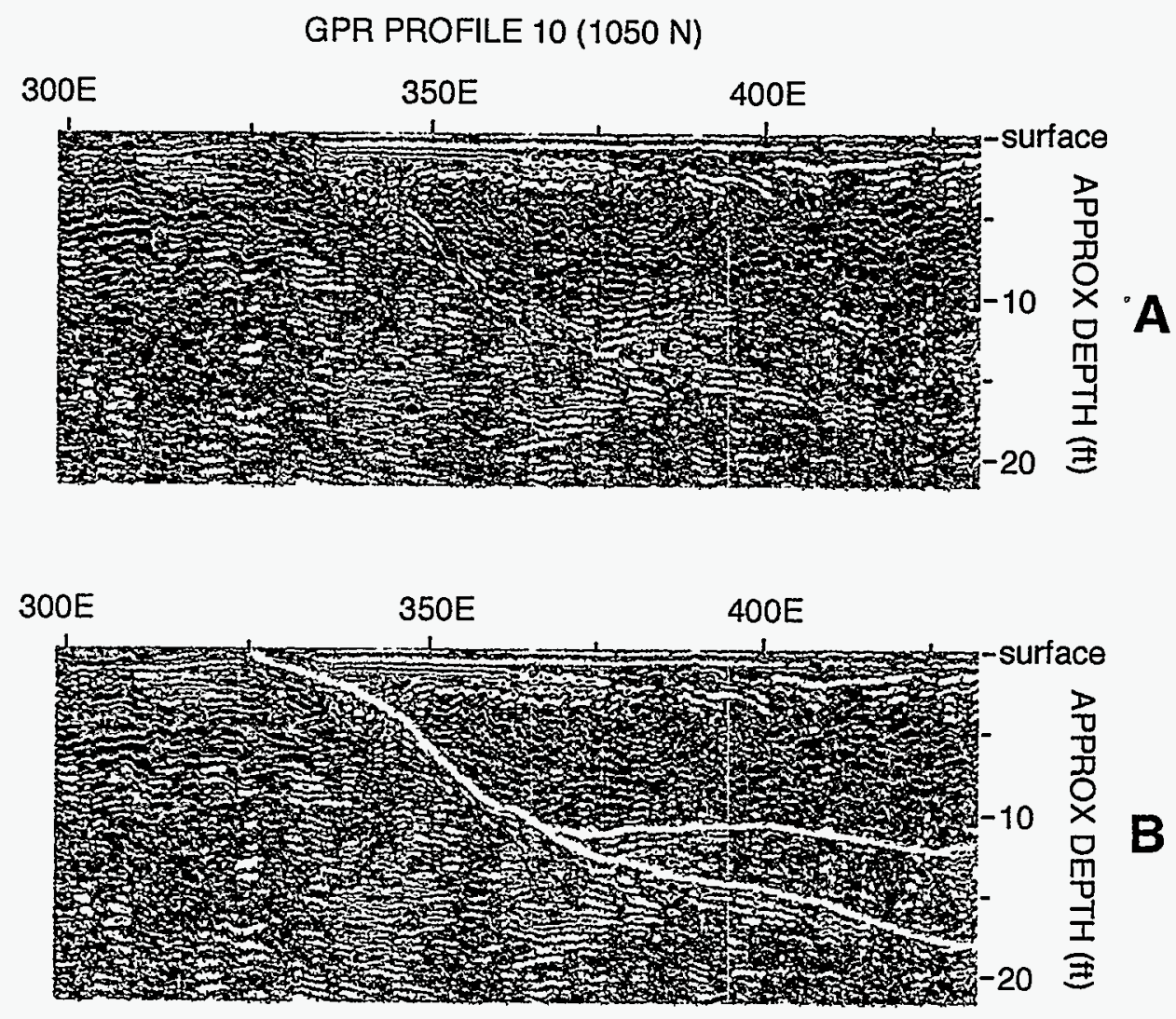

FIGURE 25 A: GPR Profile \#10 B: GPR Profile \#10 with Interpretation

Profile \#19, located along the northern edge of the Tapler Point grid system, shows strong, ringing reflections at approximately 200 East (Figure 27). This profile was collected with the $100-\mathrm{MHz}$ antenna at a range setting of $200 \mathrm{~ns}$. The reflections suggest that the ground surface has been modified by roadway construction. The anomaly crosses 28 th Street on the same profile (at approximately 300 to 320 East) where similar reflectors are noted. This zone of ringing reflectors was observed on the EM-31 map as an area of paired high and low conductivity anomalies (Figure 19). The anomaly is located in a wooded section of the Tapler Point study area.

\subsection{CMBS-3}

Three GPR profiles were collected at CMBS-3 (profiles \#21 through \#23 on Figure 24). Two north/south profiles and one east/west profile, totaling 750 linear $\mathrm{ft}$, were located along the surveyed grid system. No definitive subsurface structures were detected by GPR at CMBS-3. 

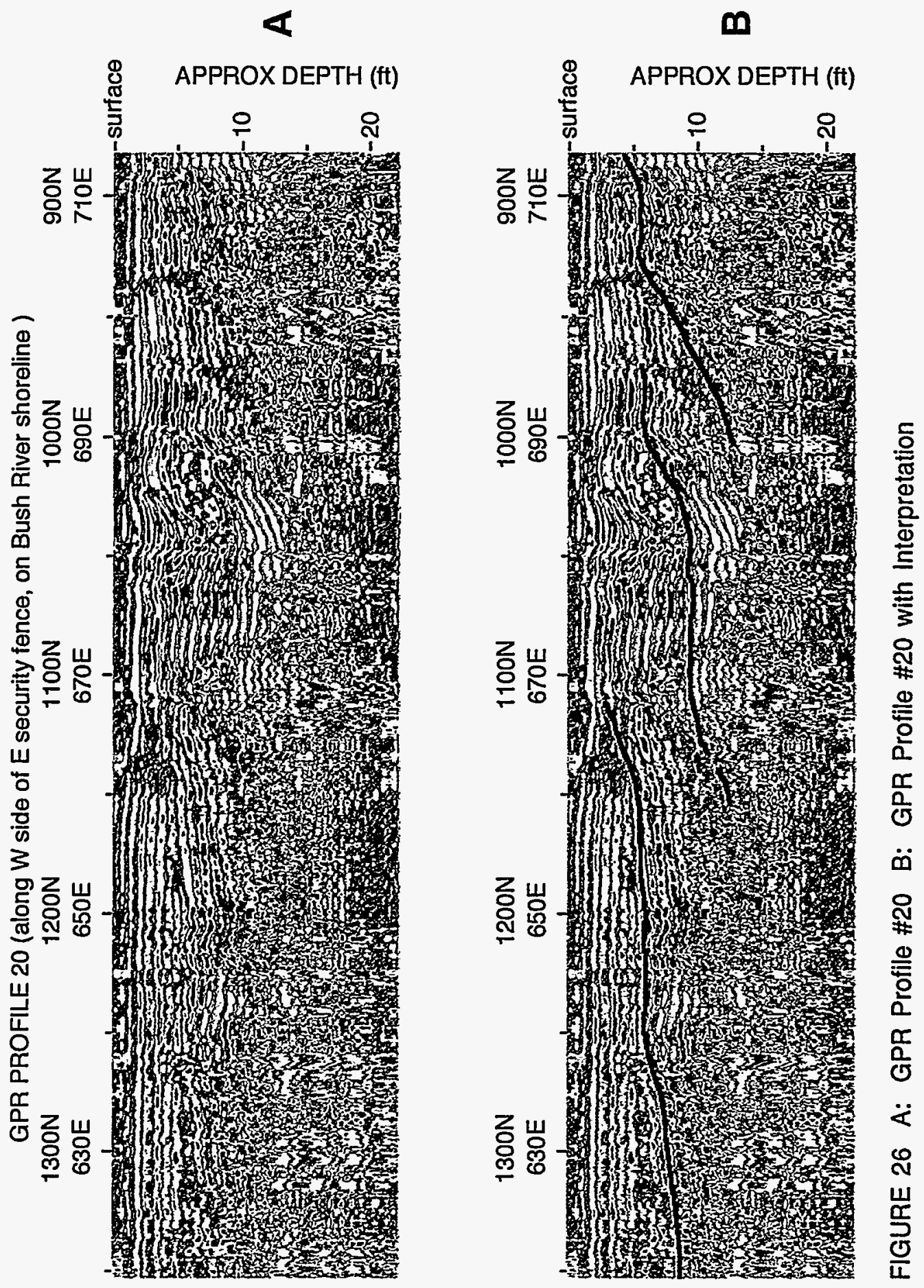


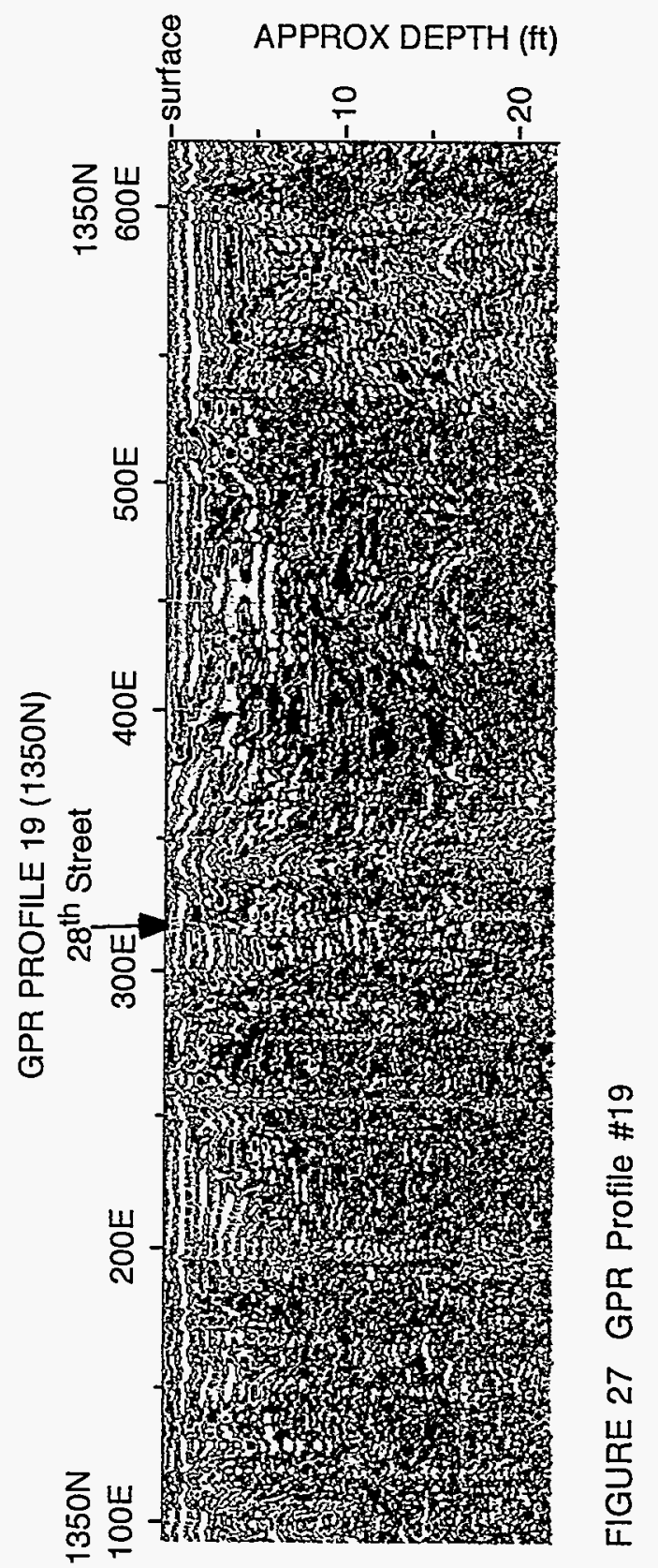




\subsection{CMBS-4}

Three GPR profiles were collected at CMBS-4: profiles \#24 through \#26 on Figure 24. Two north/south profiles, with a total distance of 575 linear $\mathrm{ft}$, were located along the surveyed grid system. The third profile was conducted south to north along 29th Street for a distance of 1,320 linear $\mathrm{ft}$. GPR reflections for profiles recorded along the CMBS-4 grid system (profiles \#25 and \#26) were generally weak, indicating poor soil conditions for GPR signal penetration. Figures $28 \mathrm{~A}$ and $28 \mathrm{~B}$ present the southern portion of profile \#24, collected along 29 th Street west of CMBS-4. The profile was collected with the $100-\mathrm{MHz}$ antenna at a range setting of $400 \mathrm{~ns}$. A paleochannel feature is apparent in the southern portion of profile \#24. The thalweg of the paleochannel is approximately $40 \mathrm{ft}$ below ground surface at a distance of about $140 \mathrm{ft}$ from the beginning of the profile. The northern edge of the paleochannel is $370 \mathrm{ft}$ from the beginning of the profile at approximately $760 \mathrm{North} / 510$ East on the CMBS-4 grid. This location corresponds to the EM-31 anomaly shown in Figure 22 and indicates a northwest/southeast trend of the paleochannel beneath CMBS-4. A rising reflector is also present at the southern end of profile \#24. This reflector represents a surface that is either the southern edge of the paleochannel or part of a channel-fill sequence.

The western portions of profiles \#9 and \#13 are also in close proximity to CMBS-4. The profiles run roughly west to east along both sides of the security fence south of CMBS- 4 . The GPR profile presented in Figures 29A and 29B (profile \#13 on Figure 24) shows a series of hyperbolic reflectors separated by what may be a small paleochannel. This profile was collected in an east/northeast direction inside the security fence with the $100-\mathrm{MHz}$ bistatic antenna at a range setting of $400 \mathrm{~ns}$. One side of the paleochannel, probably corresponding to the channel bisecting CMBS-4, is shown sloping toward the southwest, with the edge of the channel at approximately $360 \mathrm{ft}$ along the profile. The depth of the paleochannel extends beyond the depth of the profile (approximately $45 \mathrm{ft}$ below ground surface). Two other reflectors indicate undulating surfaces of the fill material within the deeper paleochannel feature. These undulating surfaces may reflect facies changes within the paleochannel-fill sequences.

Another paleochannel feature is located farther along profile \#13. The thalweg is at approximately $600 \mathrm{ft}$ along the profile, at a depth of approximately $25 \mathrm{ft}$ below ground surface (Figure 29). This location corresponds to a surface water drainageway that flows south into the phragmite marsh. Soil boring/monitor well WBR-62 is installed approximately 50 feet north of profile \#13 at this location. The boring $\log$ (Appendix A) indicates two fining-upward depositional sequences at WBR-62. The deeper sequence starts at approximately $44 \mathrm{ft}$ below ground surface and extends to approximately $28.5 \mathrm{ft}$ below ground surface. The top of this sequence is the base of the second sequence. This second sequence is the paleochannel fill of the feature observed in GPR profile \#13. This paleochannel may have followed the path of an older, deeper paleochannel. Poor GPR signal penetration farther east prevented additional interpretation along profile \#13. 

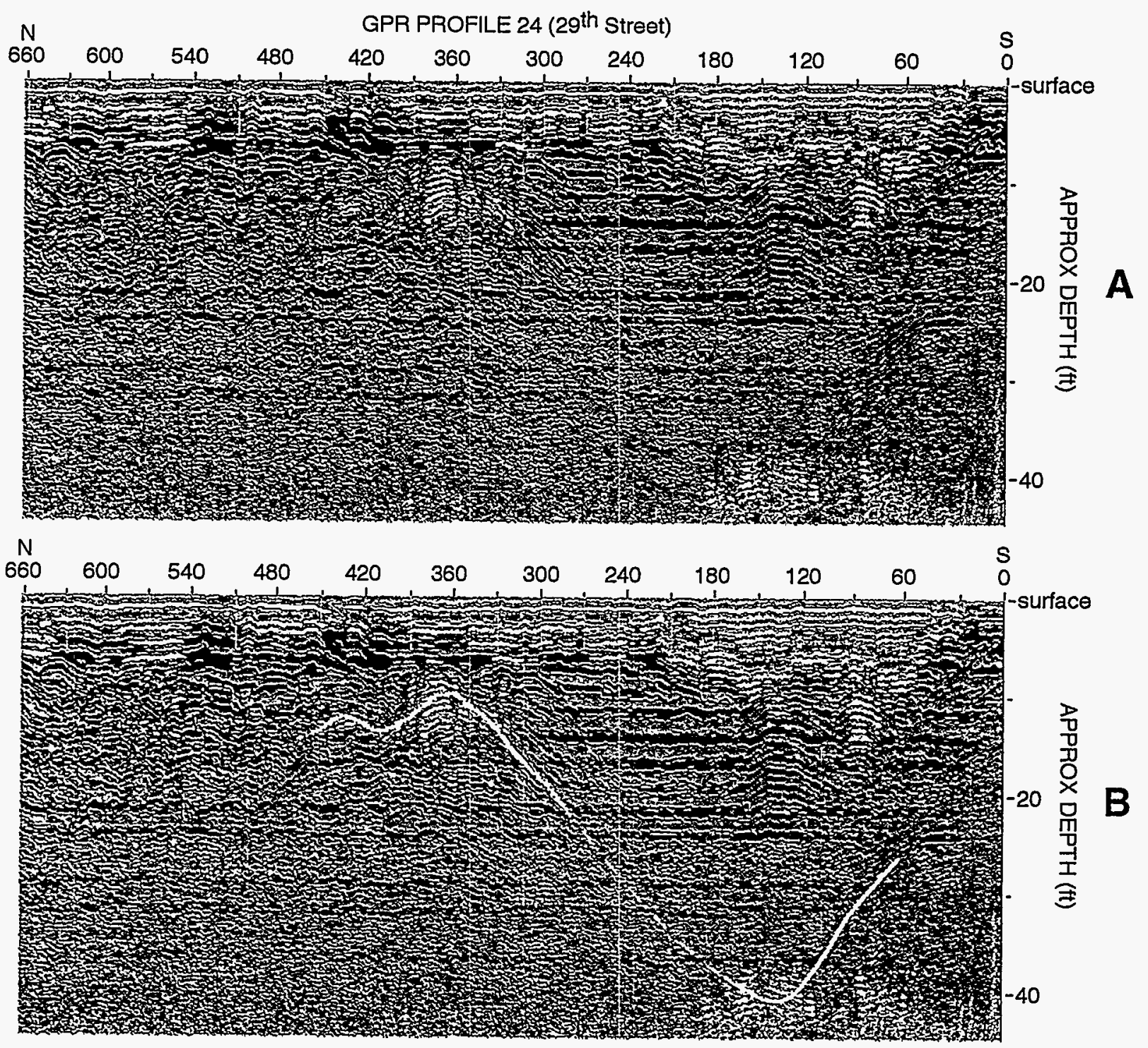

FIGURE 28 A: GPR Profile \#24 B: GPR Profile \#24 with Interpretation 

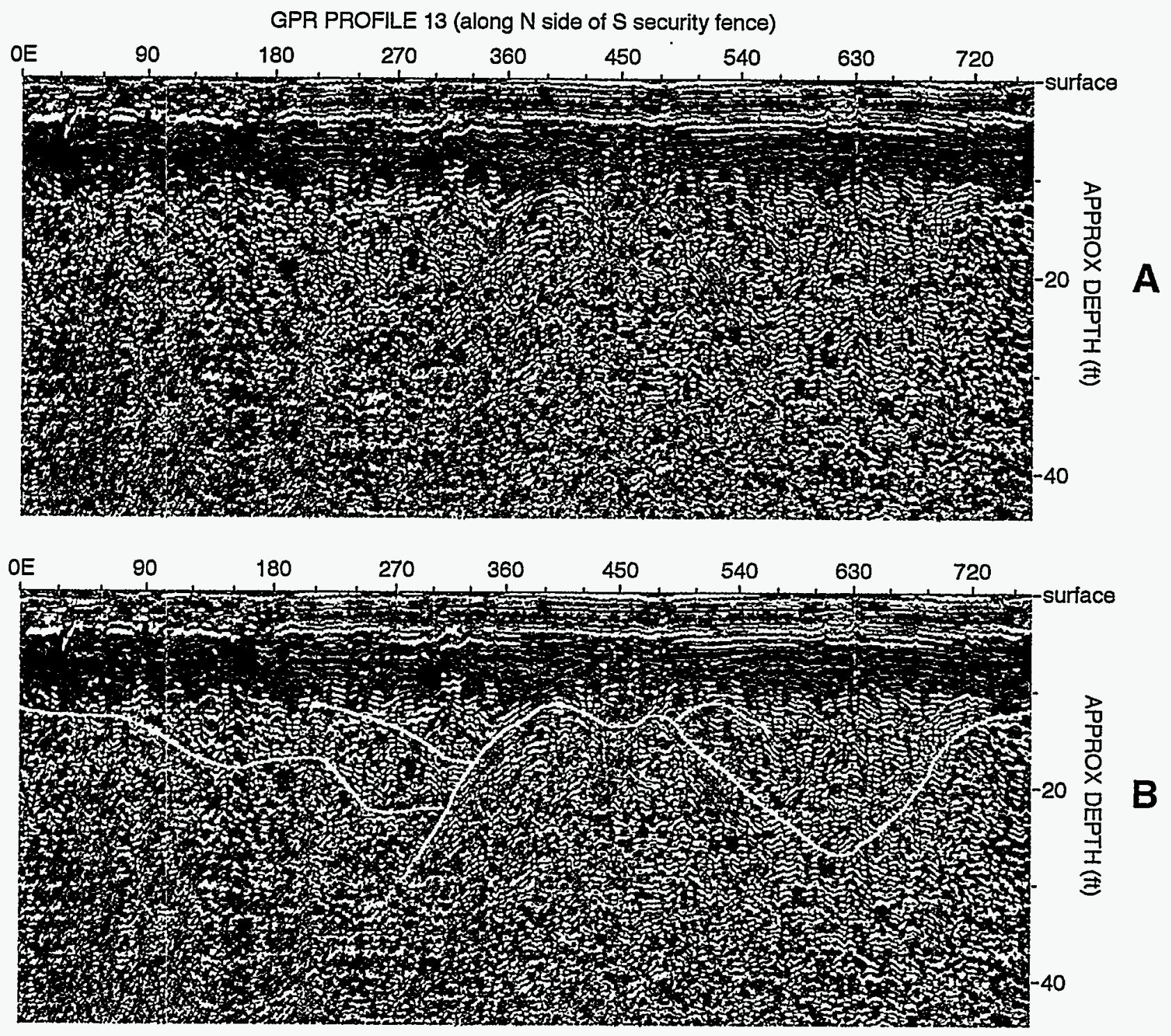

FIGURE 29 A: GPR Profile \#13 B: GPR Profile \#13 with Interpretation 


\section{Seismic Surveys}

Seismic surveys were performed in the Kings Creek and southern Bush River Peninsula areas by ANL personnel during the summer of 1994 to characterize the geologic framework from the ground surface to the crystalline basement. The surveys focused on the depth ranges below those reached by electromagnetic and GPR methods. The data set comprised three refraction profiles (BRP-1 through BRP-3) and five reflection profiles (BRP-4 through BRP-8). The locations for all seismic surveys conducted on the Bush River Peninsula are shown in Figure 30. Six of the profiles (BRP-1 through BRP-6) and surface-to-borehole average velocity measurements conducted at monitor well CC-11B (Figure 30) were previously discussed in Davies et al. 1995.

Two reflection profiles, BRP-7 and BRP-8, were collected along the north side of the security fence extending from CMBS-4 to the Tapler Point area. The lines are coincident with one another and with GPR profile \#13 (Figure 30). Distances along the profiles discussed in this section (BRP-7 and BRP-8) were measured from the fence corner southwest of the CMBS-4 site from west to east. Profile BRP-7 was conducted using an elastic wave generator (EWG) for a source; BRP-8 was collected using a 16-pound sledgehammer as a source. Survey parameters for both profiles are summarized in Table 7.

Reflection line BRP-7 was recorded by using an offset of $90 \mathrm{ft}$ (see Table 7) and a maximum shot-to-receiver distance of $228 \mathrm{ft}$. In reflection lines BRP-4 and BRP-5, collected using the same large offset and EWG source, basement reflectors were observed at depths of $450 \mathrm{ft}$ in the north and $550 \mathrm{ft}$ in the south (Davies et al. 1995). In contrast, reflection line BRP-8 was obtained using the same relatively short offset $(18 \mathrm{ft})$ and hammer source that were used for profile BRP-6 (Davies et al. 1995). The hammer source produced much higher frequencies and resolution.

The relationship between seismic velocity and depth, used for interpreting the seismic profiles, was derived from velocity borehole data (Davies et al. 1995) and is shown in Figure 31. The velocity-depth profile has been modified using shallow-refraction-derived velocities from lines BRP-7 and BRP-8. This latter step was accomplished by constructing a time-distance graph from the median arrival time for each shot-receiver pair from all shot gathers, and converting the time-distance data into velocity-depth information using standard, plane-layered, refraction analysis.

The seismic reflection profiles in the southern portion of the Bush River Peninsula are characterized by unusually large static delays caused by variations in near-surface velocity. In some cases, these delays are greater than $20 \mathrm{~ms}$. A delay of about $24 \mathrm{~ms}$ and signal attenuation are observed centered at about $807 \mathrm{ft}$ in the data for line BRP-8. Another slight delay of a few $\mathrm{ms}$ is observed in the far traces for profile BRP-7. The 24-ms delay coincides with a culvert in a topographic depression. The area is marshy and is interpreted to be underlain by gas-saturated sediments that typically result in extremely slow seismic velocities. Delay times are probably caused by a combination of culvert construction and gassy sediments contained in a paleochannel. 


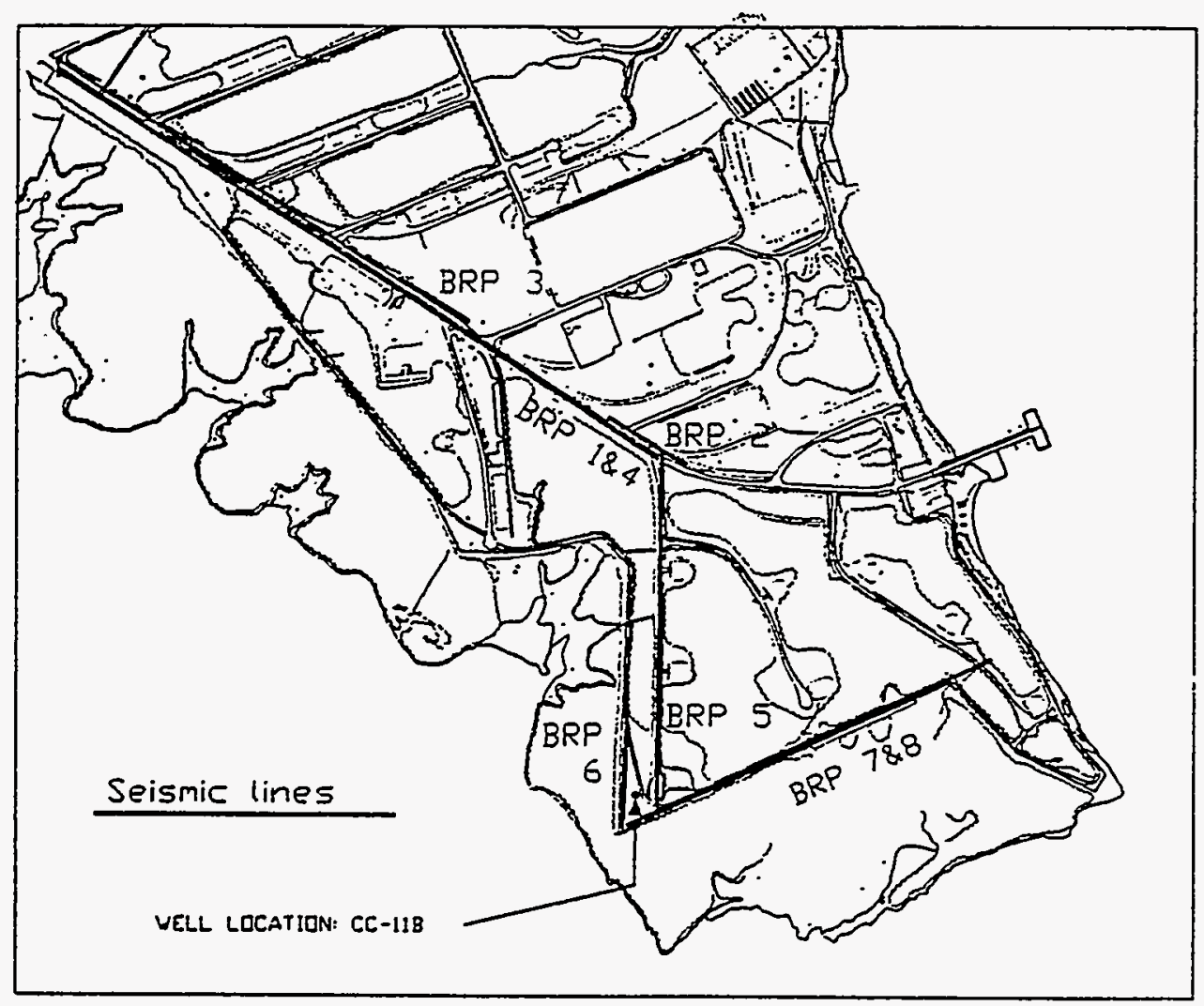

FIGURE 30 Seismic Profile Locations

TABLE 7 Seismic Reflection Profiles near the Tapler Point Study Area

\begin{tabular}{lrc}
\hline & \multicolumn{2}{c}{ Line Identification No. } \\
\cline { 2 - 3 } \multicolumn{1}{c}{ Parameters } & BRP-7 & BRP-8 \\
& & \\
\hline & & \\
Type & Deep & Shallow \\
Seismic source & EWG & Hammer \\
Offset (ft) & 90 & 18 \\
Geophone interval (ft) & 6 & 3 \\
Number of shots & 228 & 479 \\
Number of 24-channel spreads & 217 & 456 \\
Total length of survey (ft) & 1,296 & 1,365 \\
& & \\
\hline
\end{tabular}




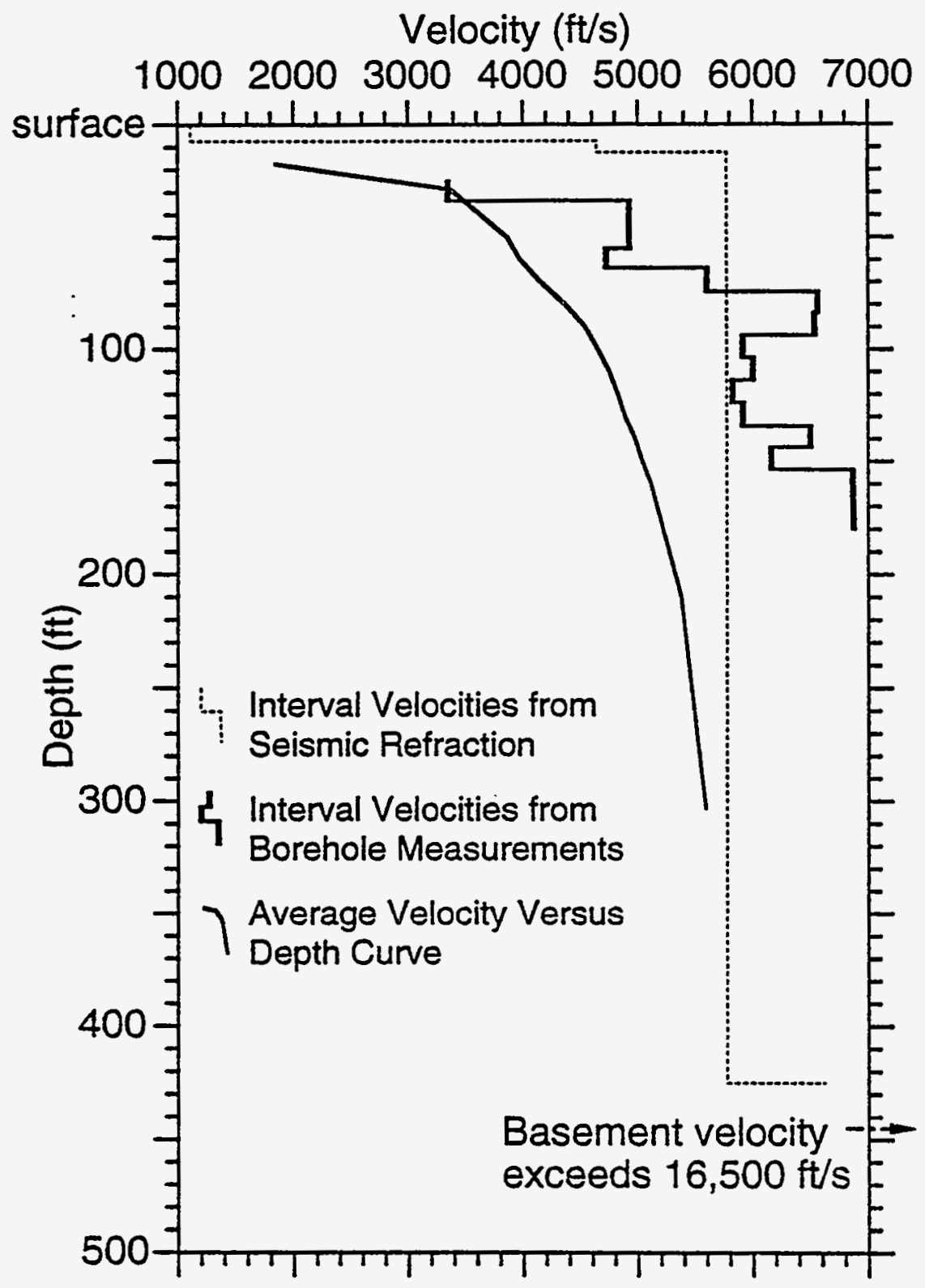

FIGURE 31 Velocity Depth Model Obtained by Inverting Seismic Refraction Data and Borehole Seismic Data

The substantial lateral variations in near-surface seismic velocities severely hampered the quality of reflection data for profiles BRP-7 and BRP-8. Static corrections were applied to individual traces in each gather to provide a uniform first arrival-distance curve. The amount of each static shift was determined relative to median time-distance arrivals computed for both profiles. In addition to the static corrections, processing steps included trace editing and muting, bandpass filtering, velocity analysis, and CDP sorting and stacking. Seismic arrivals prior to $65 \mathrm{~ms}$ were muted to remove noise and surface wave energy from the reflection data. EAVESDROPPER software, developed at the Kansas Geological Survey (1993), was used to process the seismic profiles. 
Processed seismic sections for profiles BRP-7 and BRP-8 are shown in Figures 32 and 33. Both figures show stacked seismic sections extending from west (left) to east (right). The crystalline bedrock observed in profiles BRP-4 and BRP-5 in the Kings Creek Area (Davies et al. 1995) is difficult to observe in the deep seismic data of Figure 32. A reflector in the middle of the section, at about $550 \mathrm{ft}$, may correspond to the basement. Other reflections observed in the 200to 300-ft depth range are discontinuous and probably represent Cretaceous units. Reflection energy is even less coherent in the shallow reflection data (Figure 33). A reflector is observed at a depth of about $160 \mathrm{ft}$ below ground surface in the 840- to $1,040-\mathrm{ft}$ distance range. 


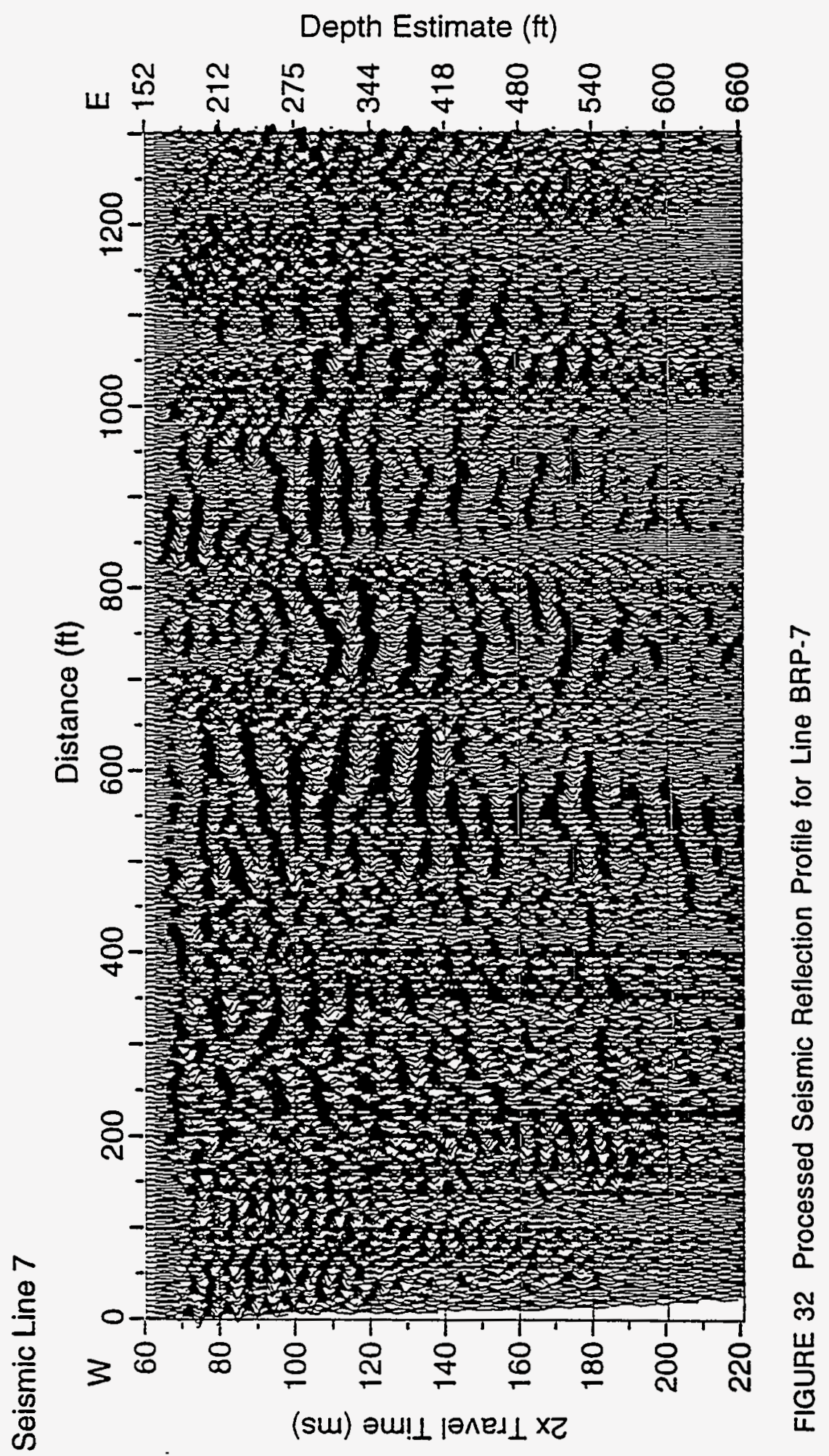




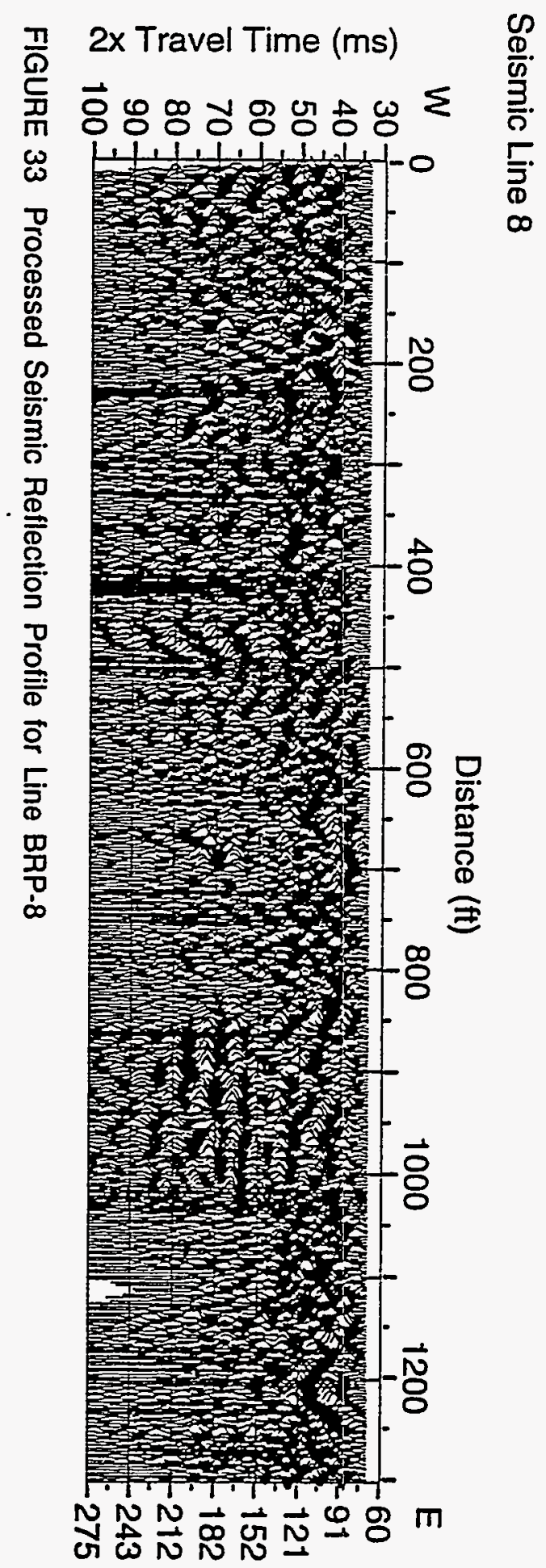

(H) әfeu!!s $\exists$ 4! də0 


\section{Discussion}

\subsection{Waste Disposal at Suspect Chemical Munitions Burial Sites}

Geophysical technologies, including magnetics, seismic reflection, electromagnetics, and GPR, have been utilized in the environmental investigation of the southern Bush River Peninsula. These geophysical techniques, combined with visual observations, have helped define the areal extent of disposal activities at the four suspected Chemical Munitions Burial Sites (CMBS-1 through CMBS-4) and the TPDMS. The areal extent and thickness of dredge materials at the TPDMS was not determined.

Total field magnetics, magnetic gradiometer, and EM-61 surveys conducted in the suspect areas indicate that metal debris is scattered throughout the survey areas. At each of the sites surveyed, unexplained, non-continuous metallic anomalies are present (see Tables 1 through 6). While these anomalous zones are not believed to represent major waste burial areas, additional characterization is necessary to confirm the source of the anomalies.

\subsubsection{Tapler Point}

Tapler Point (CMBS-1, CMBS-2, and TPDMS) was the largest area surveyed and contained the majority of the unexplained metallic anomalies detected during the surveys. Mounds of soil containing some metallic debris were found inside the security fence along the southwest side of 28 th Street (anomalies \#7, \#8, and \#9, Figure 6) and in the southeastern portion of the site (Figure 7). Similar mounds were also found outside of the security fence in the southeast portion of Tapler Point (Figure 8) and, to a lesser extent, the west-central section bordering the phragmites marsh (Figure 5). A lineament of magnetic gradiometer anomalies is also present between the mounds of soil adjacent to the phragmites marsh and the fenceline to the northeast (Figure 5). A number of unexplained buried sources are also present in the southeastern portion of the site inside the security fence (Figure 7). Portions of this area are obstructed by vegetation.

Further characterization of the areas described above, utilizing the magnetometer and EM-61 on a 5-foot grid spacing, is recommended. The locations for the recommended surveys are shown in Figure 34. Clearing fallen trees and vegetation in the areas inside the security fence will be necessary before the additional surveys can be conducted.

The southeast tip of Tapler Point was the most magnetically anomalous area, although most anomalies could be attributed to metal debris visible at the surface or to underground cables detected in a companion offshore geophysical study (Miller et al. 1995). The magnetic and electromagnetic anomalies detected during these surveys are not interpreted to be large-scale 


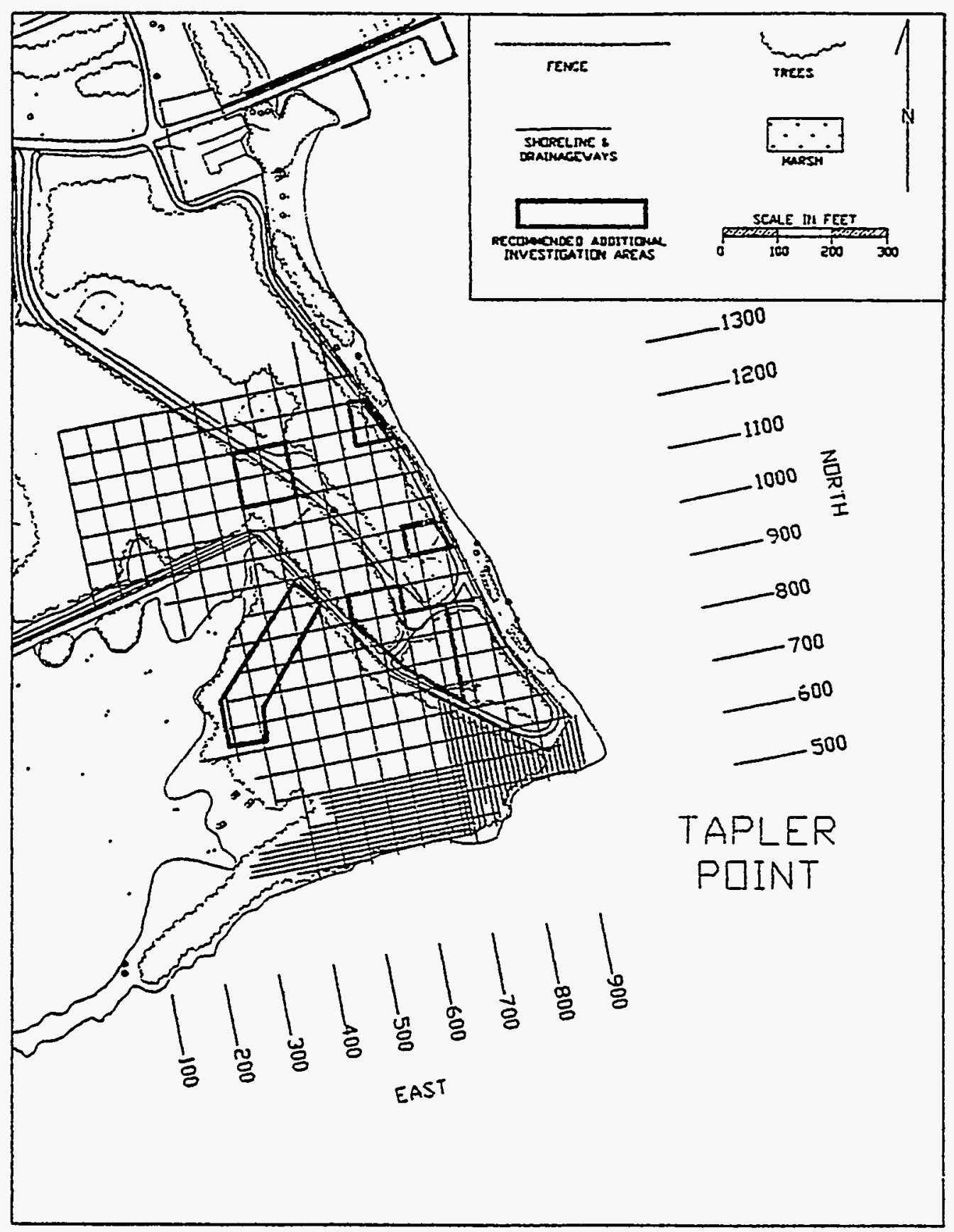

FIGURE 34 Recommended Locations for Additional Geophysical Investigation Activities, Tapler Point 
waste burial areas; but smaller, isolated areas of buried wastes and/or munitions cannot be ruled out. Additional EM-61 surveys, on a 5-foot profile spacing, would better characterize the threedimensional fill/waste distribution in this area.

\subsubsection{CMBS-3}

The surveys conducted at CMBS-3 indicate that this area is relatively undisturbed (Figures 10 and 16). Some isolated magnetic anomalies in the southern end of the site are associated with small depressions. Gradiometer and EM-61 surveys indicate that small fragments of ferrous and non-ferrous metal are present. No prominent lineaments, or objects with magnetic or electromagnetic signatures indicative of large objects, were found at CMBS-3. No additional surveying is recommended for this site.

\subsubsection{CMBS-4}

The surveys conducted at CMBS-4 indicate that this area is also relatively undisturbed. Isolated magnetic anomalies, some of which are unexplained, are scattered throughout the site (Figures 11 and 17). Mounds of soil, some containing metallic debris, are located along the eastern and southeastern portions of the site. No metallic features of a continuous nature were observed at CMBS-4; no additional surveying is necessary to characterize this site. Excavation and/or sampling would be required to determine the nature of the unexplained anomalies found at CMBS-4.

\subsection{Hydrogeologic Framework}

Soil boring logs of recently installed monitor wells provide the basic subsurface geologic control for the remedial investigation/feasibility study currently being conducted in the Bush River Peninsula area (see Figure 23 and Appendix A). Geophysical methods (including GPR, EM-31, and seismic methods) complement the basic, area-wide geologic studies conducted to define the geologic and hydrogeologic framework.

GPR imaging provides a detailed display of reflectors to depths up to $45 \mathrm{ft}$ below ground surface. These images often correlate well with EM-31 trends. The reflectors represent contacts separating recently deposited channel-fill complexes from underlying sediments. These contacts also constitute irregularities in the base of the surficial aquifer. The channel-fill complexes in the APG area are the result of multiple erosion/deposition events that occurred during the successive low sea-level stands and subsequent marine transgressions of the Pleistocene Epoch. The GPR profile presented in Figure 29 is a good example of multiple erosion/deposition events beneath the southern Bush River Peninsula. At this location, more recent, shallow channel features may be superimposed on older, deeper paleochannels. 
Seismic imaging, performed to study deeper geologic features, was less successful in the southern Bush River Peninsula than in other areas at APG. The complex nature of the superimposed, multiple erosion/deposition events prevented meaningful high-resolution seismic mapping along the east/west roadway in the southern portion of the peninsula (profiles BRP-7 and BRP-8, Figure 30). This result confirms that the Pleistocene sediments in this area consist of a series of largely non-continuous, fine- and coarse-grained deposits. Some penetration is observed below the unconformity where images of the Cretaceous coastal plain sediments are seen. Additional seismic data collected in the Bush River Peninsula were presented previously in Davies et al. (1995).

\subsection{Subsurface Paleochannel Locations}

It is important to define the paleochannel locations and depths because the basal sediments within these features often consist of materials of greater hydraulic conductivity (sands and gravels) that form the base of the surficial aquifer. The current drainageway and wetland locations in the Bush River Peninsula are often good indicators of the locations of Pleistocene drainage systems. The Pleistocene paleochannels can be deeply incised into the underlying Cretaceous sediments. Depths to the base of these features have been found to be greater than $50 \mathrm{ft}$ below ground surface (soil borings WBR-56A and WBR-61A, Appendix A).

Mapping the location of these potential hydraulically conductive zones is very important in understanding the hydrology of the surficial aquifer and the potential for interconnection between the surficial aquifer and the underlying upper confined aquifer (referred to as the Canal Creek Aquifer on Figure 4). Five soil borings (BR-1 through BR-5, Figure 1) and recently installed monitor well WBR-48, located southwest of CMBS-4 (Figure 23), provide depth information for the top of the Cretaceous upper confined aquifer. The top of the upper confined aquifer at the location of WBR-48 is approximately $100 \mathrm{ft}$ below ground surface (approximately $90 \mathrm{ft}$ below $\mathrm{msl}$ ). The total thickness of the surficial aquifer is greater than $50 \mathrm{ft}$ at the locations of monitor wells WBR-56A and WBR-61A. Additional monitor wells, WBR-56B and WBR-61B (located approximately $15 \mathrm{ft}$ and $25 \mathrm{ft}$ from monitor wells WBR-56A and WBR-61A, respectively), were installed to determine the depth to the base of the surficial aquifer. The depth to the base of the sandy unit was approximately $56.5 \mathrm{ft}$ below ground surface in monitor well WBR-56B, and approximately $45.5 \mathrm{ft}$ below ground surface in monitor well WBR-61B.

On the basis of GPR and EM-31 geophysical measurements and soil boring information, the approximate locations of detected paleochannel features have been mapped and are presented in Figure 35. The orientations of the features presented in Figure 35 are based upon a limited number of data points and should be considered estimations. The paleochannel features found during the geophysical surveys at the southern Bush River Peninsula are variable in depth and trend. A relatively shallow paleochannel, approximately 20 to $25 \mathrm{ft}$ below ground surface, is located in the northwestern portion of the Tapler Point grid system (Figures 19 and 25). EM-31 


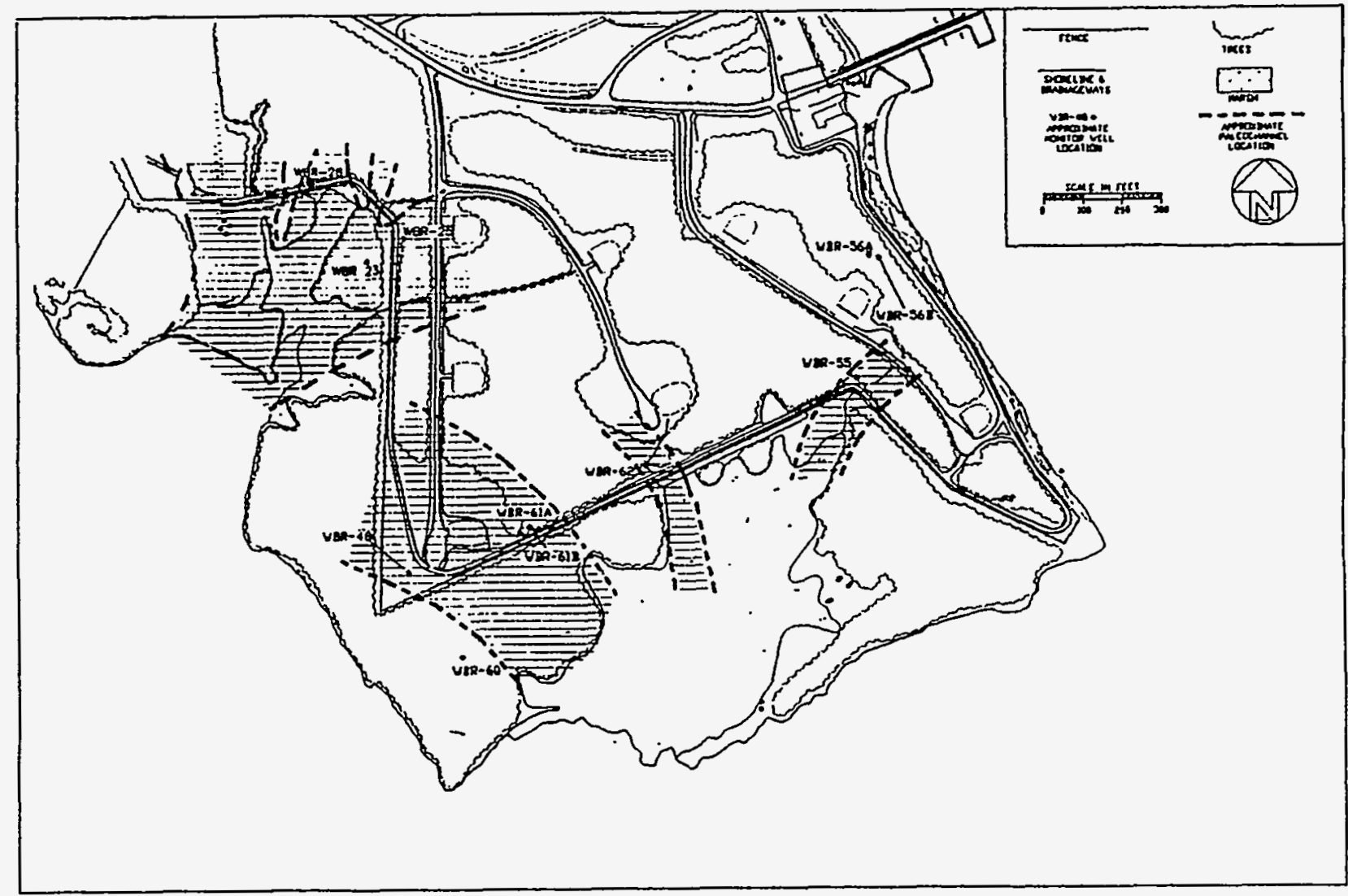

FIGURE 35 Approximate Paleochannel Locations Inferred from GPR and EM-31 Data and Boring Logs

data suggest that this paleochannel may trend east-northeast/west-southwest following the existing site drainage, but anthropogenic features prevent good correlation. A much deeper sand unit, probably associated with a paleochannel, is found on the northern edge of the Tapler Point grid at the locations of monitor wells WBR-56A and WBR-56B (Figure 23). Limited geophysical surveys (one GPR profile) did not confirm the presence or orientation of a paleochannel in this area.

Another deeper paleochannel, generally trending northwest/southeast, is located beneath the southern part of CMBS-4. GPR data indicate that the base of this paleochannel is approximately $40 \mathrm{ft}$ below ground surface at 29 th Street. This depth estimate is based on a twoway travel time of $9 \mathrm{~ns} / \mathrm{ft}$. Monitor well WBR-48 is within this paleochannel feature. The base of the surficial aquifer is located at a depth between 45 and $49 \mathrm{ft}$ in WBR-48. The GPR data also indicate a possible channel-flank structure adjacent to WBR-48. On the basis of these conflicting data, it is probable that the GPR data are highlighting internal structures within the larger paleochannel. Monitor well WBR-61A, located $450 \mathrm{ft}$ east of 29th Street, was also installed within this deeper paleochannel feature. The total depth to the base of the surficial aquifer at WBR-61A is greater than $50 \mathrm{ft}$ below ground surface. The boring log for monitor well WBR-61B, located approximately $25 \mathrm{ft}$ east of WBR-61A, indicates that the elevation of the base of the surficial aquifer is at least 4 feet higher at this location. This is consistent with the 
orientation of the paleochannel indicated in Figure 35. GPR measurements along additional profiles are necessary to further characterize the orientations and continuity of these observed features.

A reflector believed to represent a paleochannel, approximately $25 \mathrm{ft}$ in depth, was observed farther east along GPR profile \#13 at the location of a current drainageway. The orientation of this paleochannel is believed to be generally parallel to the current site drainage, as shown in Figure 35. Monitor well WBR-62 was installed within this paleochannel and has a basal sand unit extending to approximately $45 \mathrm{ft}$ below ground surface. A thin, clayey silt lens is present within sand units in WBR-62 at a depth of approximately $28.5 \mathrm{ft}$. The reflector observed in GPR profile \#13 at $630 \mathrm{ft}$ may represent a shallow paleochannel superimposed over a deeper, older paleochannel not visible on the GPR data. 


\section{Summary and Conclusions}

Munition disposal procedures during the 1920s and 1930s included burial of deteriorated or failed munitions in unused portions of APG. A review of historic aerial photographs with limited resolution indicated that ground scars may have been present in the southern Bush River Peninsula (Nemeth 1989). Dredge material obtained from the area around the Bush River Dock was also placed in the southern portion of the peninsula.

A series of geophysical surveys, supported by a site drilling program, was undertaken to define the hydrogeologic framework and potential contaminant migration pathways beneath the study area. The areal extent of metallic wastes was mapped by using magnetic and electromagnetic methods. The following specific conclusions have been drawn on the basis of the survey results.

1. No large-scale disposal by burial appears to be associated with the four suspected chemical munitions burial sites or the dredge material site, but smallscale burials cannot be ruled out. Further characterization of the buried metallic anomalies detected during the magnetic and EM-61 surveys is recommended to determine the presence of munition disposal at these locations.

2. The general hydrogeologic framework beneath the five study sites has been defined. A Pleistocene paleochannel-fill complex, extending greater than $50 \mathrm{ft}$ below ground surface, is present beneath the CMBS-4 area. This channel-fill complex is part of a larger feature encompassing the marsh east of CMBS-4, with extensions toward the north and east into the Tapler Point area. The configuration of the paleochannel system beneath the Bush River Peninsula could be more clearly defined with a combination of additional GPR and EM-31 measurements.

3. Potential contaminant pathways from the southern Bush River Peninsula along the base of the surficial aquifer have been mapped for possible future integration with hydrogeologic data collected offshore in a companion report (Miller et al. unpublished information). This integrated map could be used to guide further investigations, if the site soil and groundwater chemistry data currently being collected and analyzed as part of the remedial investigation of the Bush River Peninsula indicate that further investigation is necessary. 


\section{References}

Bennett, R.R., and R.R. Meyer, 1952, Geology and Ground-Water Resources of the Baltimore Area, Bulletin 4, Maryland Department of Geology, Mines, and Water Resources.

Cordell, L., et al., 1992, Potential Field Geophysical Software: Version 2, U.S. Geological Survey Open-File Report 92-18.

Davies, B.E., et al., 1995, Environmental Geophysics at Kings Creek Disposal Site and 30th Street Landfill, Aberdeen Proving Ground, Maryland, ANL/ESD/TM-83, Argonne National Laboratory, Argonne, Ill.

Dingman, R.J., et al., 1956, The Water Resources of Baltimore and Harford Counties, Bulletin 17, Maryland Department of Geology, Mines, and Water Resources.

Geonics Limited, 1992, EM-31 Operating Manual (for Models with Two Digital Meters), Mississauga, Ontario.

Geophysical Survey Systems, Inc., 1987, Operations Manual for Subsurface Interface Radar (SIR System-3).

GSSI: see Geophysical Survey Systems, Inc.

Kansas Geological Survey, 1993, EAVESDROPPER Seismic Reflection Processing Software, Version 3.0, 1930 Constant Ave., Campus West, Lawrence, Kansas.

Kehrin, R.T., et al., 1988, The Surficial Sediments of the Chesapeake Bay, Maryland - Physical Characteristics and Sediment Budget, Report No. 48, Maryland Geological Survey.

Lorah, M.M., and D.A. Vroblesky, 1989, Inorganic and Organic Ground-Water Chemistry in the Canal Creek Area of Aberdeen Proving Ground, Maryland, Water Resources Investigations Report 89-4022, U.S. Geological Survey.

McGinnis, L.D., et al., 1994a, Environmental Geophysics at Beach Point, Aberdeen Proving Ground, Maryland, ANL/ESD-23, Argonne National Laboratory, Argonne, Ill.

McGinnis, L.D., et al., 1994b, Environmental Geophysics of the Pilot Plant on the West Branch of Canal Creek, Aberdeen Proving Ground, Maryland, ANL/ESD/TM-74, Argonne National Laboratory, Argonne, Ill. 
Miller, S.F., et al., 1995, unpublished information, Argonne National Laboratory, Argonne, Ill.

Nemeth, G., 1989, RCRA Facility Assessment Report, Edgewood Area, Aberdeen Proving Ground, Maryland, prepared for Aberdeen Proving Ground, Test and Evaluation Command, U.S. Army Material Command.

Oliveros, J.P., and D.A. Vroblesky, 1989, Hydrogeology of the Canal Creek Area, Aberdeen Proving Ground, Maryland, Water Resources Investigations Report 89-4021, U.S. Geological Survey.

Otton, E.G., and R.J. Mandle, 1984, Hydrogeology of the Upper Chesapeake Bay Area, Maryland, with Emphasis on Aquifers in the Potomac Group, Report No. 39, Maryland Geological Survey.

RIMROCK Geophysics, Inc., 1992, SIPT2 Refraction Processing Software, Version 3.2, Boulder, Colo.

Southwick, D.L., et al., 1969, The Geology of Harford County, Maryland, Maryland Geological Survey.

Thurmond, V., 1993, North-South Stratigraphic Cross-Section of the Bush River Area, U.S. Army Corps of Engineers-Baltimore District, Internal Document.

U.S. Army Corps of Engineers, Baltimore District, 1994, Detailed RI Work Plan for Cluster 15, Edgewood Area, Aberdeen Proving Ground, Maryland. 


\section{Appendix A:}

Soil Boring Logs 


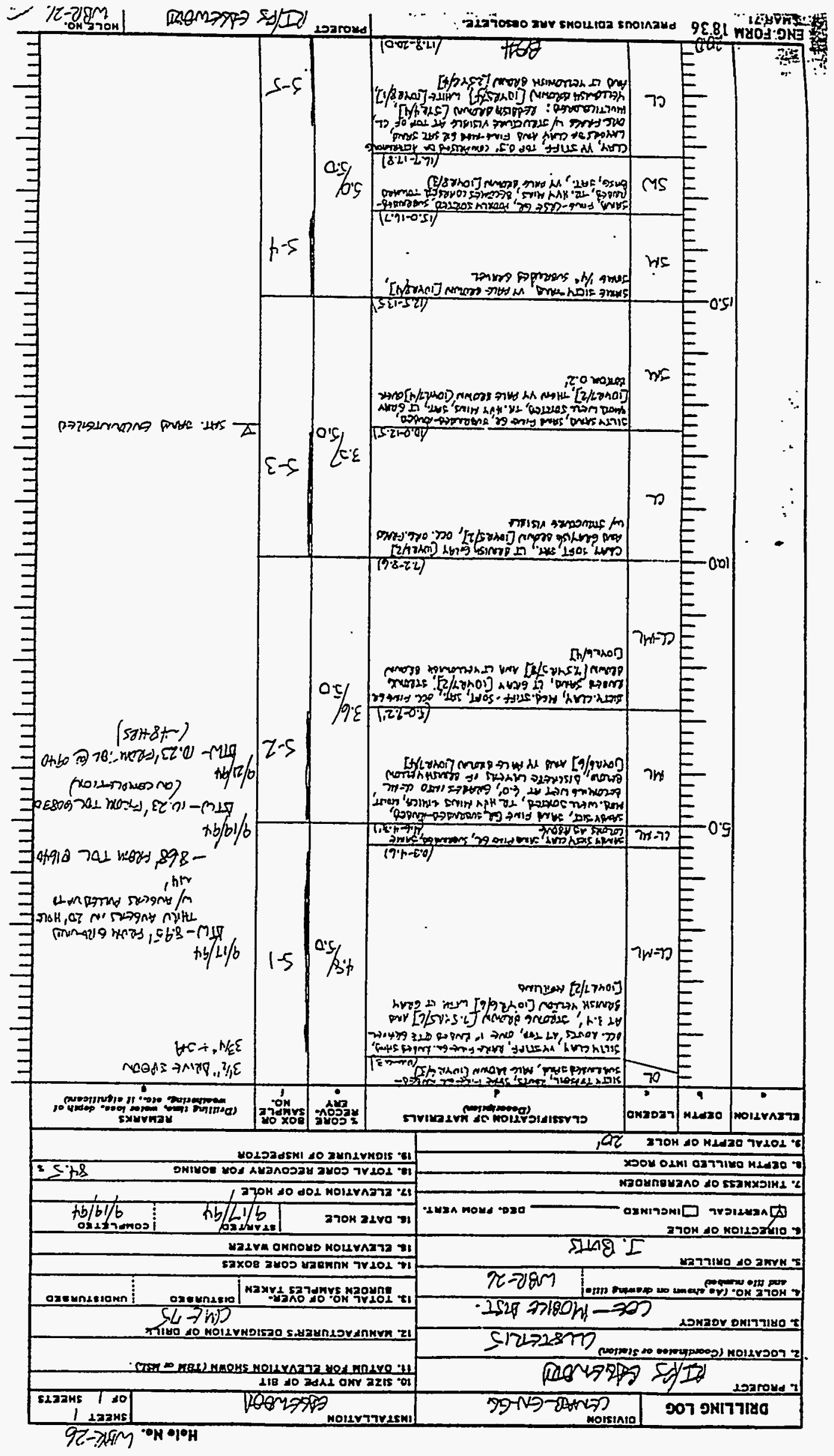




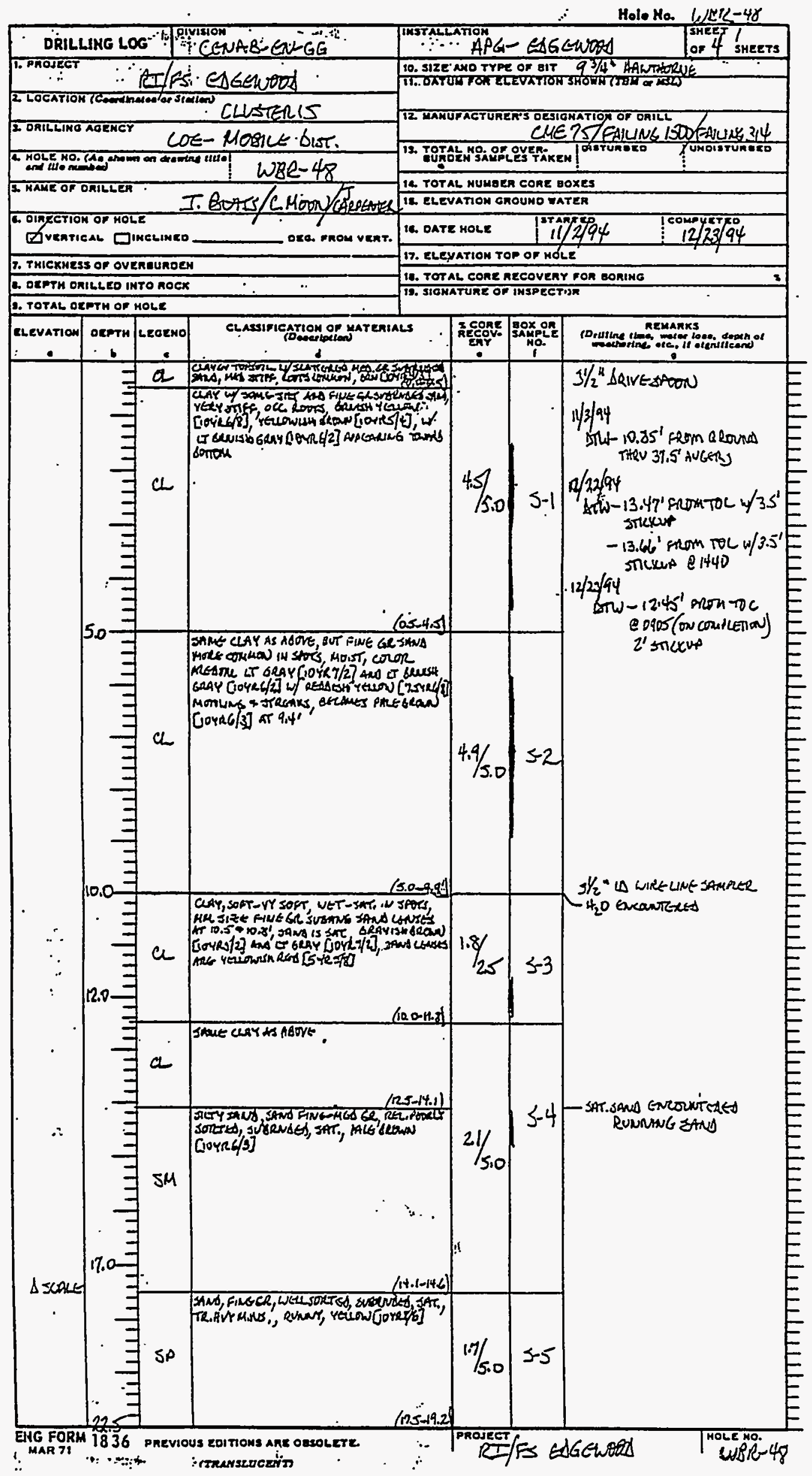




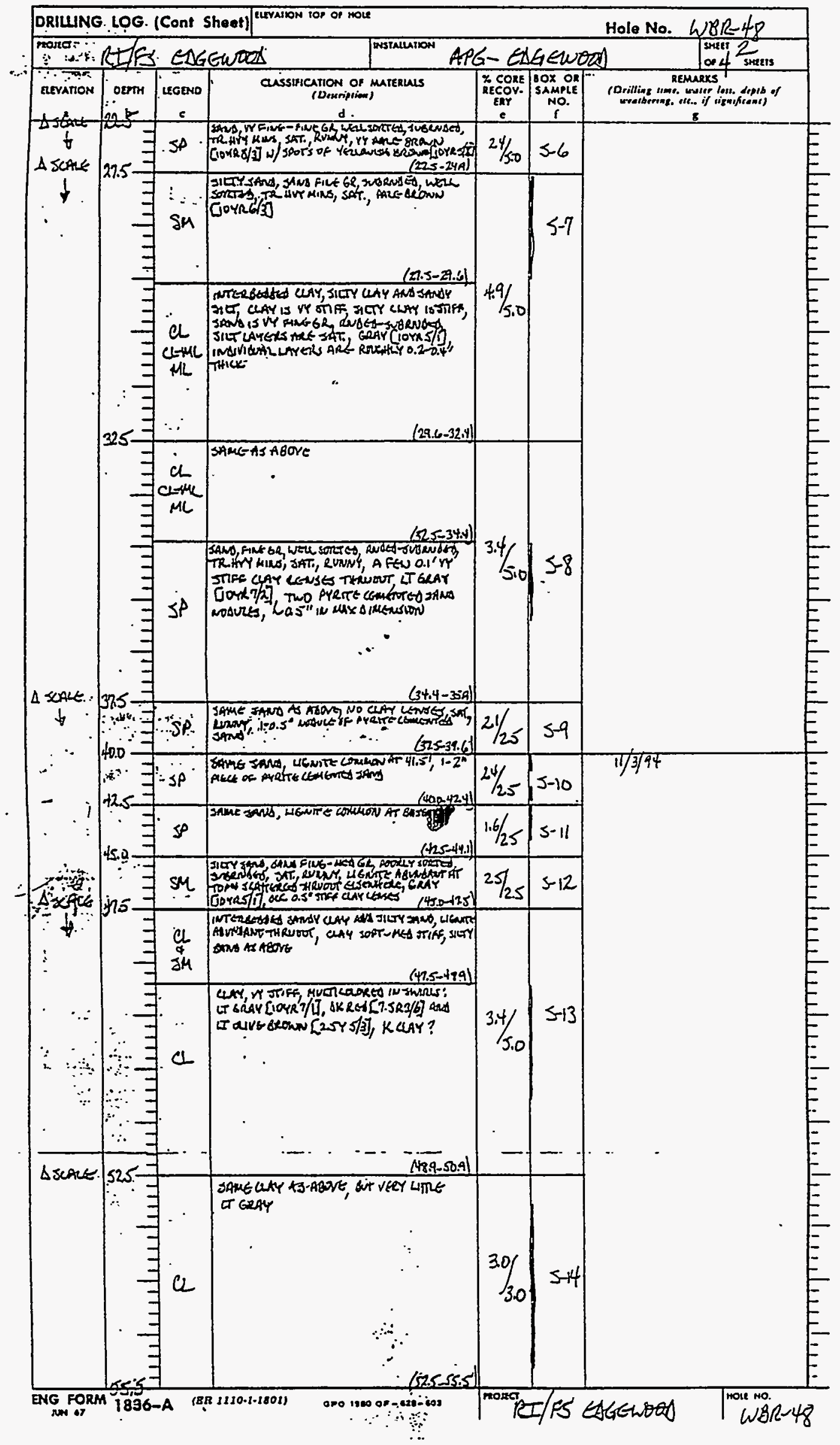




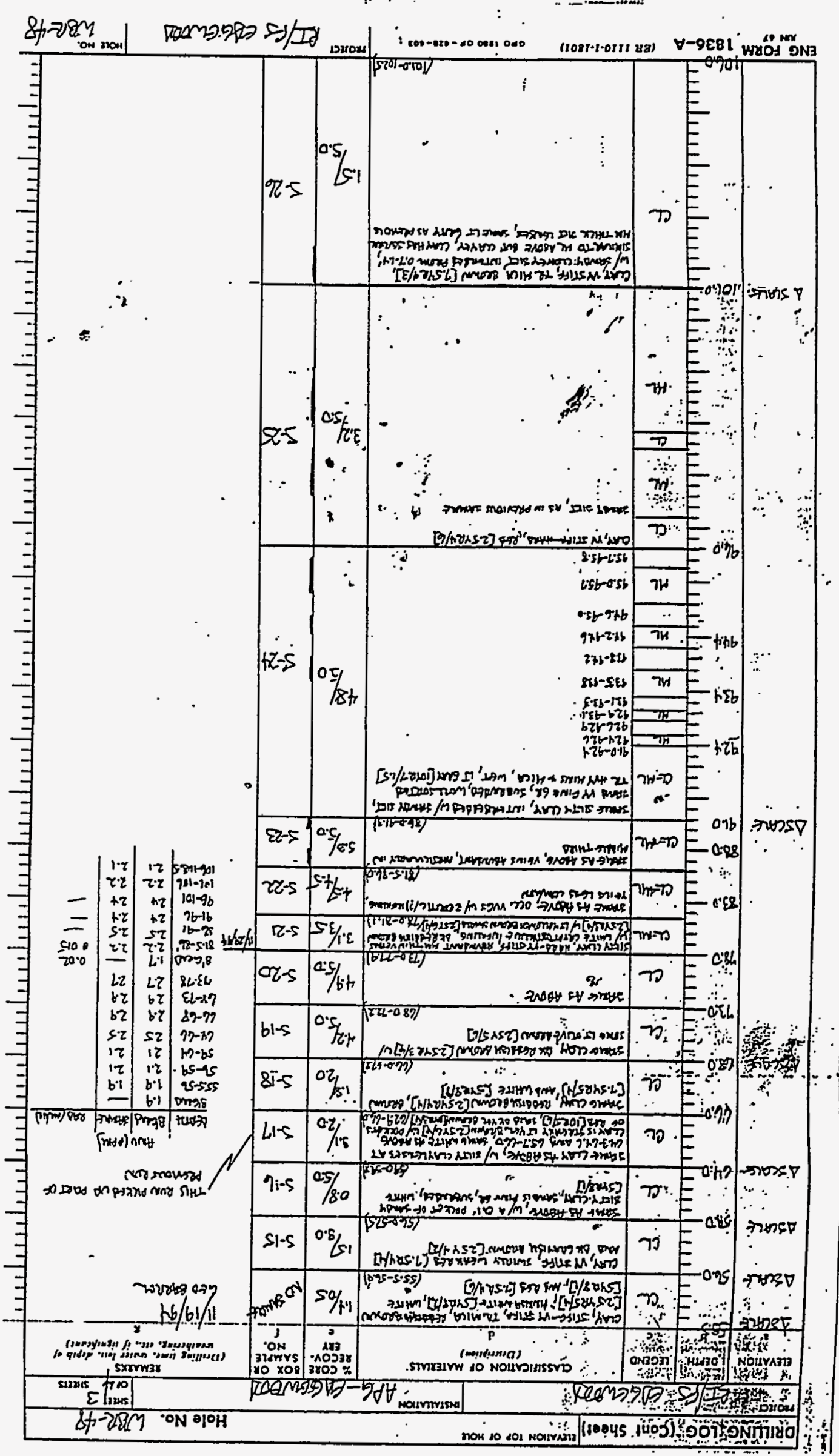




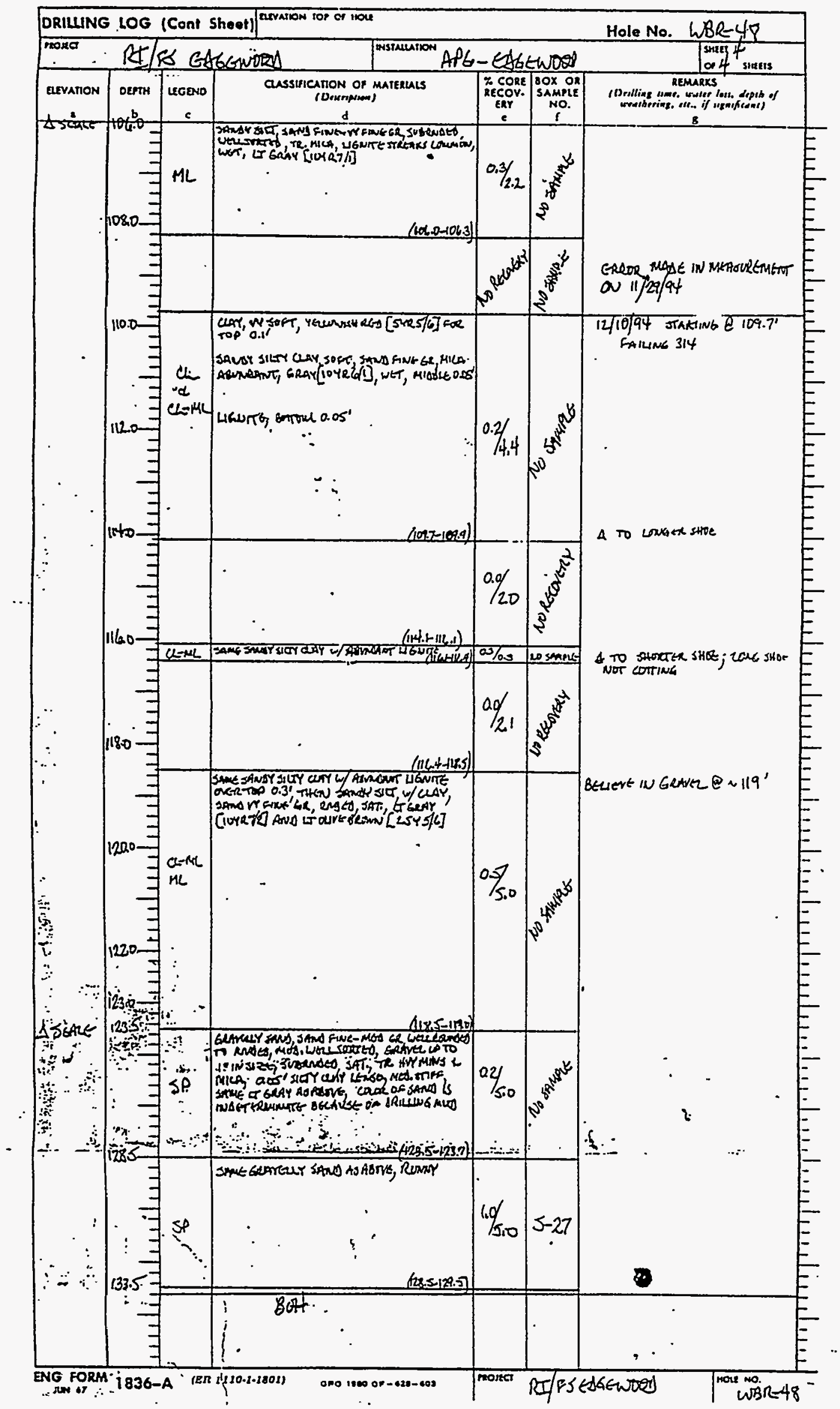




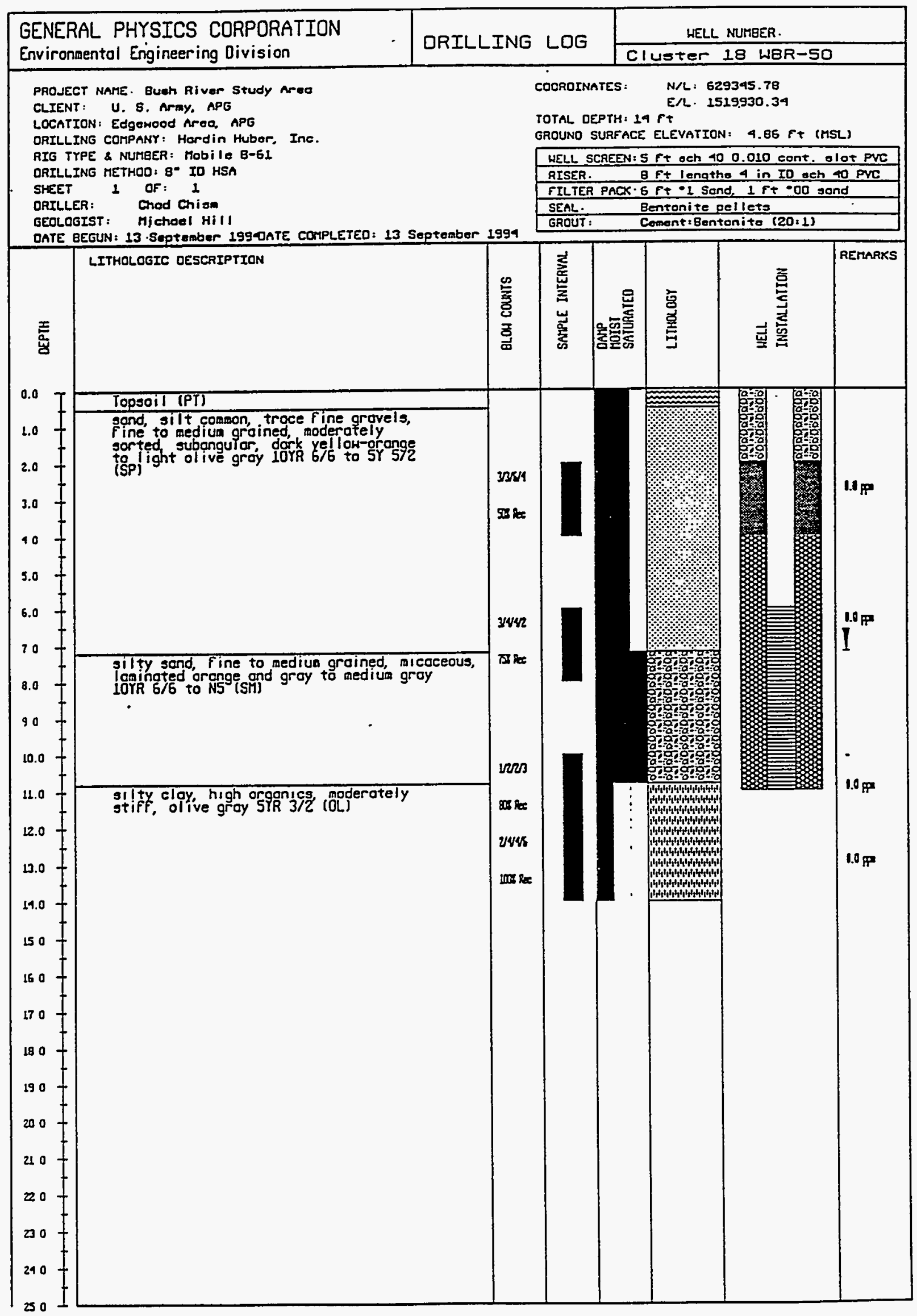




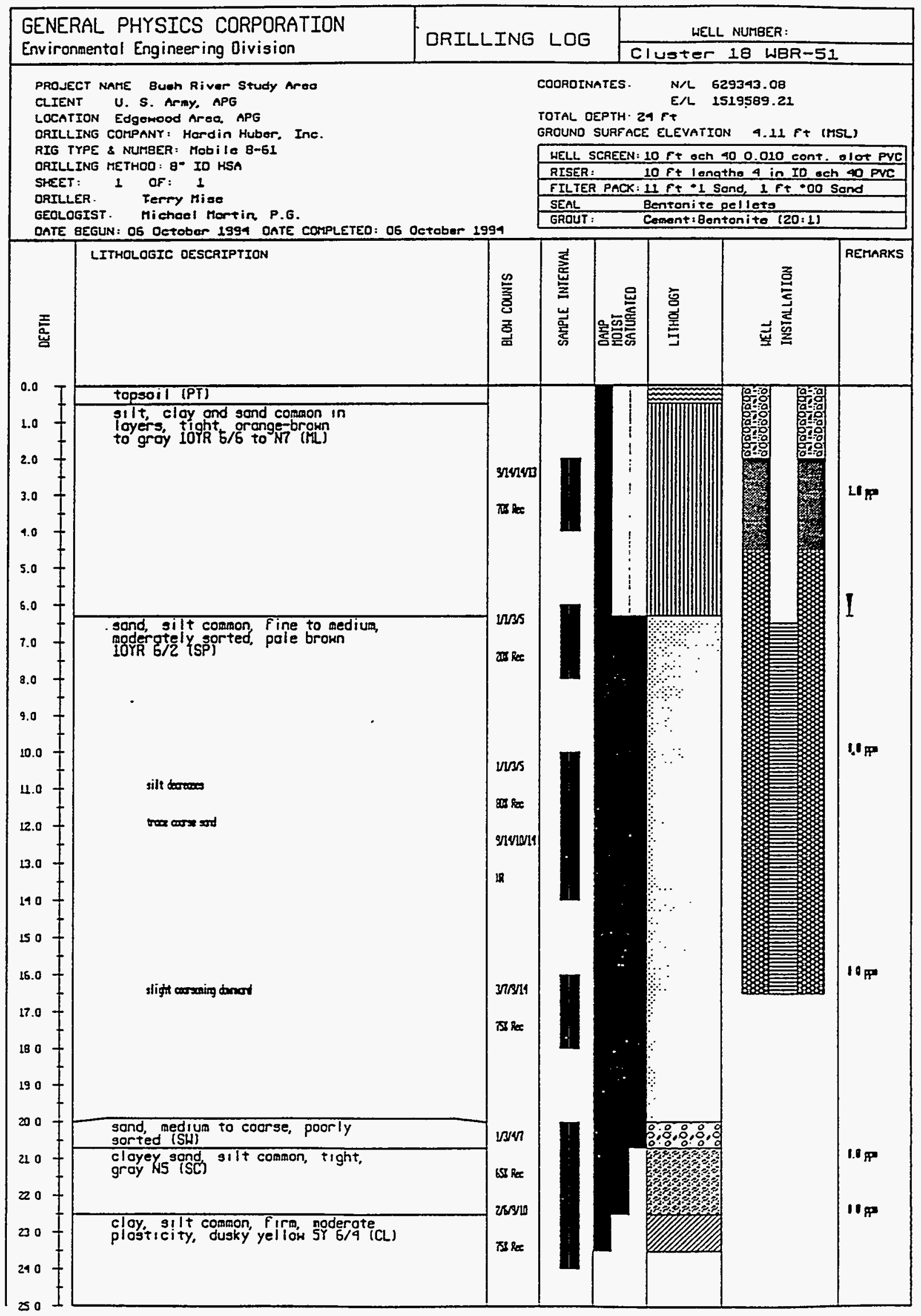




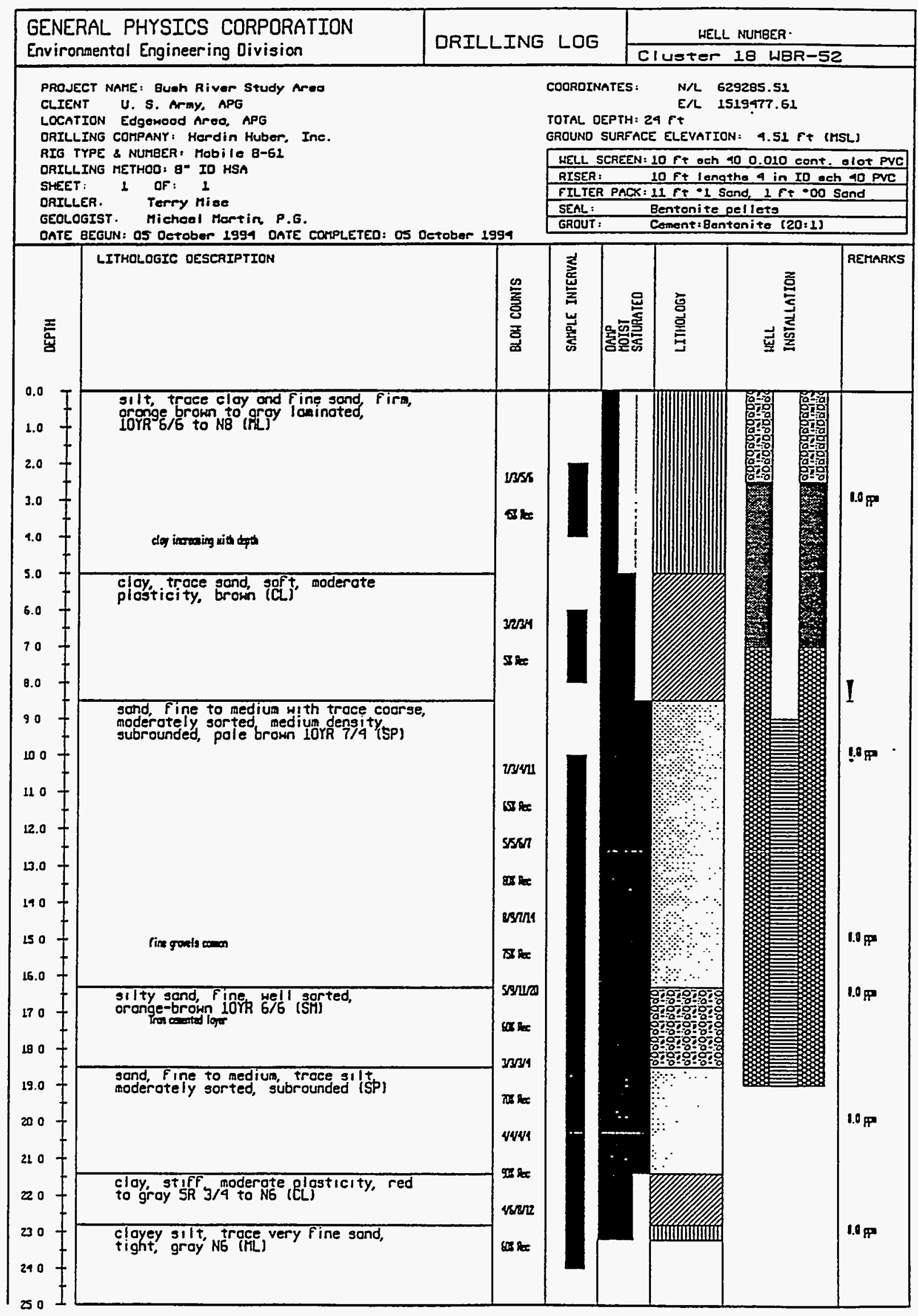




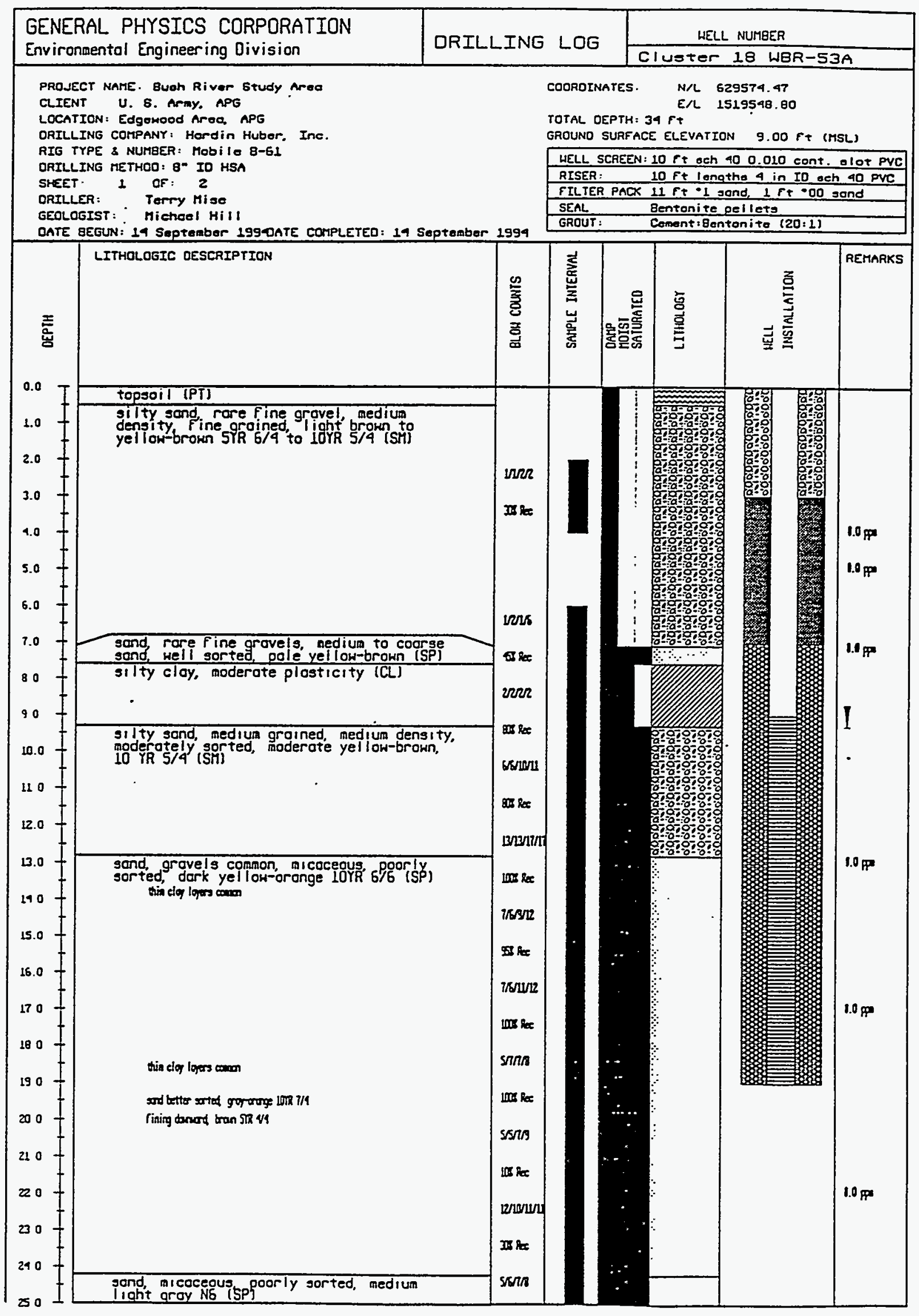




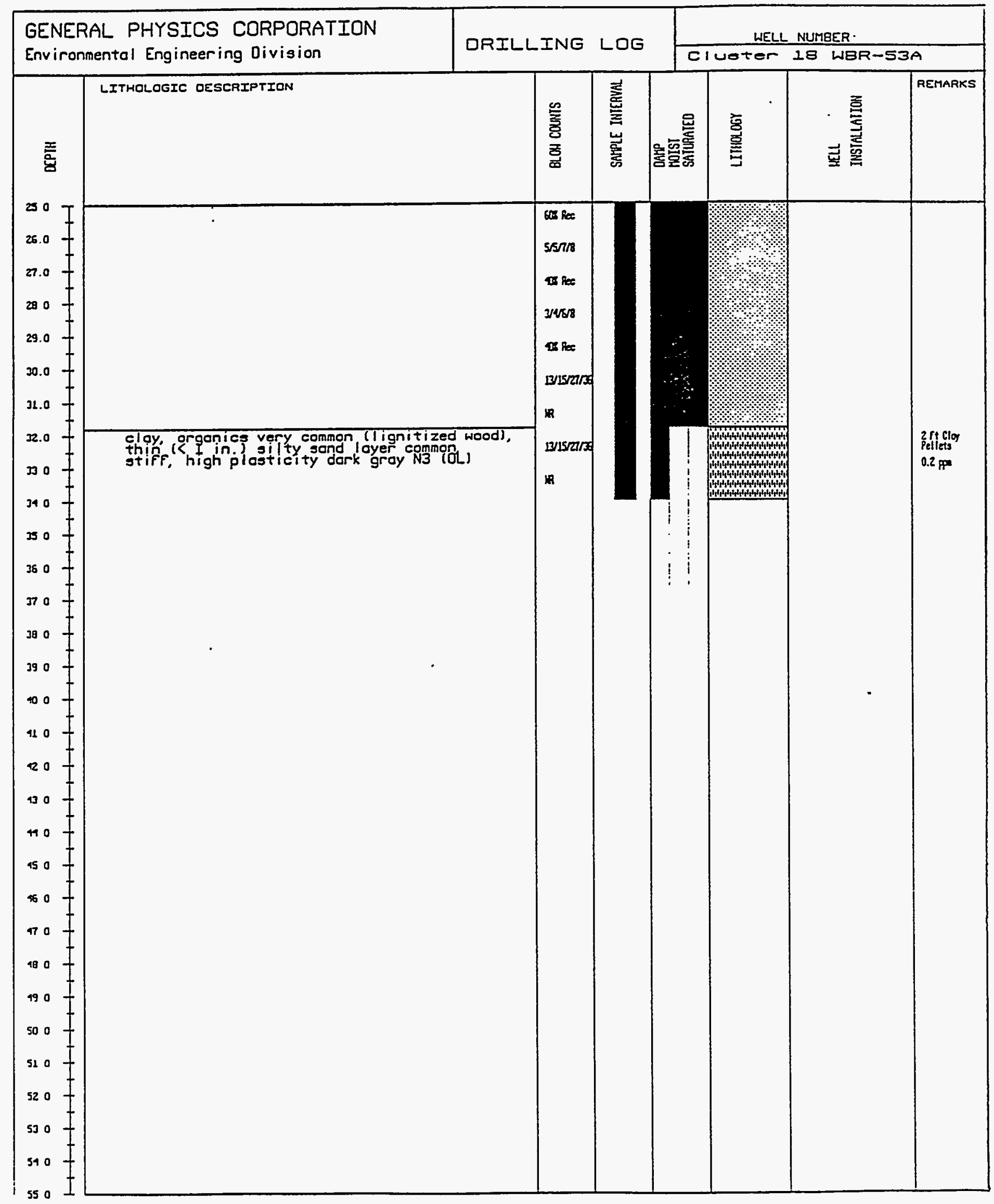




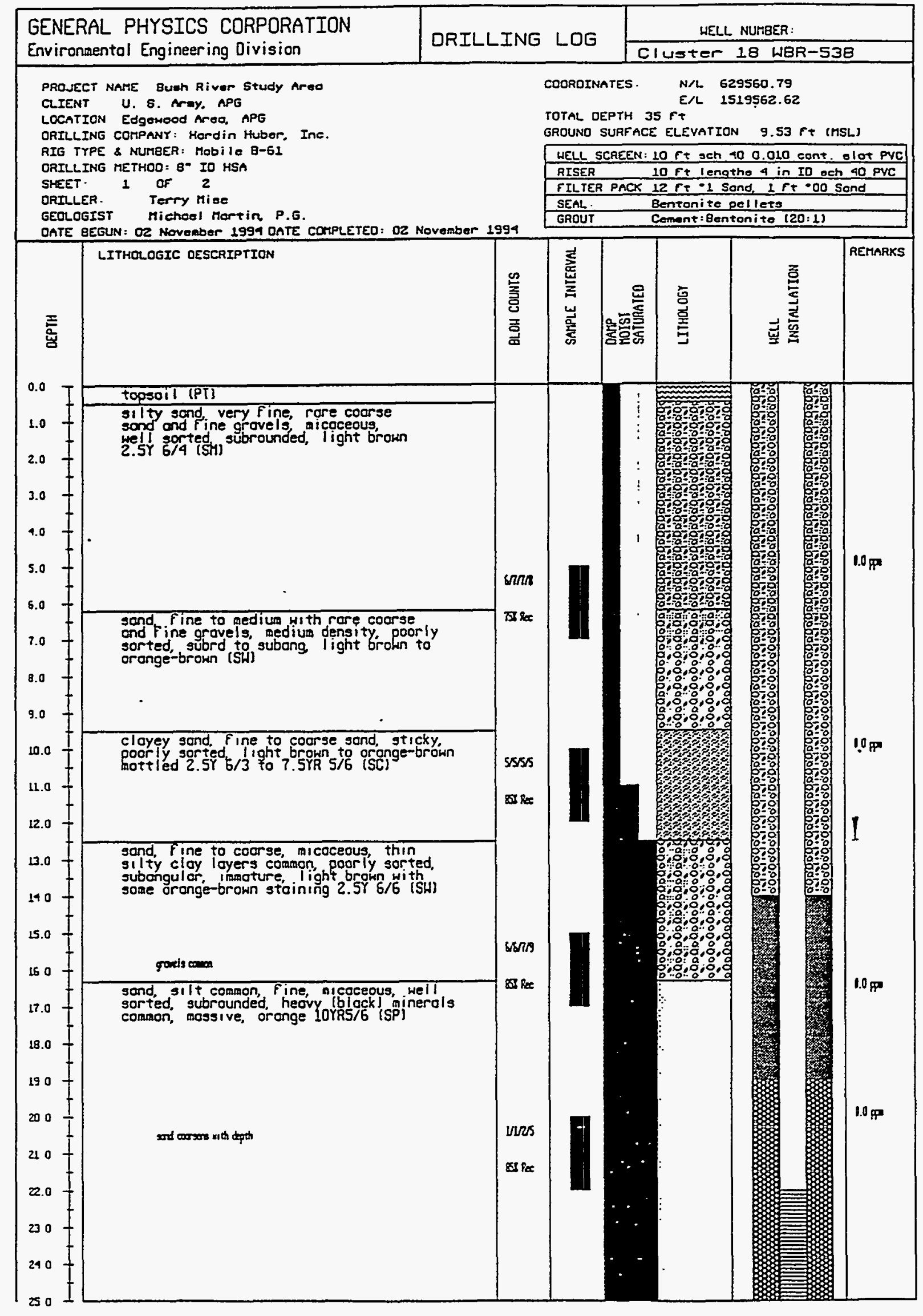




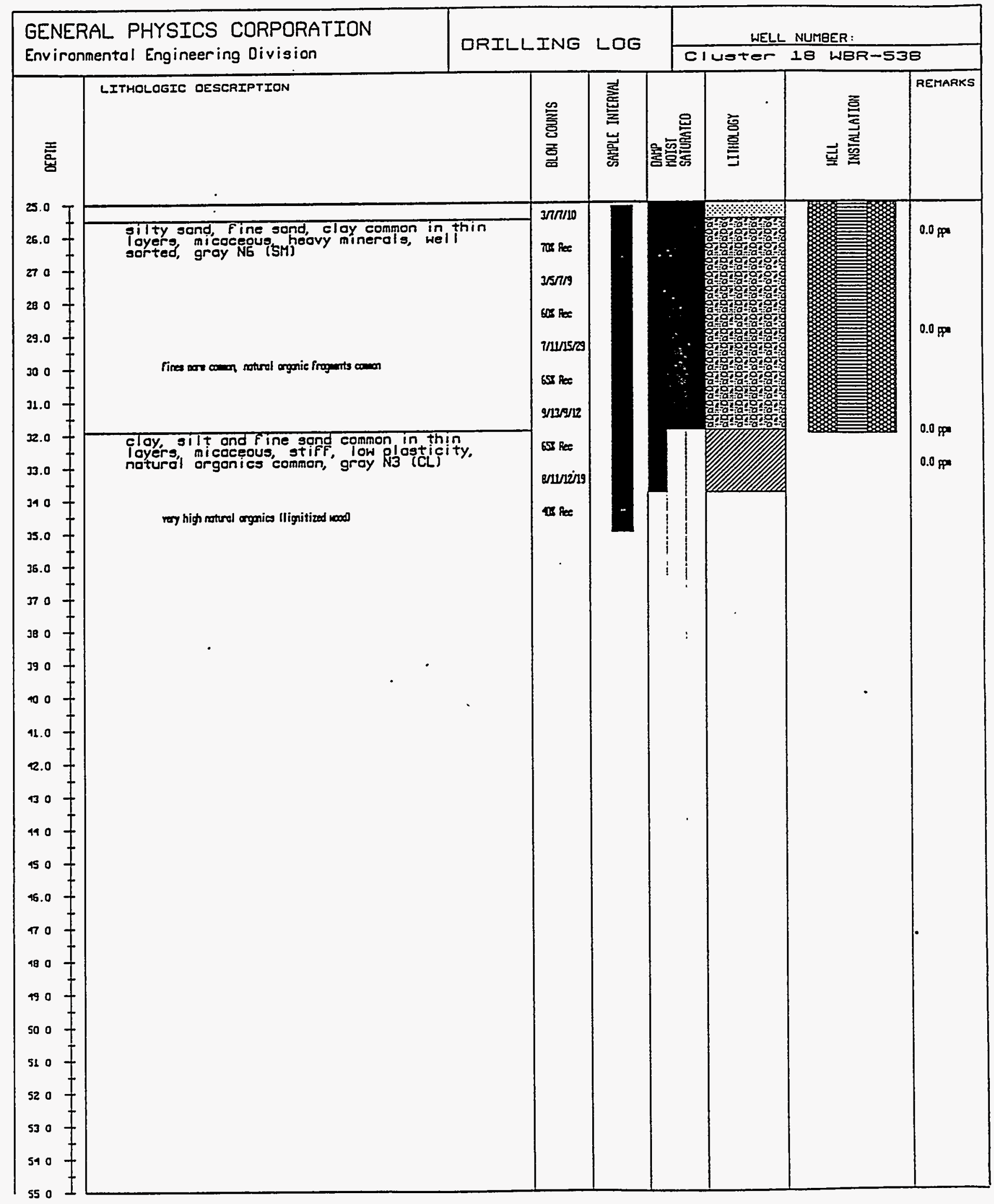




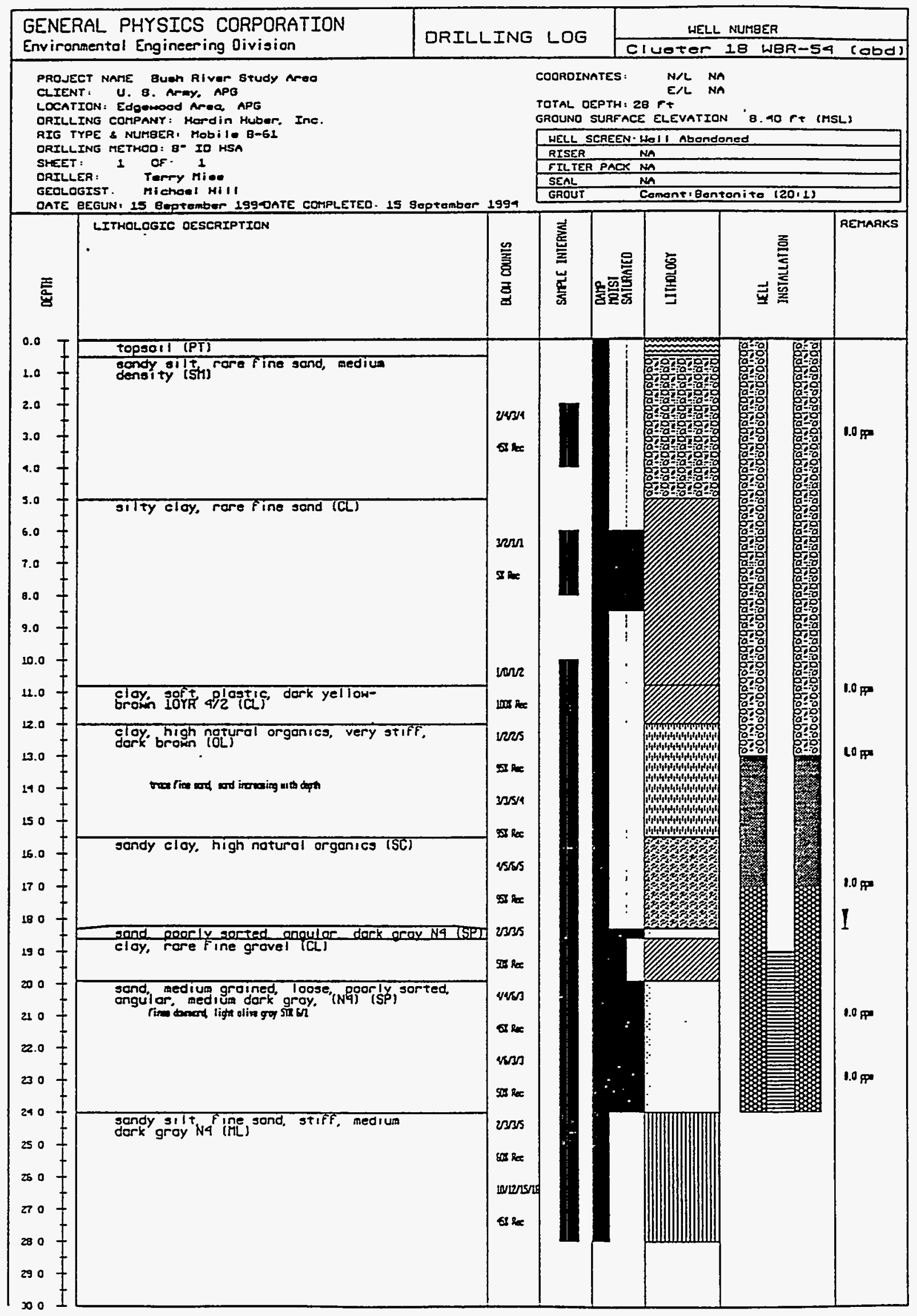




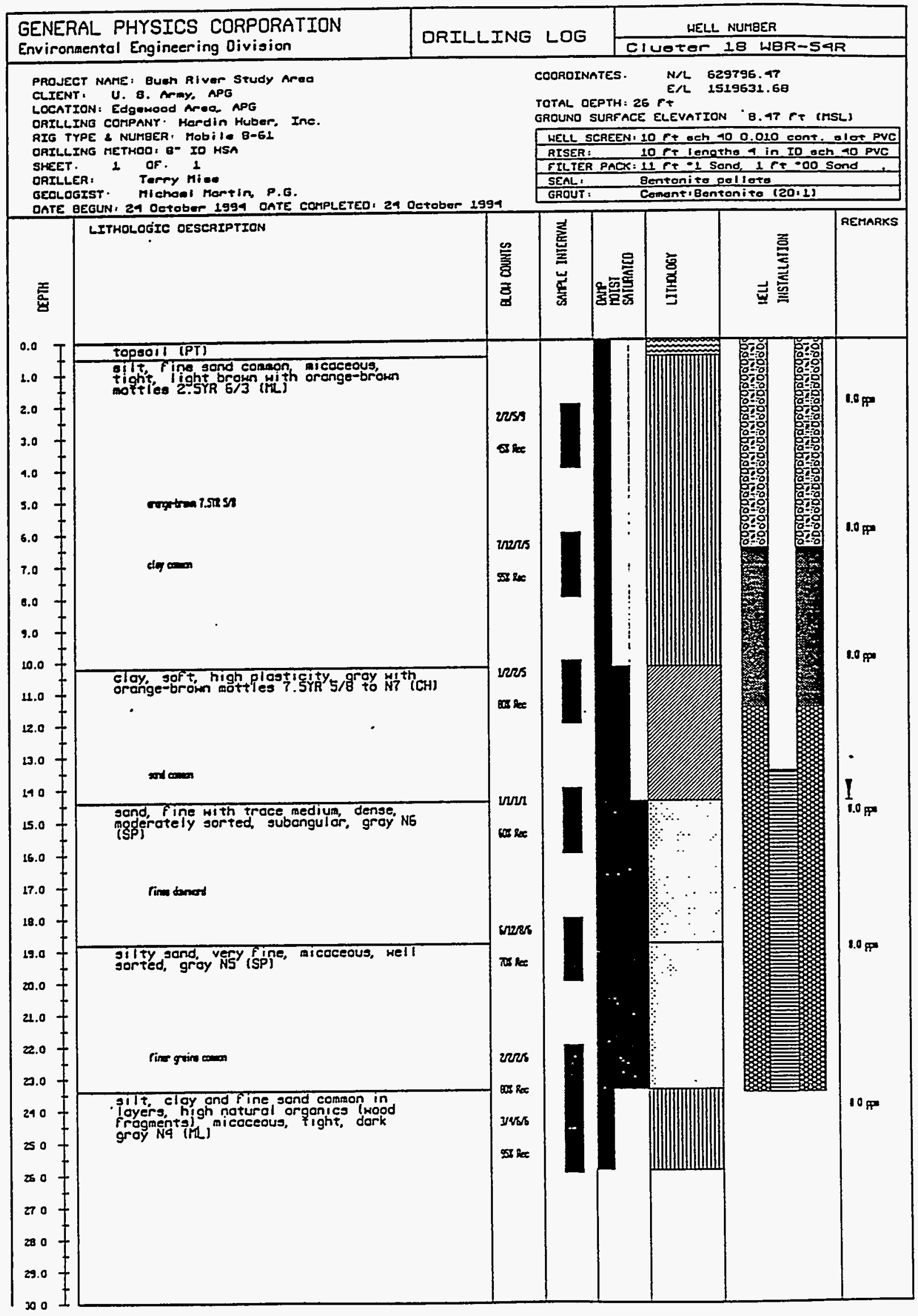




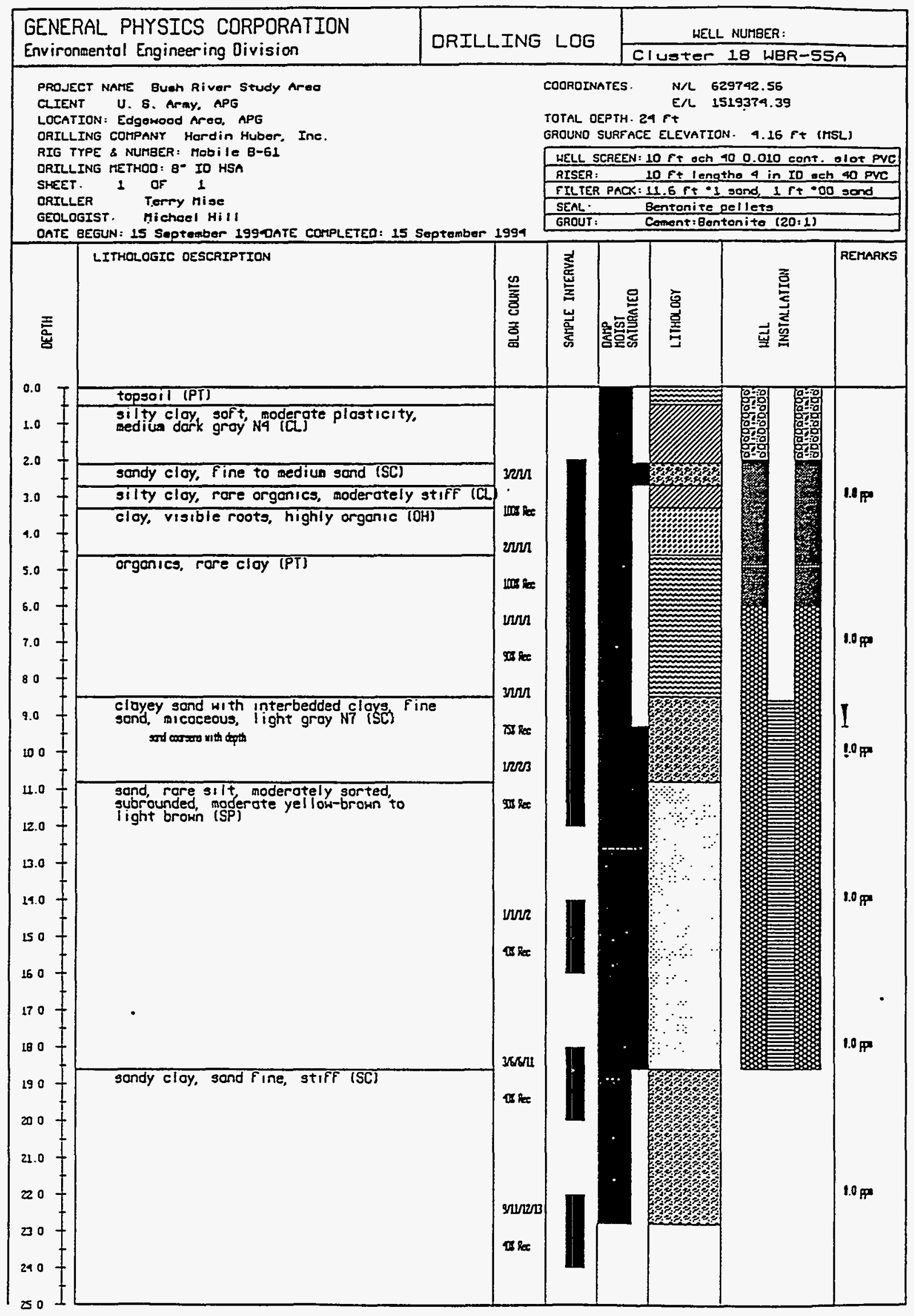




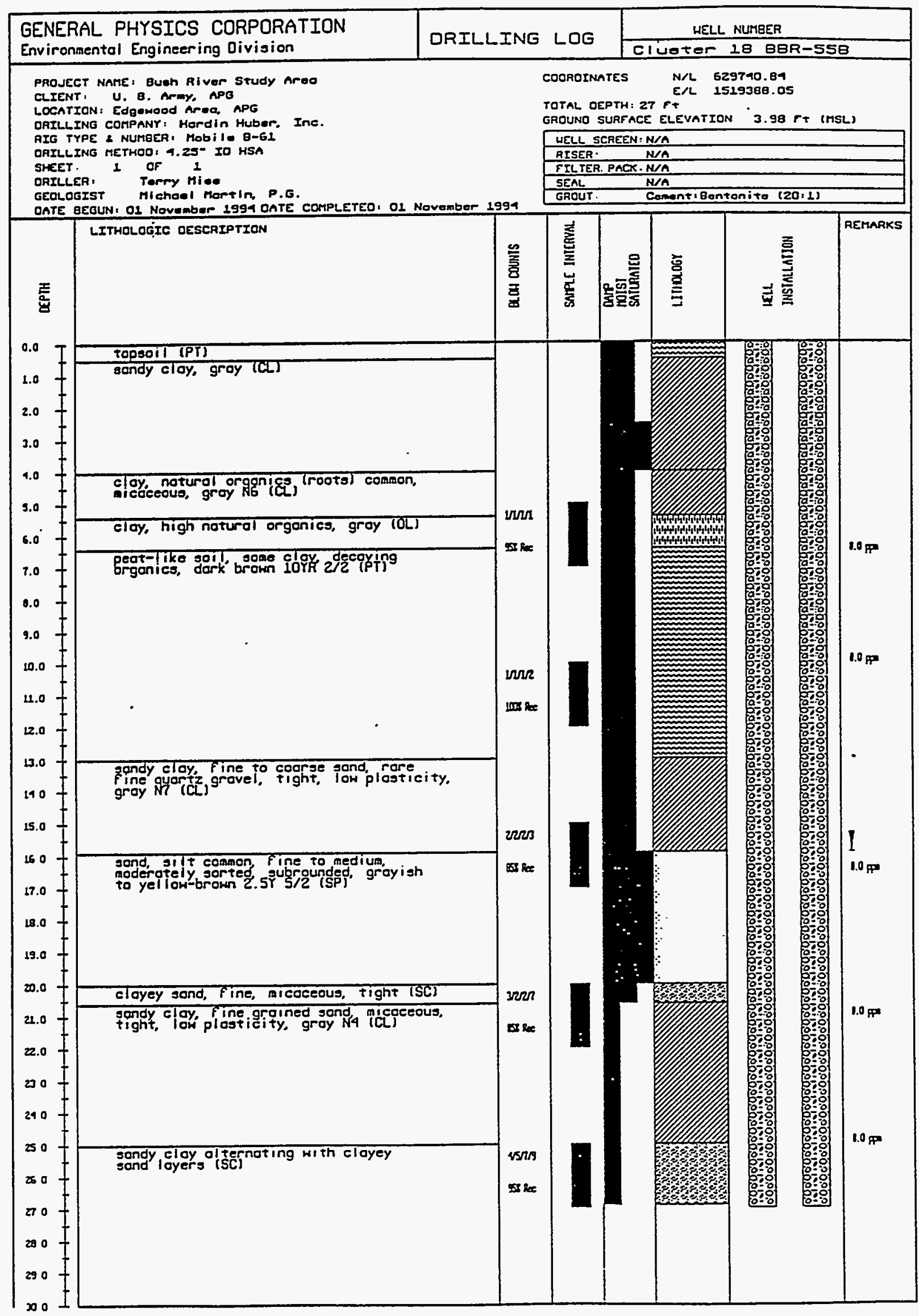




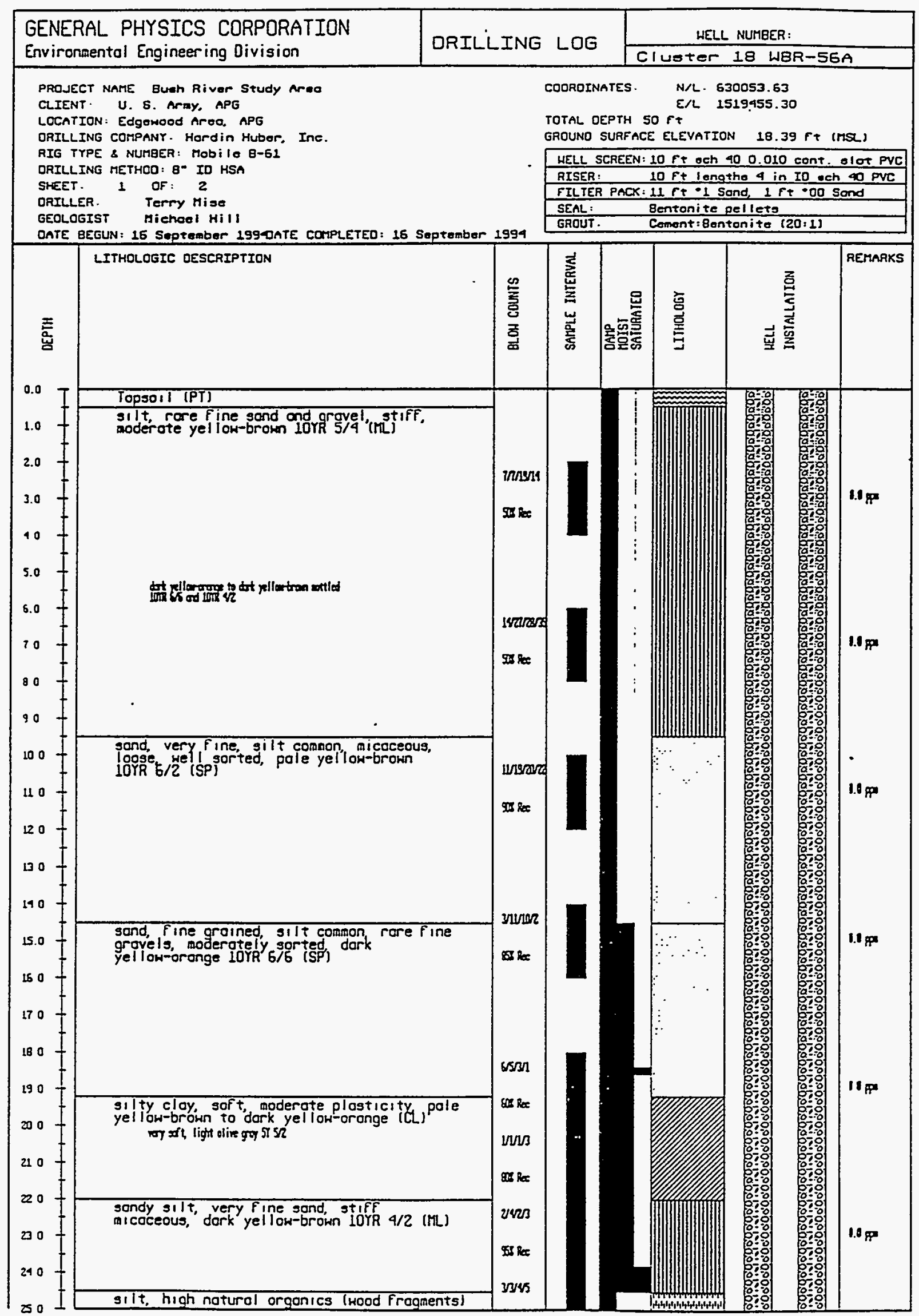




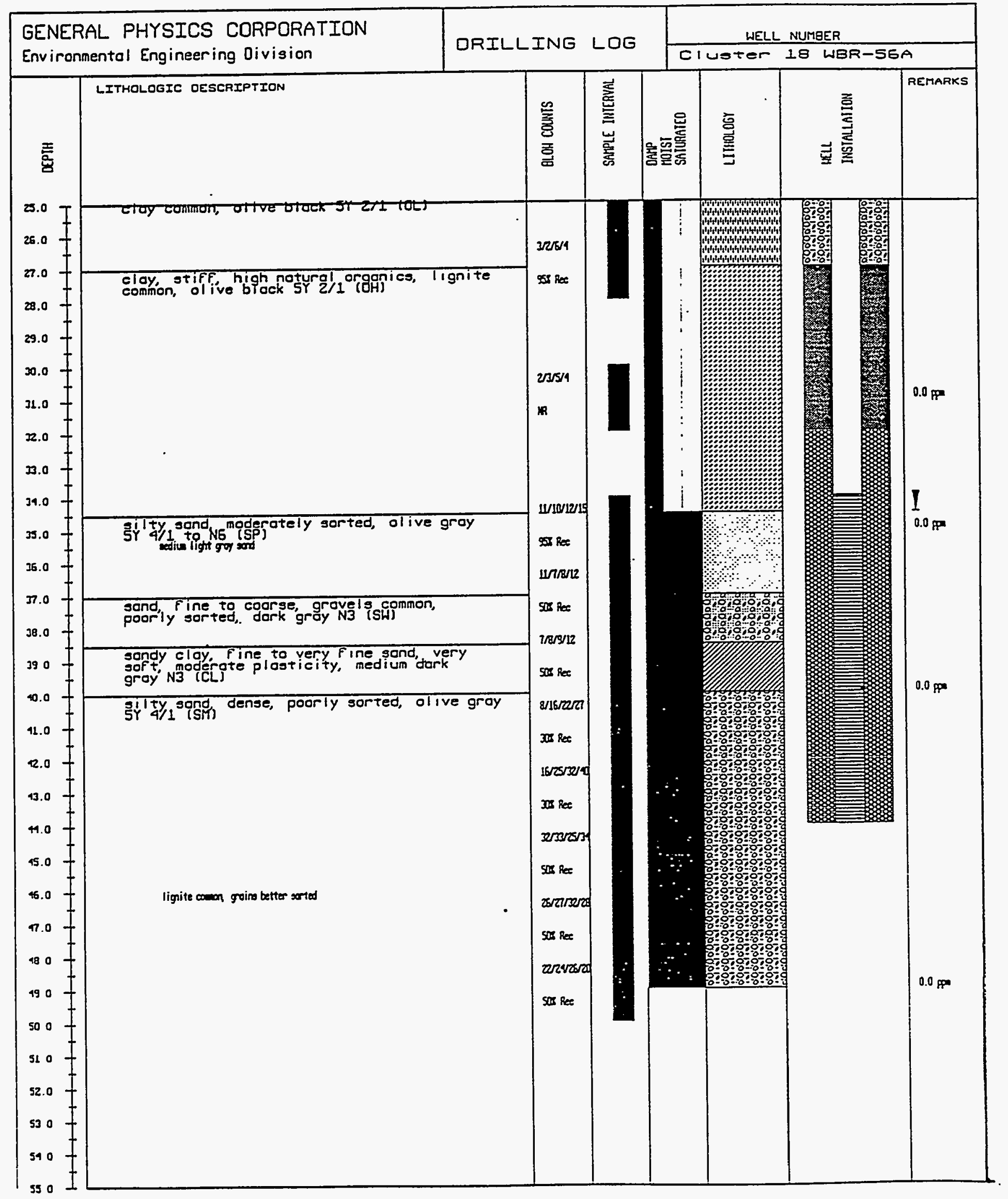




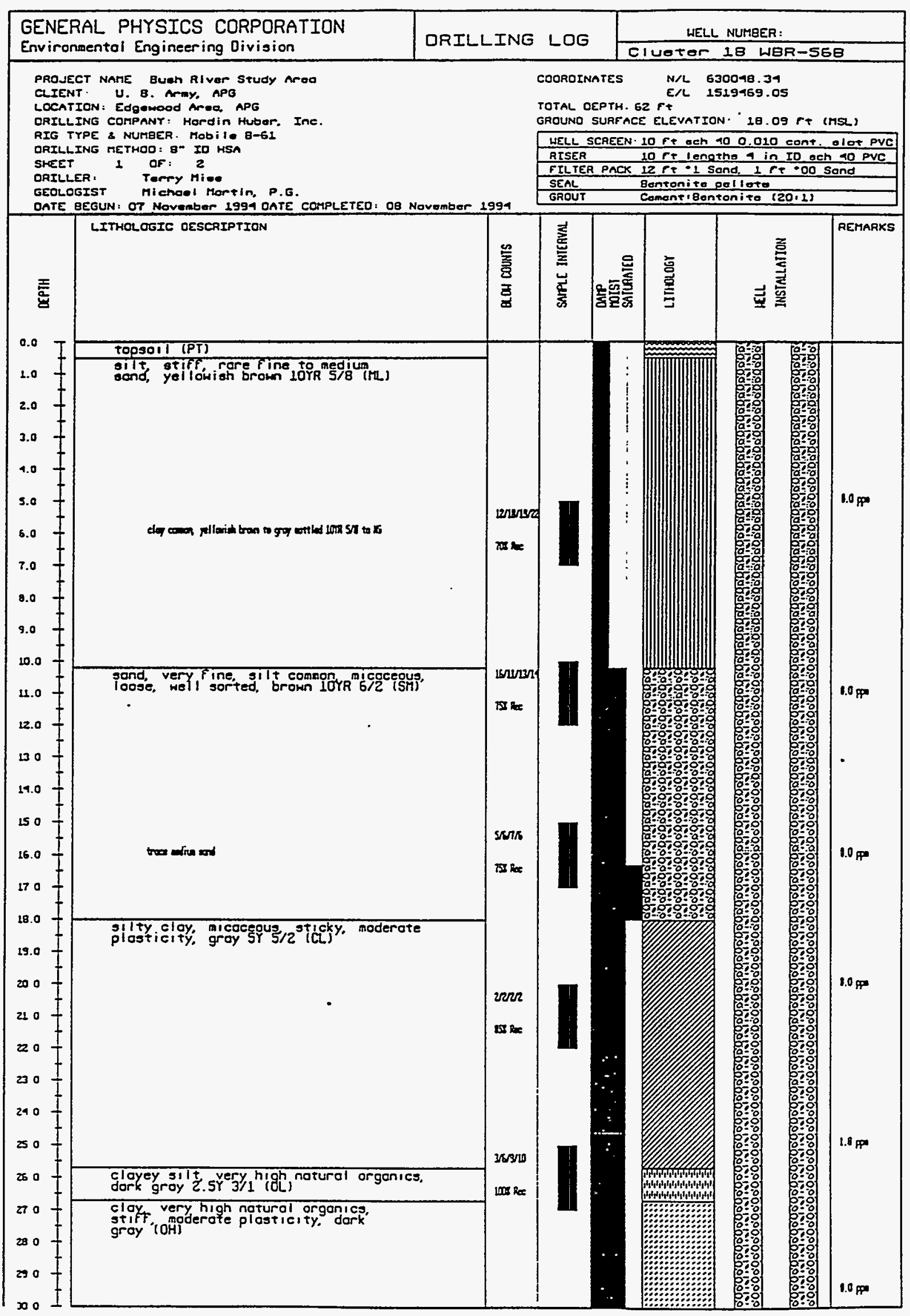




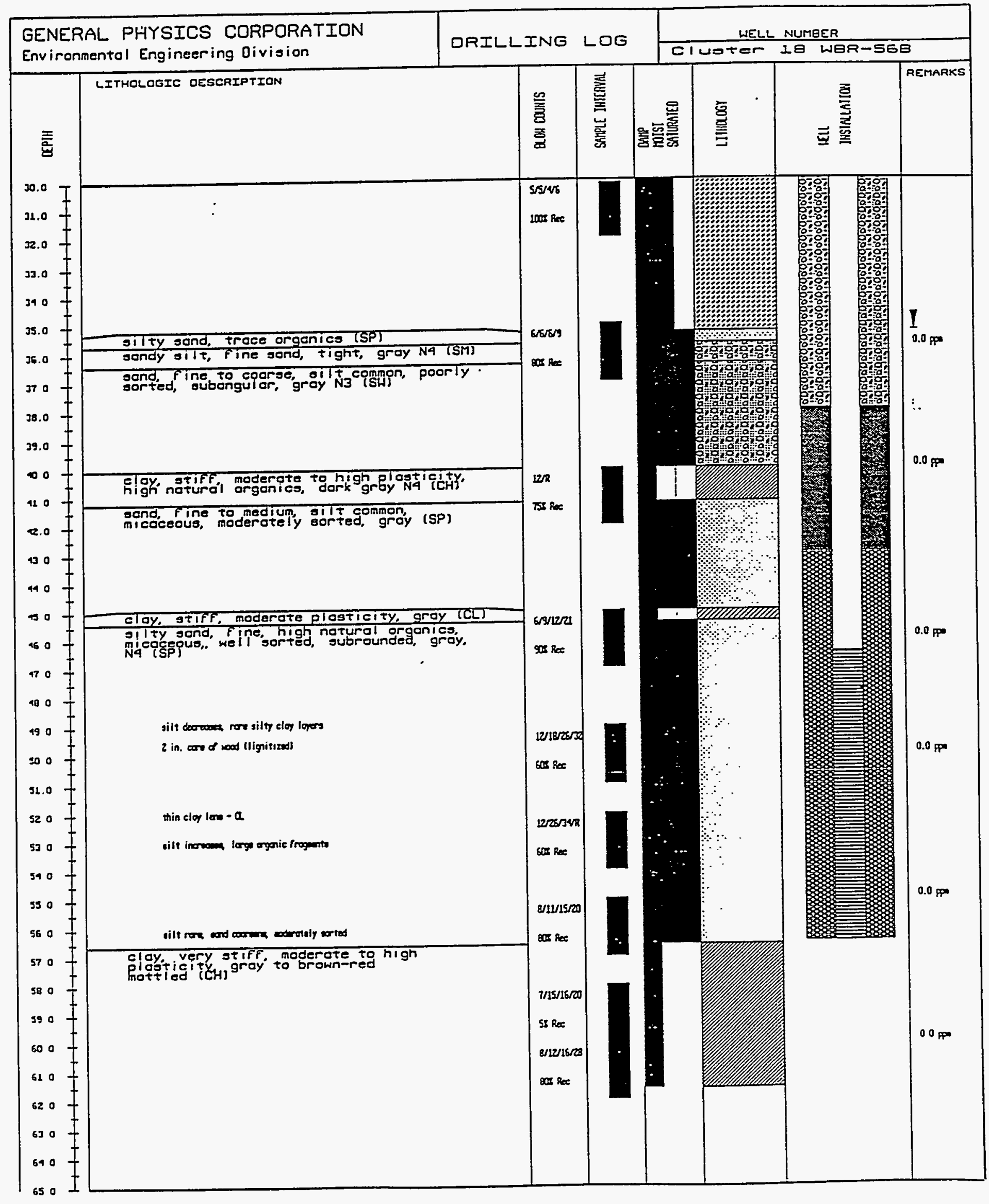




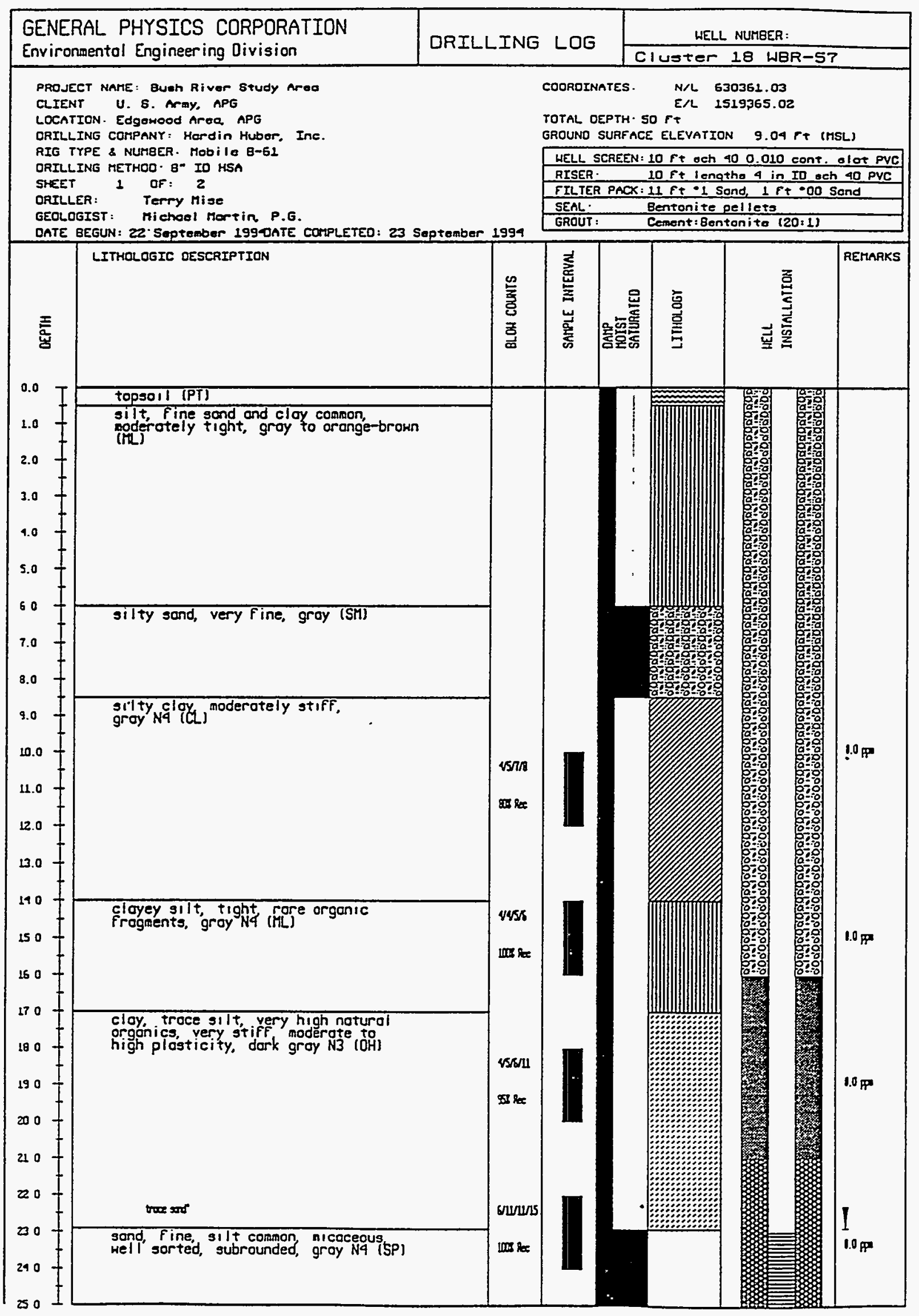




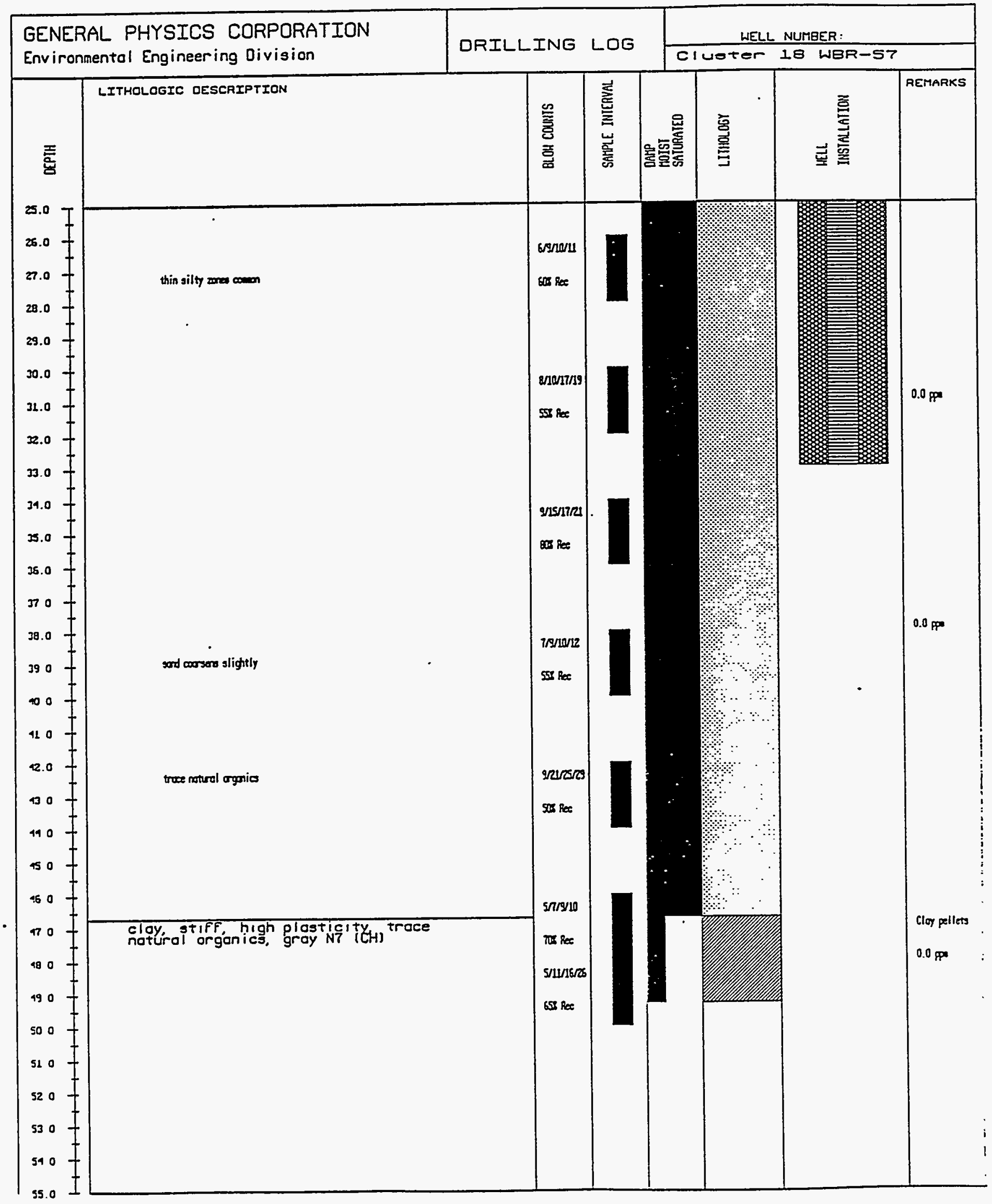




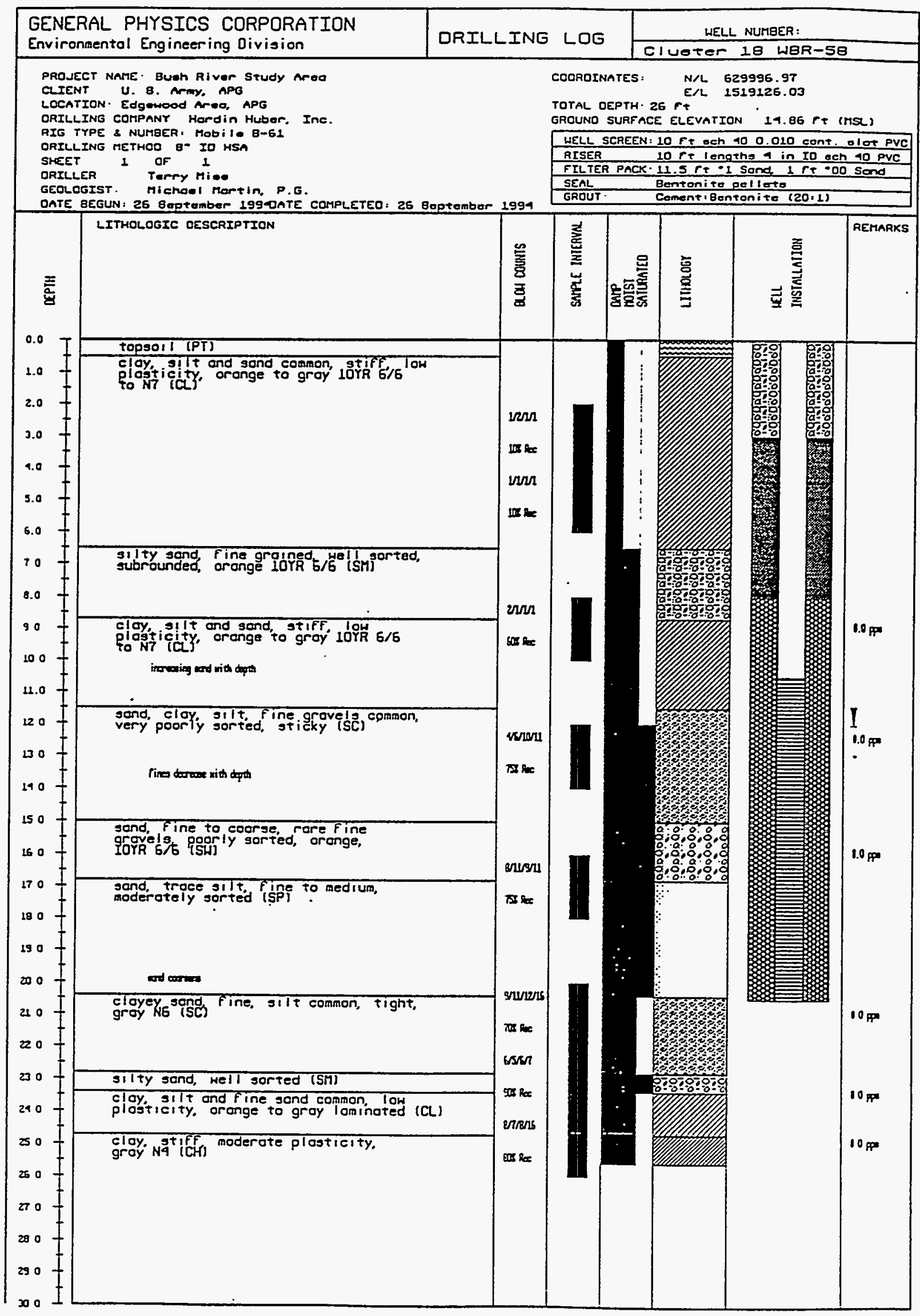




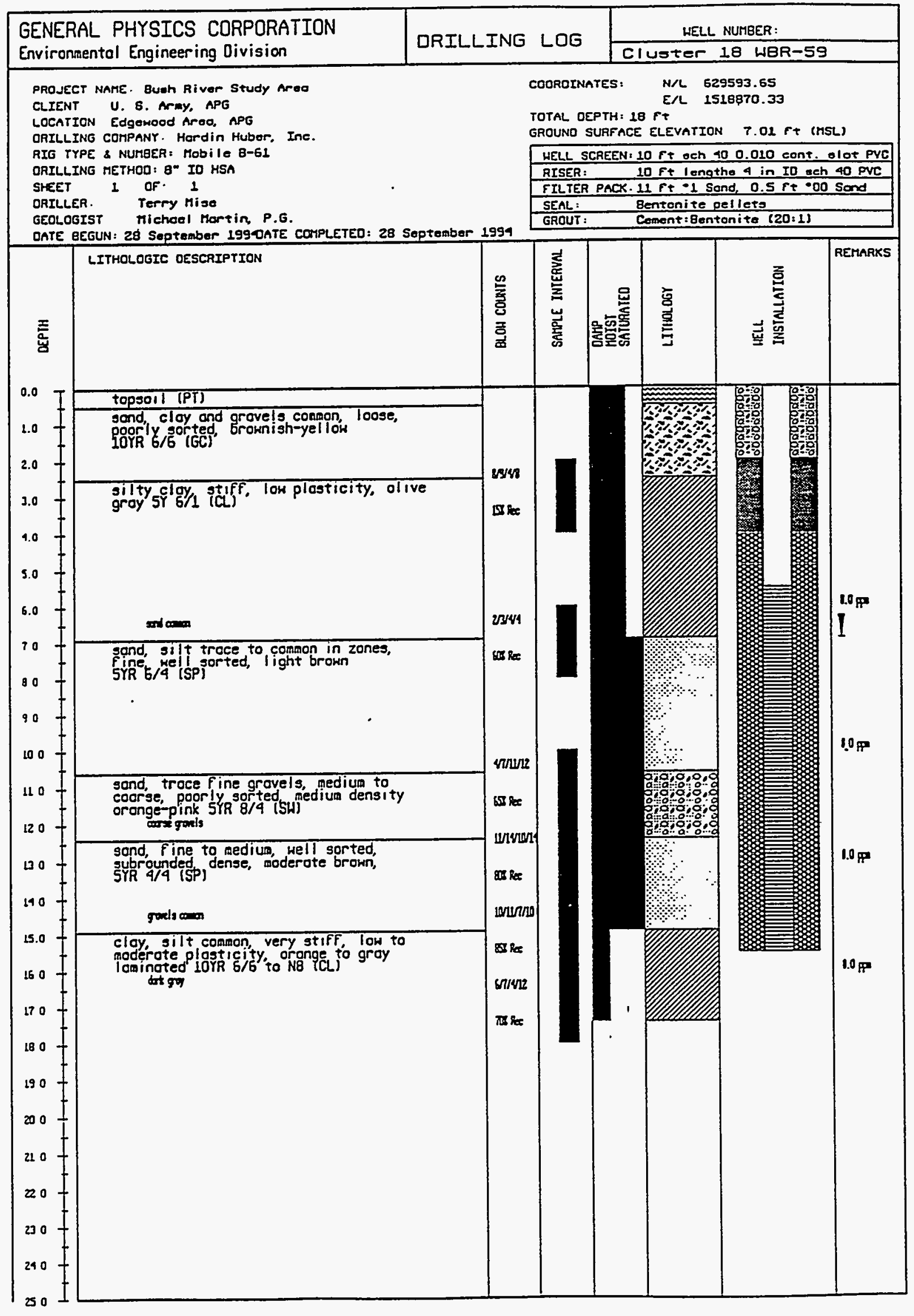




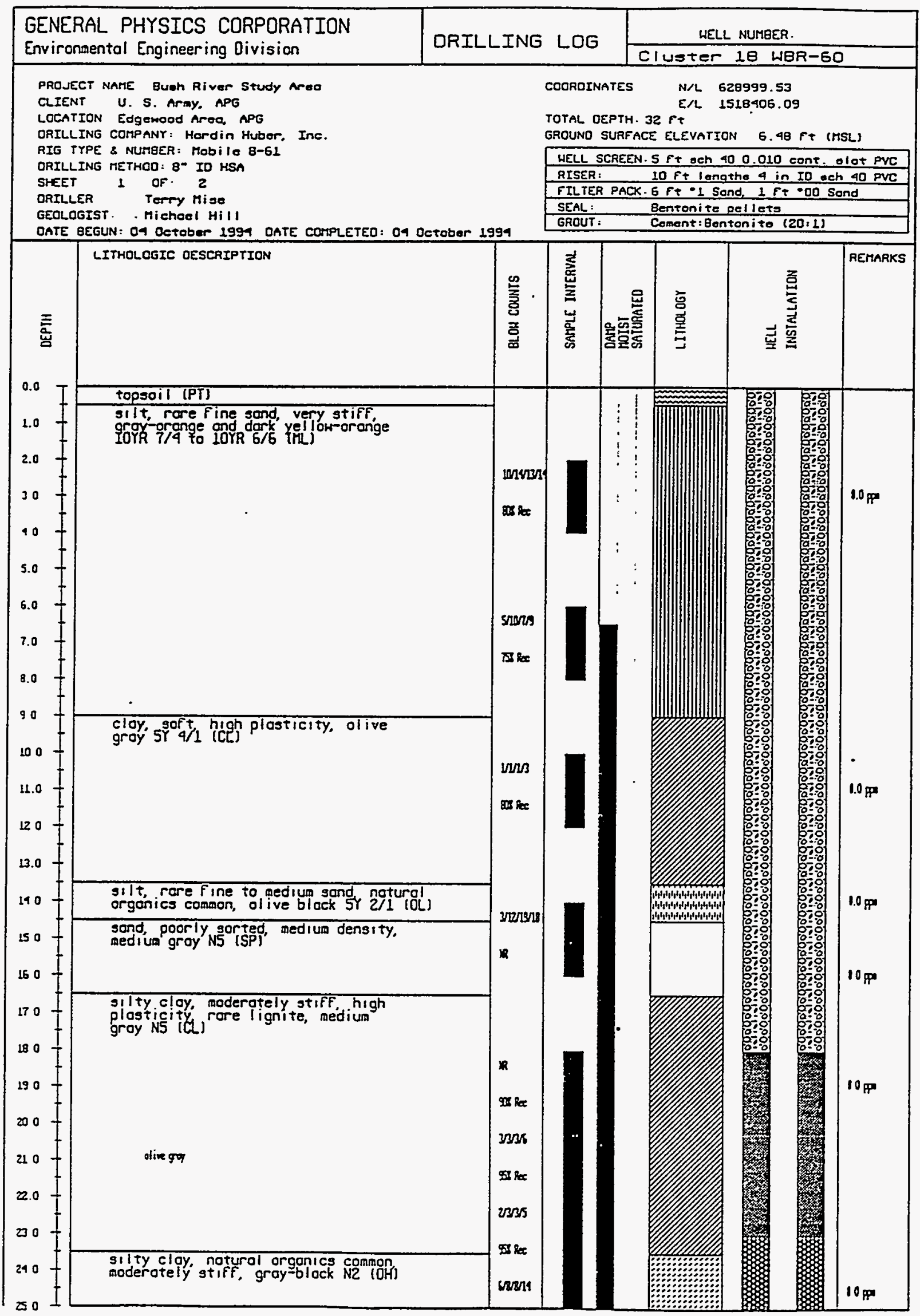




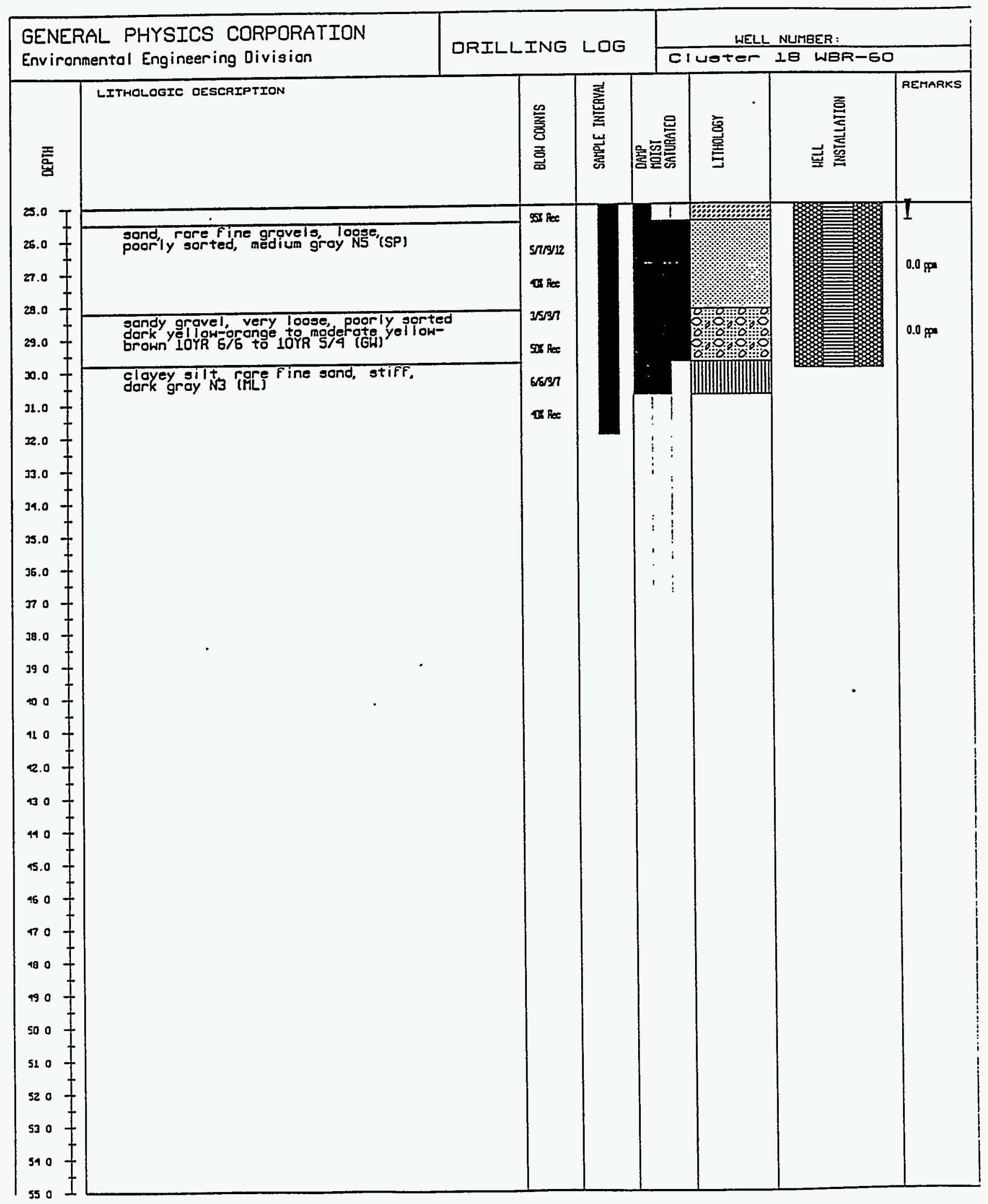




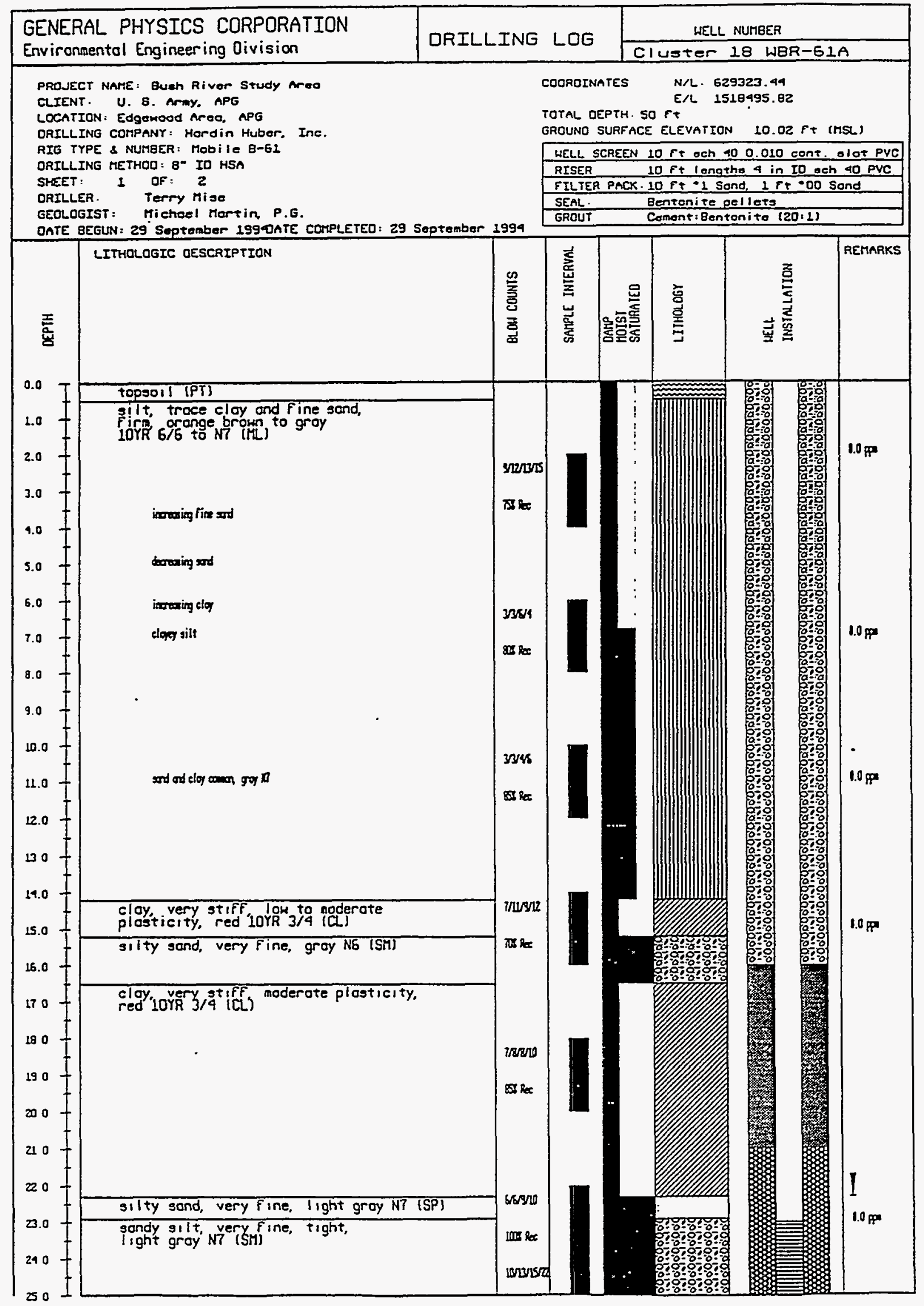




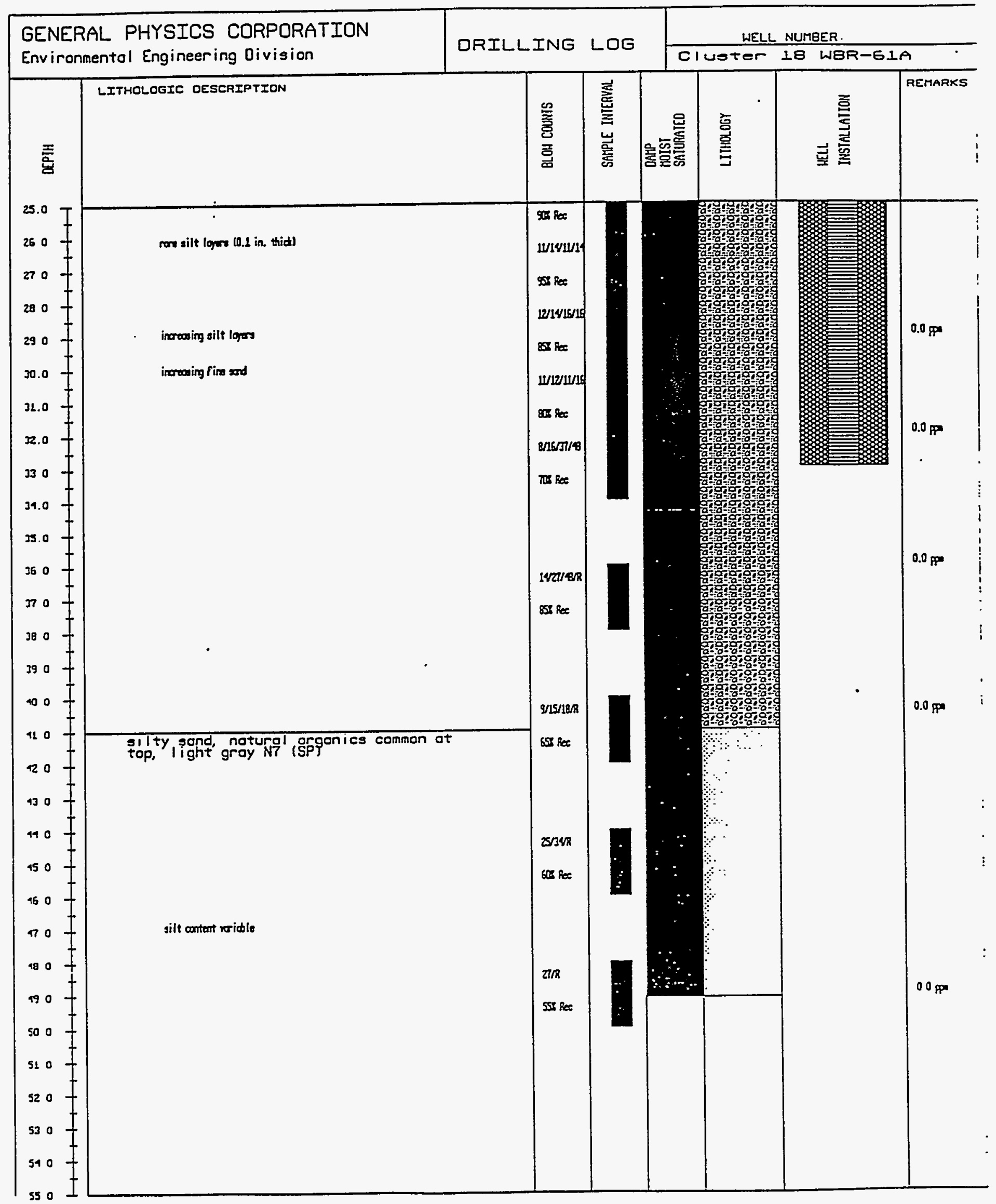




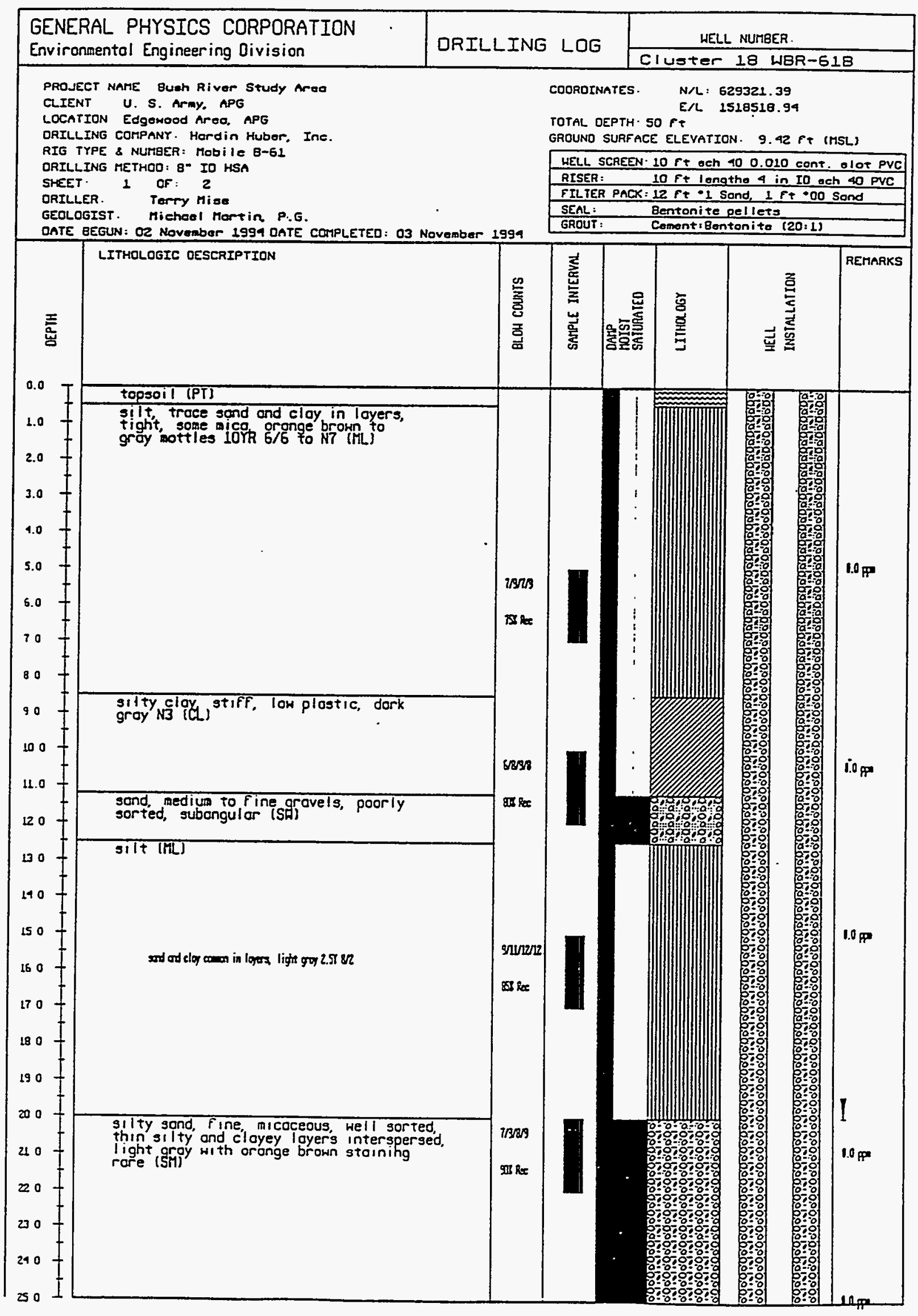




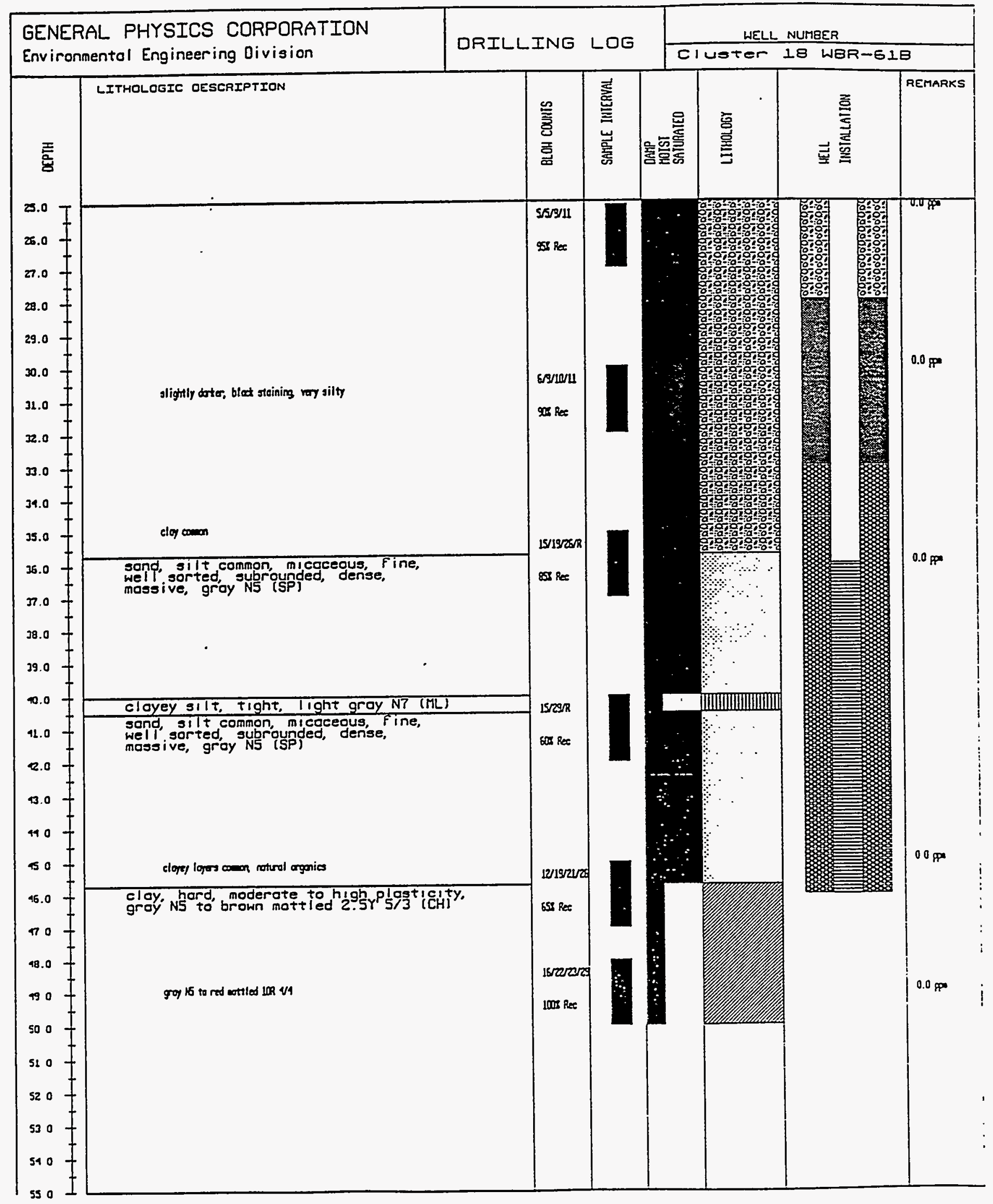




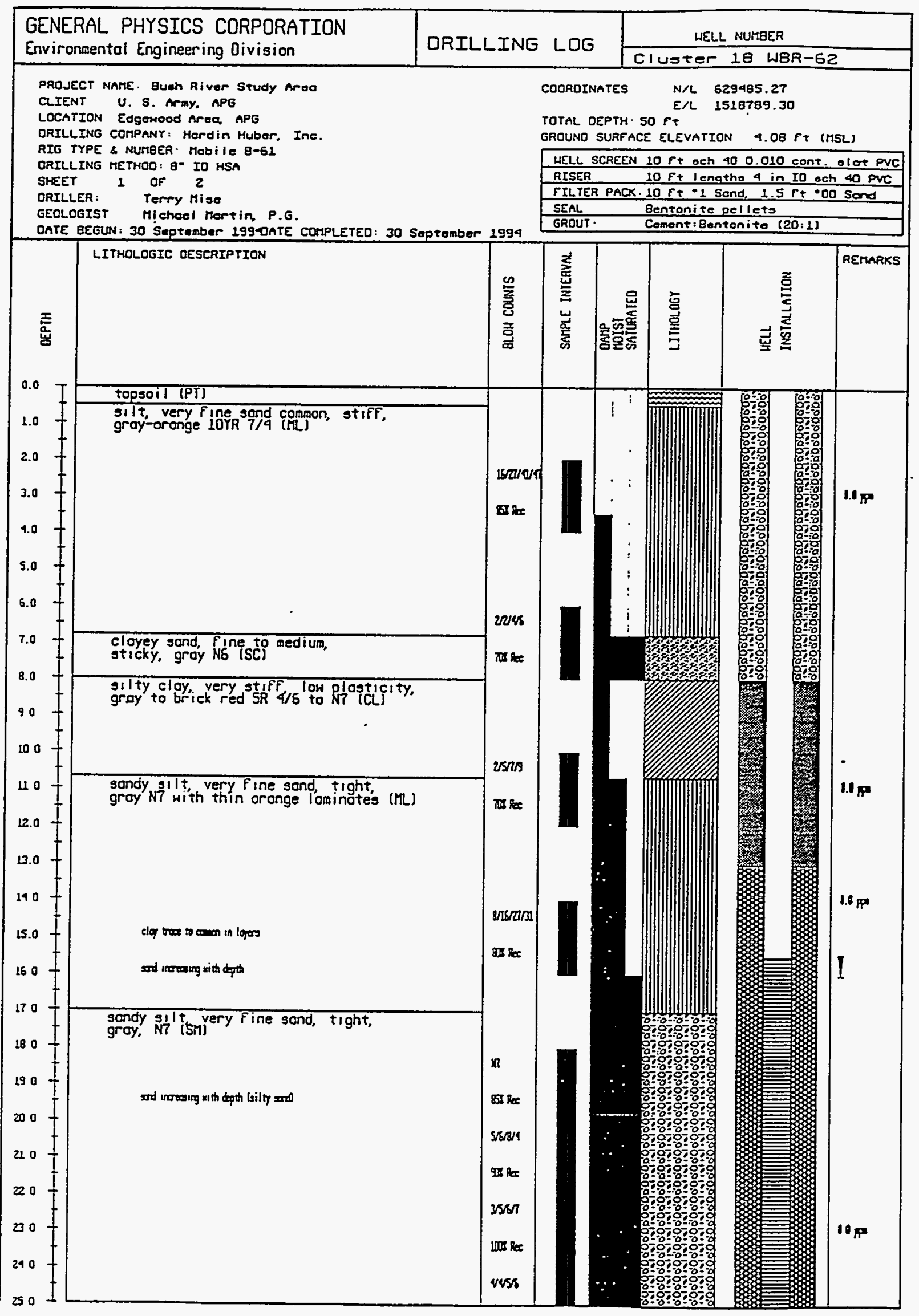




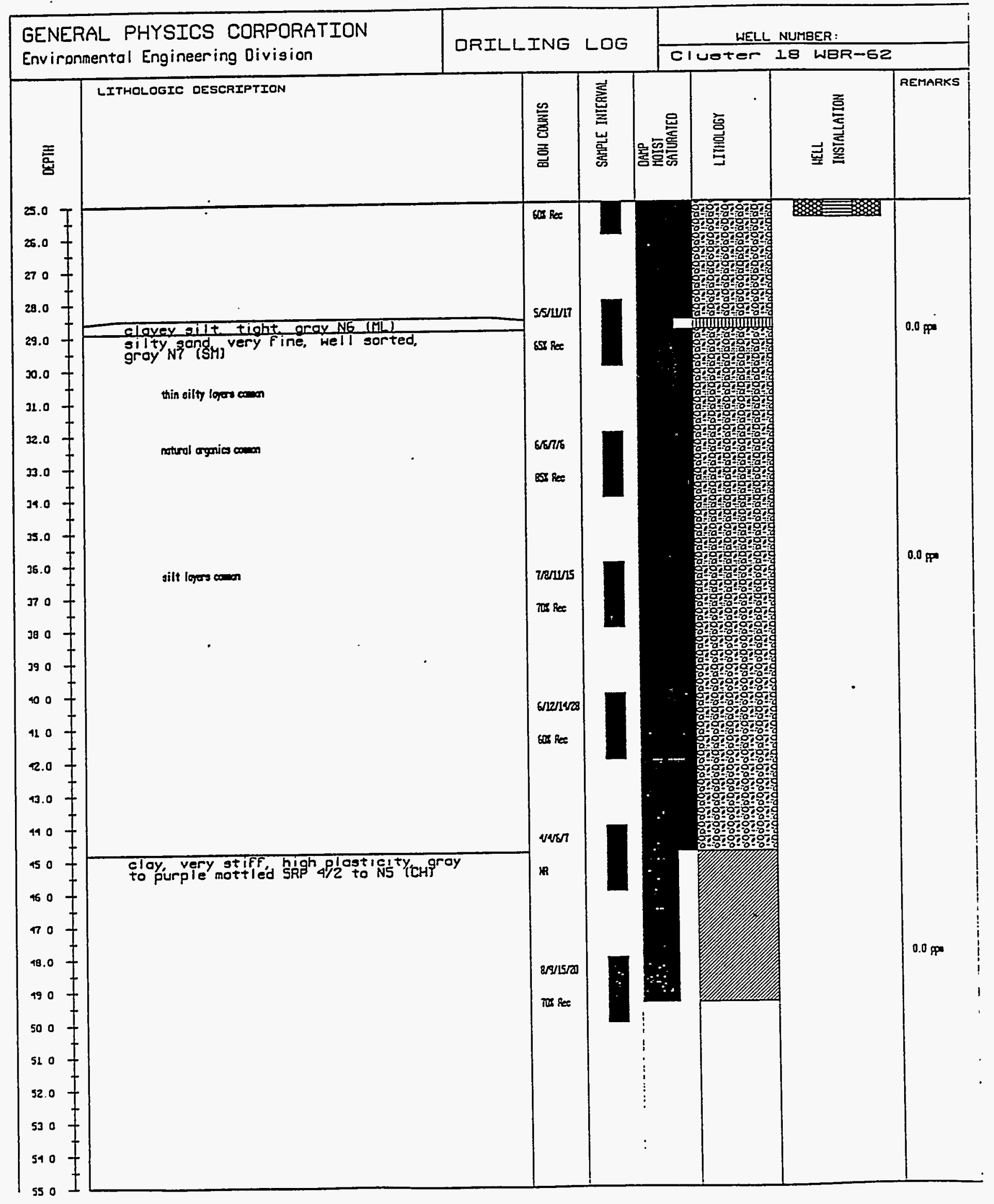




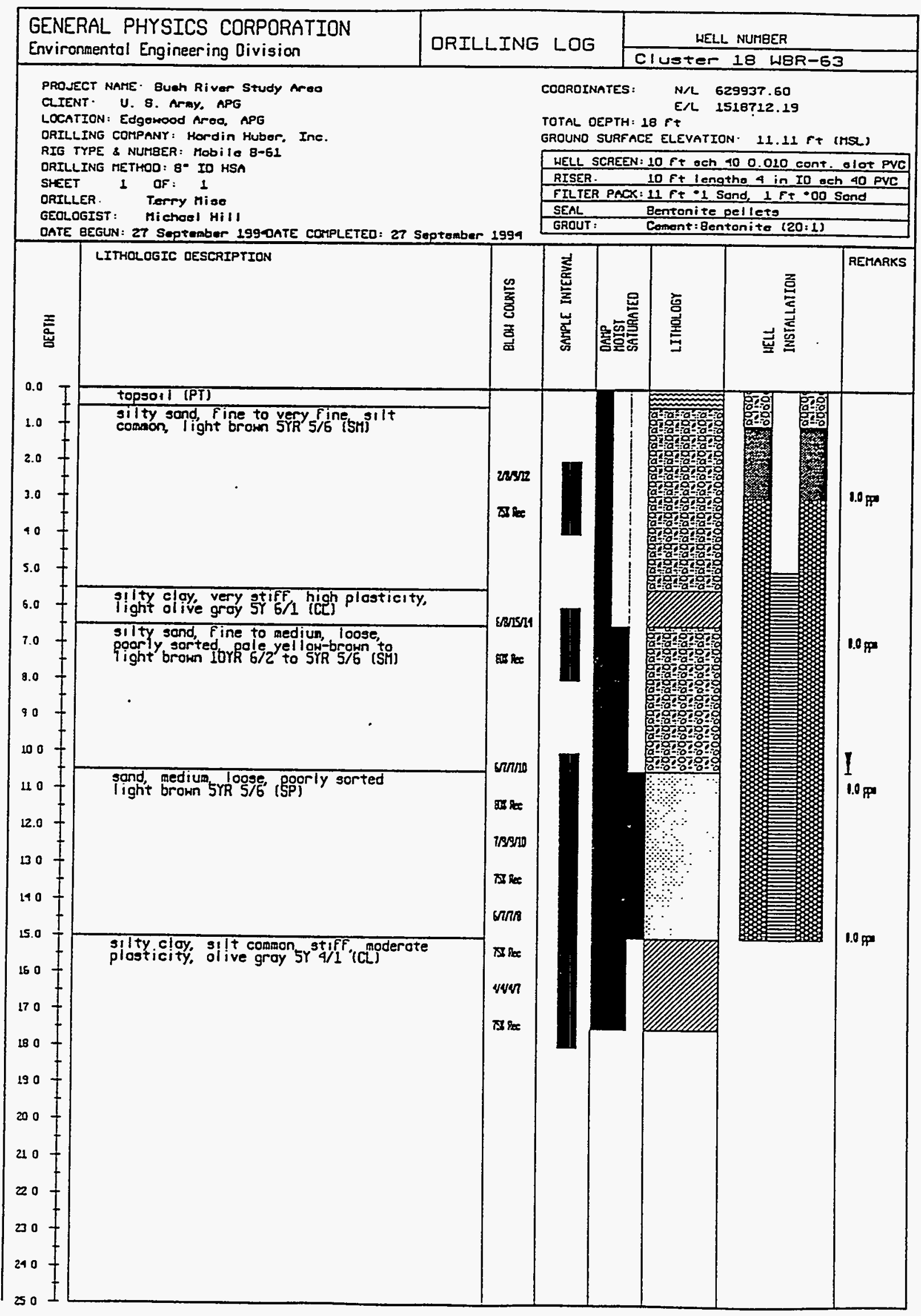




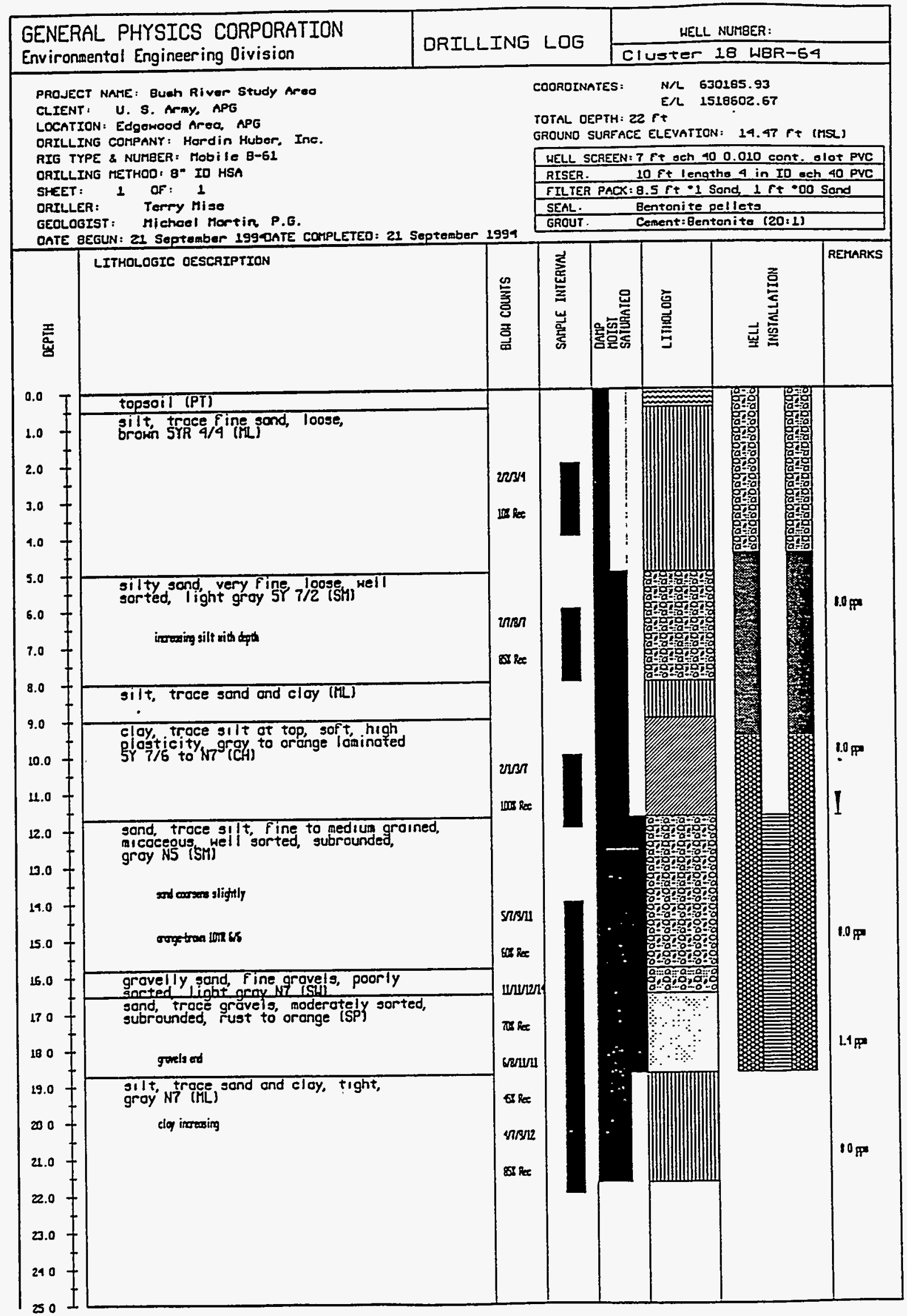


